\title{
Spatial and temporal variability of the soil saturated hydraulic conductivity in gradients of disturbance.
}

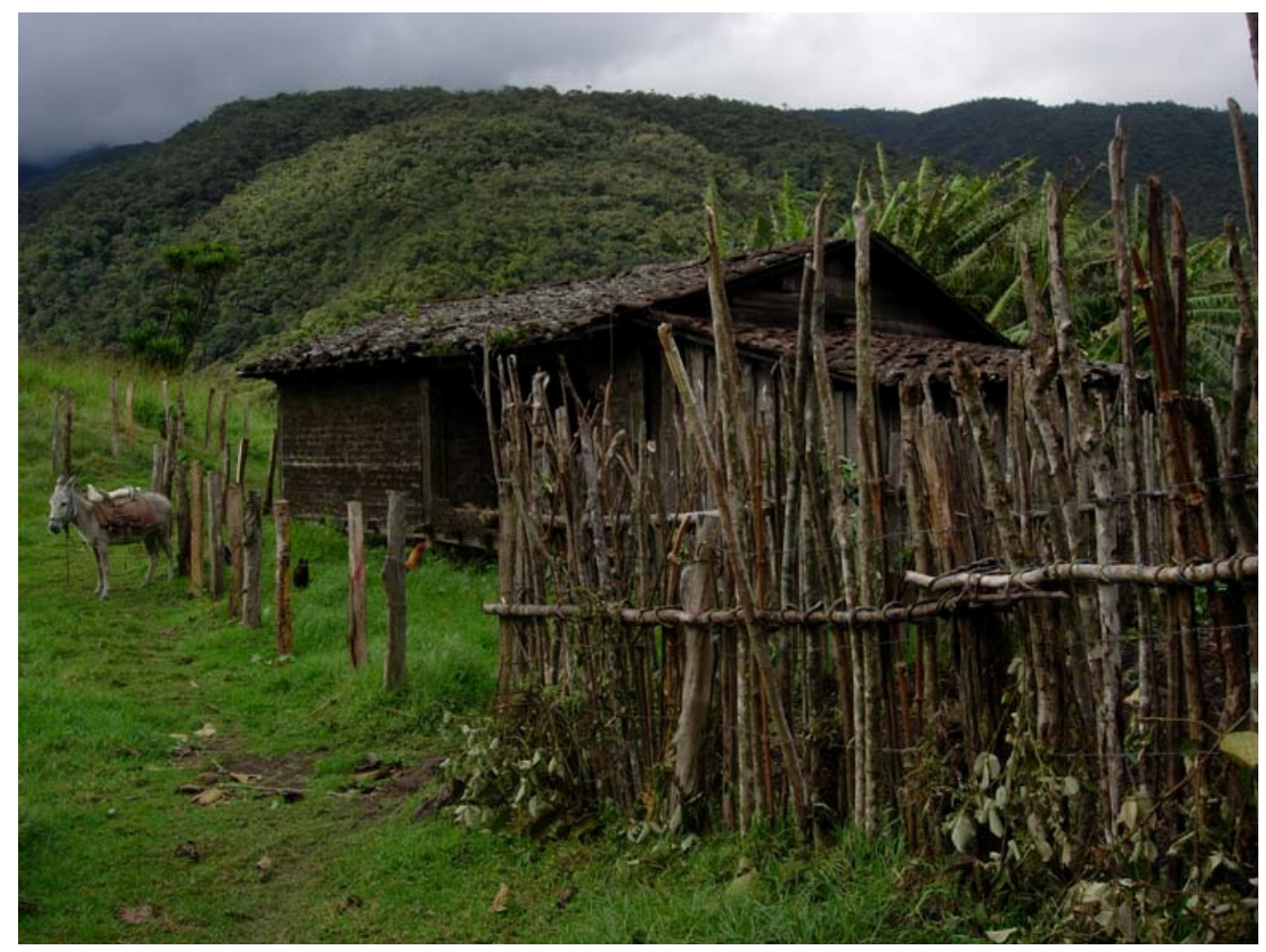

\section{Dissertation}

zur Erlangung des Doktorgrades Dr. rer. nat.

der Mathematisch - Naturwissenschaftlichen Fakultät der Universität Potsdam

vorgelegt von

Beate Zimmermann

Potsdam, 30.11.2007 
Elektronisch veröffentlicht auf dem

Publikationsserver der Universität Potsdam:

http://opus.kobv.de/ubp/volltexte/2008/1640/

urn:nbn:de:kobv:517-opus-16402

[http://nbn-resolving.de/urn:nbn:de:kobv:517-opus16402] 


\section{Summary}

As land-cover conversion continues to expand into ever more remote areas in the humid tropics, montane rainforests are increasingly threatened. In addition to the loss of biodiversity, land-use change potentially deteriorates regional water cycles, which may have undesirable effects for local populations such as decreased water supply during dry seasons, enhanced flooding in the rainy season, or deterioration of drinking water quality.

Montane rainforests in the south Ecuadorian Andes are not only subject to man-made disturbances but also to naturally occurring landslides. I was interested in the impact of this ecosystem dynamics on a key parameter of the hydrologic cycle, the soil saturated hydraulic conductivity (synonym: permeability; Ks from here on), because it is a sensitive indicator for soil disturbances. Depending on the rainfall regime, the potential disturbance-induced decrease of Ks may become relevant for regional watersheds.

My general objective was to quantify the effects of the regional natural and human disturbances on the saturated hydraulic conductivity and to describe the resulting spatialtemporal patterns. The main hypotheses were: 1) disturbances cause an apparent displacement of the less permeable soil layer towards the surface, either due to a loss of the permeable surface soil after land-sliding, or as a consequence of the surface soil compaction under cattle pastures; 2) 'recovery' from disturbance, either because of landslide re-vegetation or because of secondary succession after pasture abandonment, involves an apparent displacement of the less permeable layer back towards the original depth an 3) disturbances cause a simplification of the Ks spatial structure, i.e. the spatially dependent random variation diminishes; the subsequent recovery entails the re-establishment of the original structure. In my first study, I developed a synthesis of recent geostatistical research regarding its applicability to soil hydraulic data, including exploratory data analysis and variogram estimation techniques; I subsequently evaluated the results in terms of spatial prediction uncertainty. Concerning the exploratory data analysis, my main results were: 1) Gaussian uniand bivariate distributions of the log-transformed data;2) the existence of significant local trends; 3) no need for robust estimation; 4) no anisotropic variation. I found partly considerable differences in covariance parameters resulting from different variogram estimation techniques, which, in the framework of spatial prediction, were mainly reflected in the spatial connectivity of the Ks-field. Ignoring the trend component and an arbitrary use of robust estimators, however, would have the most severe consequences in this respect. Regarding variogram modeling, I encouraged restricted maximum likelihood estimation 
because of its accuracy and independence on the selected lags needed for experimental variograms.

The second study dealt with the Ks spatial-temporal pattern in the sequences of natural and man-made disturbances characteristic for the montane rainforest study area. To investigate the disturbance effects both on global means and the spatial structure of Ks, a combined designand model-based sampling approach was used for field-measurements at soil depths of 12.5, 20 , and $50 \mathrm{~cm}(\mathrm{n}=30-150 /$ depth) under landslides of different ages ( 2 and 8 years), under actively grazed pasture, fallows following pasture abandonment ( 2 to 25 years of age), and under natural forest. Concerning global means, our main findings were 1) global means of the soil permeability generally decrease with increasing soil depth;2) no significant Ks differences can be observed among landslides and compared to the natural forest; 3 ) a distinct permeability decrease of two orders of magnitude occurs after forest conversion to pasture at shallow soil depths, and 4) the slow regeneration process after pasture abandonment requires at least one decade. Regarding the Ks spatial structure, we found that 1) disturbances affect the Ks spatial structure in the topsoil, and 2) the largest differences in spatial patterns are associated with the subsoil permeability. In summary, the regional landslide activity seems to affect soil hydrology to a marginal extend only, which is in contrast to the pronounced drop of Ks after forest conversion. The generally short correlation lengths suggested that other upscaling techniques than geostatistics may be more feasible in our study region.

We used this spatial-temporal information combined with local rain intensities to assess the partitioning of rainfall into vertical and lateral flowpaths under undisturbed, disturbed, and regenerating land-cover types in the third study. It turned out that 1) the montane rainforest is characterized by prevailing vertical flowpaths in the topsoil, which can switch to lateral directions below $20 \mathrm{~cm}$ depth for a small number of rain events, which may, however, transport a high portion of the annual runoff; 2) similar hydrological flowpaths occur under the landslides except for a somewhat higher probability of impermeable layer formation in the topsoil of a young landslide, and 3) pronounced differences in runoff components can be observed for the human disturbance sequence involving the development of near-surface impeding layers for 24,44 , and $8 \%$ of rain events for pasture, a two-year-old fallow, and a ten-year-old fallow, respectively.

In summary, the drop of Ks due to forest conversion for pasture is likely associated with consequences for the water cycle of the south-Ecuadorian montane rainforest region, which seem to integrate into tropical standards. 


\section{Acknowledgements}

The research project which was the basis for my $\mathrm{PhD}$ thesis was funded by the German Research Foundation (FOR 402, TP B3, E1 255/4-1). During the fieldwork in Ecuador, the Fundación Científica San Francisco (Nature and Culture International (NCI)) provided the research station and the study area.

First, I gratefully acknowledge my supervisor Prof. Helmut Elsenbeer for offering me the opportunity to work on this interesting research topic. I owe some unforgettable memories to him of our field trips in Ecuador (for example the 'bracken walk'), and he introduced me to his colleagues all over the world.

This work is entirely based on field data that had to be collected under difficult conditions: climbing the same steep paths every early morning, carrying all the stuff on the back, and then staying the whole day at the same plot making always the same measurements... This would have been impossible without the help of the field assistants! Most important, my ex-fellow student and good friend Christin Leiberg who took part in the entire field season during the second half of the year 2005. With the help of Christin and "my" first project students Daniela Reetz and Dorothee Hodapp we took 900 measurements in less than two months! Then Jörn Pagel and Sebastian Vogel came for the dangerous work on the landslides, most notably the towage of water cans at slopes that partly exceeded 40 degrees. And last but not least my husband Alex, who was solely responsible for the important work at the pine plantation. If I had been on my own, I would have needed two years for the 2136 measurements instead of the actual six months. Thank you all for this great saving of time and all your friendship and support!

Though not accompanying us in the field, the most indispensable person in Ecuador was Rocio. She was the best nanny my daughter Luisa ever had. The possibility to manage the field work I solely owe to her.

Many thanks go to numerous members of the other project groups of the DFG research unit who provided a lot of information, data, and the possibility for discussions: Dr. Rütger Rollenbeck and Thorsten Peters for data and comments on the local climate, Prof. Wolfgang Wilcke for the landslide data, Prof. Bernd Huwe and Prof. Franz Makeschin as well as their collaborators for information on soils, and Florian Werner for plant identification. 
Special thanks go to Prof. Erwin Zehe for his support. He had always time for some 'geopoetry', and he contributed considerably in helping me sit out hard times in the last year. Thanks to Dr. Boris Schröder who proposed the use of spline correlograms. I want to thank Sonja Germer, my office roommate, for her friendship and all the discussions we had on pastures and forests in the humid tropics.

Especially during the final stage of this work, my friends and neighbors came to the aid of me by taking care of Luisa: many thanks to Claudia, Ludwig, Andrea, and Ulrike! Alex and my parents are by far the ones that have suffered most from all this, but they never gave up on me. Of course none of this would have been possible without their support. 


\section{Contents}

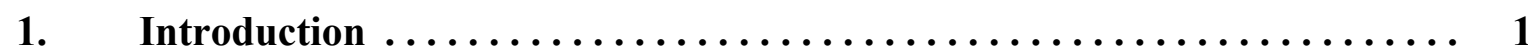

1.1. The montane rainforest ecosystem in southern Ecuador $\ldots \ldots \ldots \ldots \ldots \ldots$

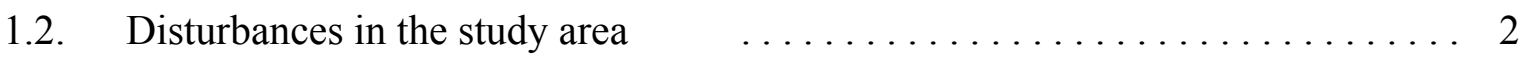

1.3. Hydrological flowpaths in soils of undisturbed tropical forests $\ldots \ldots \ldots 2$

1.4. Influence of disturbances on hydrological flowpaths $\quad \ldots \ldots \ldots \ldots \ldots \ldots$

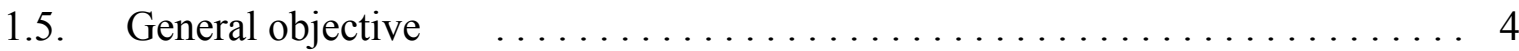

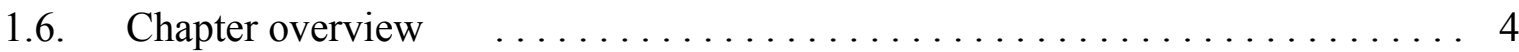

2. Analyzing spatial data: an assessment of assumptions, new methods, and uncertainty using soil hydraulic data $\quad \ldots \ldots \ldots \ldots \ldots \ldots \ldots \ldots$

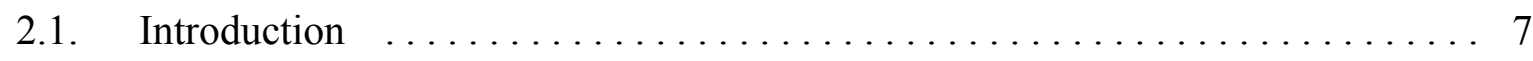

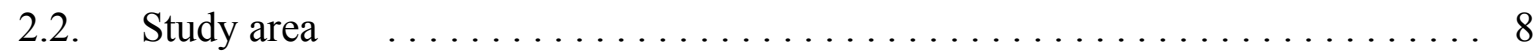

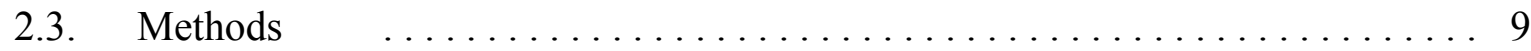

2.3.1. Field measurements and sampling strategy $\ldots \ldots \ldots \ldots \ldots \ldots$

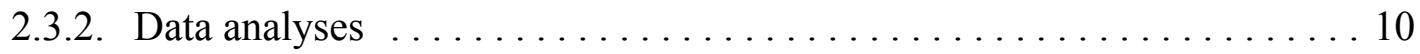

2.3.2.1. Exploratory data analysis $\quad \ldots \ldots \ldots \ldots \ldots \ldots$

2.3.2.2. Geostatistical analysis $\quad \ldots \ldots \ldots \ldots \ldots \ldots \ldots 11$

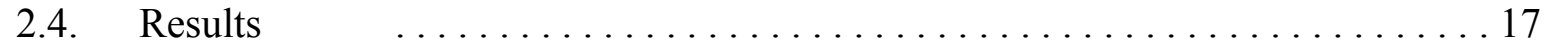

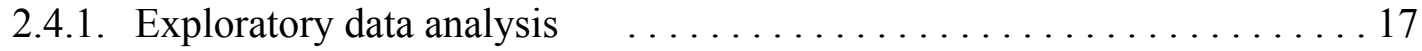

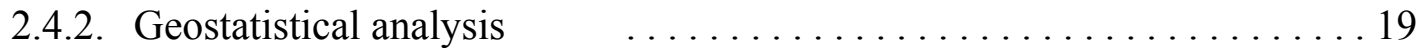

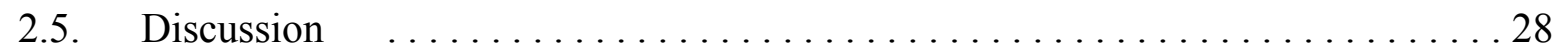

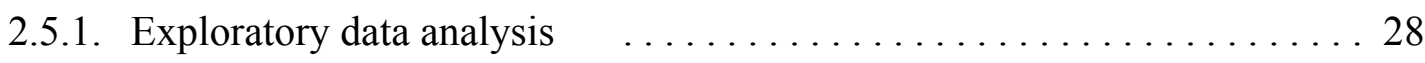

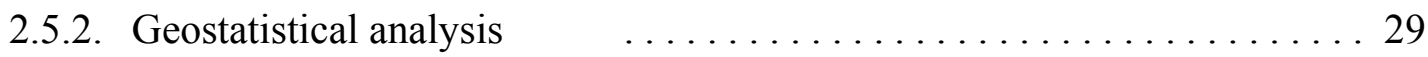

2.5.3. Comparison with other studies of the spatial variability of Ks $\ldots . .32$

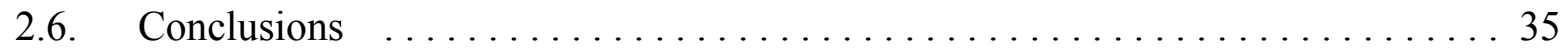

3. The soil hydraulic response to disturbance and recovery. I. Spatial and temporal variability of the saturated hydraulic conductivity $\quad \ldots \ldots \ldots \ldots \ldots . \ldots 38$

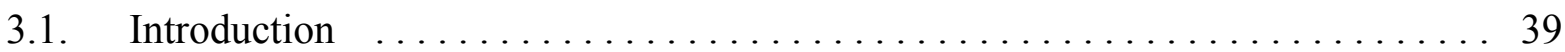

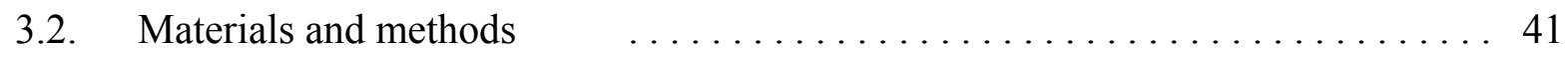

3.2.1. Study area $\quad \ldots \ldots \ldots \ldots \ldots \ldots \ldots \ldots \ldots \ldots \ldots \ldots \ldots \ldots \ldots \ldots \ldots \ldots \ldots \ldots \ldots$

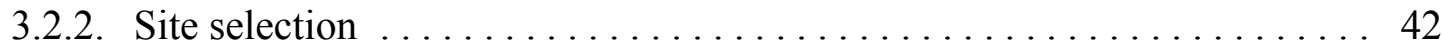


3.2.3. Sampling $\ldots \ldots \ldots \ldots \ldots \ldots \ldots \ldots \ldots \ldots \ldots \ldots \ldots \ldots \ldots, 44$

3.2.4. Statistical and geostatistical analyses $\quad \ldots \ldots \ldots \ldots \ldots \ldots \ldots, 45$

3.2.4.1. Initial conditions $\quad \ldots \ldots \ldots \ldots \ldots \ldots \ldots \ldots 45$

3.2.4.2. Exploratory data analysis $\quad \ldots \ldots \ldots \ldots \ldots \ldots \ldots 47$

3.2.4.3. Global comparisons $\ldots \ldots \ldots \ldots \ldots \ldots \ldots \ldots \ldots 47$

3.2.4.4. Spatial analysis $\quad \ldots \ldots \ldots \ldots \ldots \ldots \ldots \ldots \ldots 48$

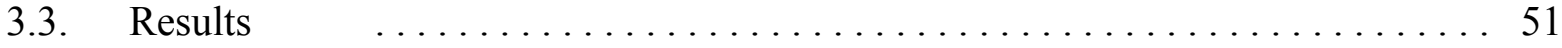

3.3.1. Exploratory data analysis $\quad \ldots \ldots \ldots \ldots \ldots \ldots \ldots \ldots \ldots \ldots \ldots \ldots \ldots \ldots \ldots$

3.3.2. Global comparisons $\ldots \ldots \ldots \ldots \ldots \ldots \ldots \ldots \ldots \ldots \ldots \ldots \ldots$

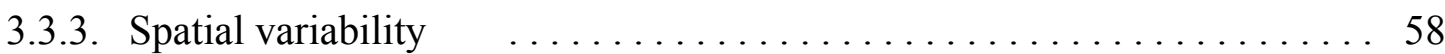

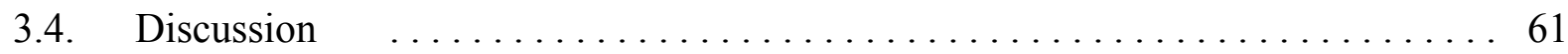

3.4.1. Global comparisons $\ldots \ldots \ldots \ldots \ldots \ldots \ldots \ldots \ldots \ldots \ldots \ldots \ldots \ldots \ldots$

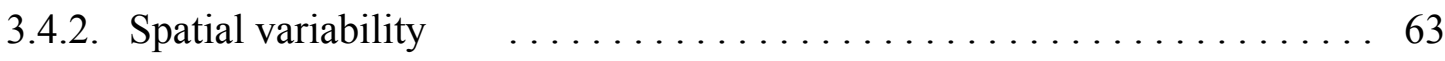

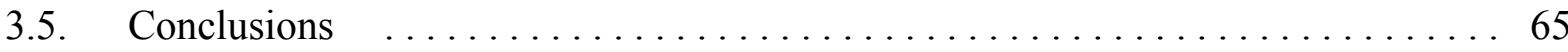

4. The soil hydraulic response to disturbance and recovery. II. Partitioning of rainfall in vertical and lateral flowpaths $\ldots \ldots \ldots \ldots \ldots \ldots \ldots \ldots \ldots 6$

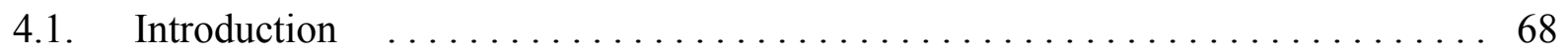

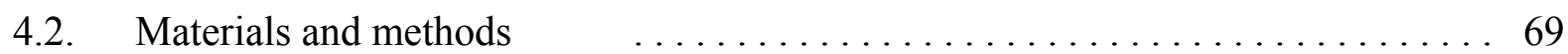

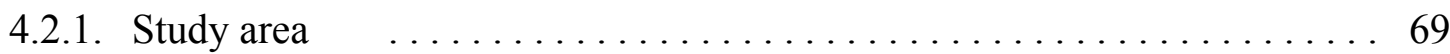

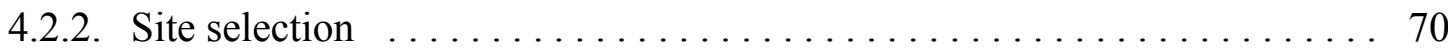

4.2.3. Sampling $\quad \ldots \ldots \ldots \ldots \ldots \ldots \ldots \ldots \ldots \ldots \ldots \ldots \ldots \ldots \ldots \ldots \ldots \ldots \ldots, 71$

4.2.4. Rainfall in the montane rainforest $\ldots \ldots \ldots \ldots \ldots \ldots \ldots \ldots \ldots \ldots$

4.2.5. Partitioning of rain in hydrological flowpaths $\quad \ldots \ldots \ldots \ldots \ldots \ldots 72$

4.2.6. Comparison with a lowland tropical rainforest $\quad \ldots \ldots \ldots \ldots \ldots . \ldots 73$

4.3. Results. ...................................... 75

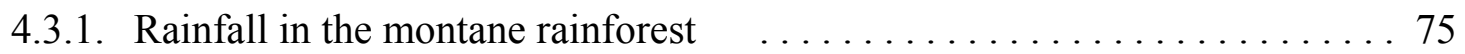

4.3.2. Partitioning of rain in hydrological flowpaths as a function of disturbance . 76 4.3.2.1. Probability of impeding layer formation $\ldots \ldots \ldots \ldots 76$

4.3.2.2. Frequency of near-surface lateral flowpaths .......... 82

4.3.2.3. Rainfall amount in lateral flowpaths .............. 85

4.3.3. Comparison with a lowland tropical rainforest $\quad \ldots \ldots \ldots \ldots \ldots 86$

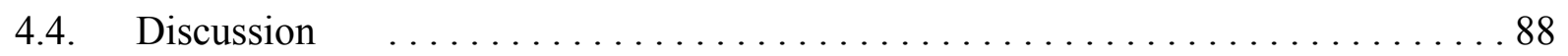

4.4.1. Significance of the plot study at the catchment level $\quad \ldots \ldots \ldots \ldots 88$ 
4.4.2. Flowpaths in the south Ecuadorian montane rainforest $\quad \ldots \ldots \ldots \ldots 89$

4.4.3. Influence of landslides on hydrological flowpaths $\ldots \ldots \ldots \ldots \ldots$. . . . 89

4.4.4. Influence of land-cover change on hydrological flowpaths . . . . . . . . 90

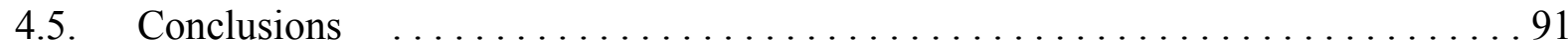

5. Summary of the research results and implications for future work $\ldots \ldots \ldots 92$

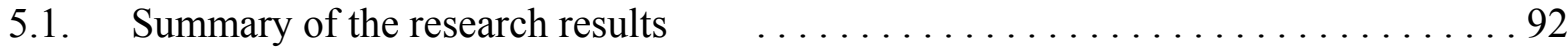

5.1.1. Spatial analysis of soil hydraulic data $\quad \ldots \ldots \ldots \ldots \ldots \ldots \ldots 2$

5.1.2. Spatial and temporal variability of the saturated hydraulic conductivity . . 94

5.1.3. Hydrological flowpaths in the studied tropical montane rainforest ecosystem 94

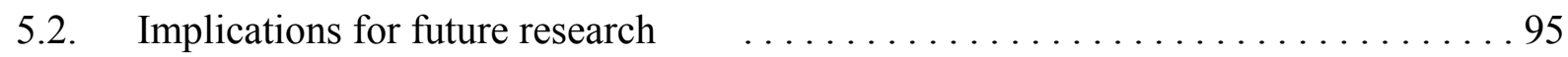

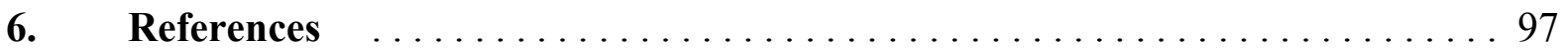




\section{List of Figures}

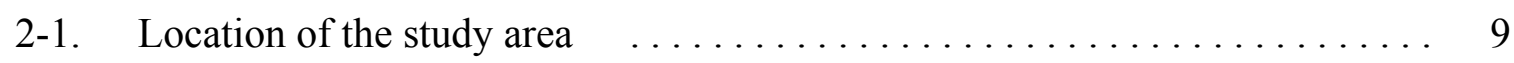

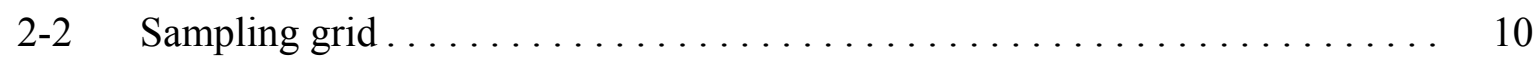

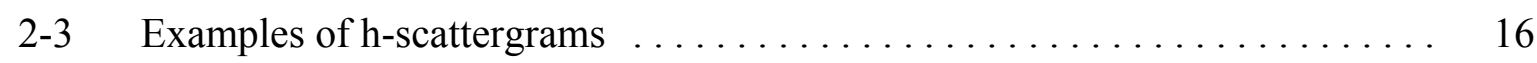

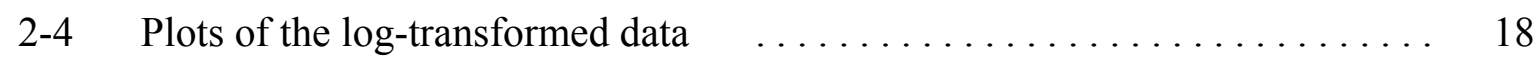

2-5 Univariate distribution of the residuals $\quad \ldots \ldots \ldots \ldots \ldots \ldots \ldots \ldots$

2-6 Bivariate distribution of the residuals $\quad \ldots \ldots \ldots \ldots \ldots \ldots \ldots \ldots$

2-7 Directional variograms of the residuals $\quad \ldots \ldots \ldots \ldots \ldots \ldots \ldots \ldots \ldots \ldots \ldots$

2-8 Directional variograms of the $\log$-transformed data $\ldots \ldots \ldots \ldots \ldots \ldots \ldots$

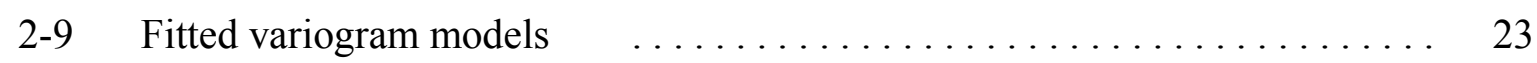

2-10 Deviations between kriged Ks-values $\quad \ldots \ldots \ldots \ldots \ldots \ldots \ldots \ldots \ldots$

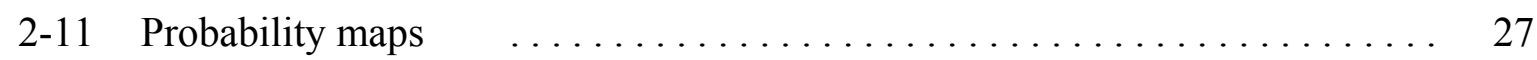

2-12 Boxplots of the absolute deviations between predicted Ks-values . . . . . . 28

2-13 Proposed flowchart for spatial data analysis $\ldots \ldots \ldots \ldots \ldots \ldots \ldots \ldots \ldots \ldots$

3-1 Conceptual framework of the study $\ldots \ldots \ldots \ldots \ldots \ldots \ldots \ldots \ldots \ldots \ldots \ldots$

3-2 Map and aerial view of the research area $\ldots \ldots \ldots \ldots \ldots \ldots \ldots \ldots \ldots \ldots$

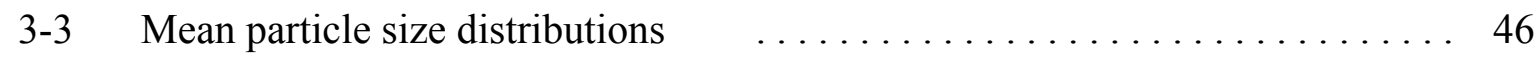

3-4 Bivariate distributions of the data or the residuals for the $12.5 \mathrm{~cm}$ soil depth . . 53

3-5 Bivariate distributions of the data or the residuals for the $20 \mathrm{~cm}$ soil depth . . . 54

3-6 Bivariate distributions of the data or the residuals for the $50 \mathrm{~cm}$ soil depth . . . 55

3-7 Depth gradient of Ks for the natural disturbance sequence $\ldots \ldots \ldots \ldots \ldots 6$

3-8 Depth gradient of Ks for the human disturbance sequence $\ldots \ldots \ldots \ldots \ldots 6$

3-9 Ks under different zones on the old landslide $\quad \ldots \ldots \ldots \ldots \ldots \ldots$. 57

3-10 Correlation length estimated by the spline correlograms $\ldots \ldots \ldots \ldots \ldots 60$

3-11 Possible effect of soil disturbances on Ks spatial structure $\ldots \ldots \ldots \ldots \ldots 6$

4-1 Frequency and quantity of the maximum 30-minute rain intensities $\ldots 76$

4-2 Probability maps $(12.5 \mathrm{~cm}$ soil depth) $\ldots \ldots \ldots \ldots \ldots \ldots \ldots \ldots$

4-3 Probability maps $(20 \mathrm{~cm}$ soil depth) $\ldots \ldots \ldots \ldots \ldots \ldots \ldots \ldots \ldots \ldots \ldots \ldots \ldots \ldots \ldots \ldots$

4-4 Probability maps $(20 \mathrm{~cm}$ soil depth $) \ldots \ldots \ldots \ldots \ldots \ldots \ldots \ldots \ldots \ldots \ldots \ldots \ldots \ldots$

4-5 Thresholds for the extensive formation of impermeable layers $\ldots \ldots \ldots 83$

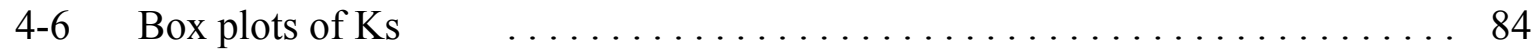


4-7 Predicted partitioning of rainwater in vertical and lateral flowpaths $\ldots$. 86

4-8 Frequency and quantity of the maximum 30-minute rain intensities $\ldots 87$

4-9 Cumulative frequency distribution of Ks for land-cover types $\ldots \ldots \ldots 88$ 


\section{List of Tables}

2-1 Comparison of selected studies of Ks spatial variability $\ldots \ldots \ldots \ldots \ldots 34$

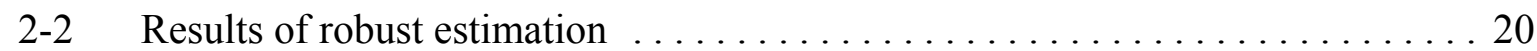

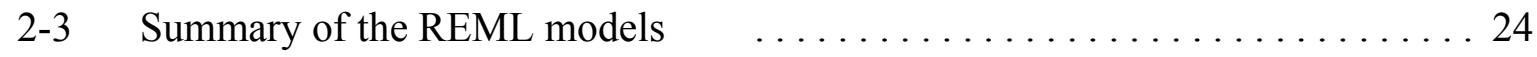

2-4 Probability that the median of the maximum 30-minute rain intensities exceeds

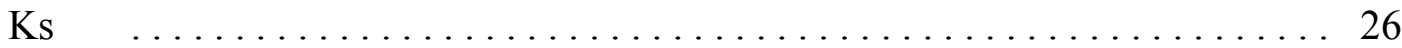

2-5 Comparison of sample variance and sill variance $\ldots \ldots \ldots \ldots \ldots \ldots$

3-1 Selected site properties $\quad \ldots \ldots \ldots \ldots \ldots \ldots \ldots \ldots \ldots \ldots \ldots \ldots$

3-2 Summary statistics of the Ks-data $\ldots \ldots \ldots \ldots \ldots \ldots \ldots \ldots \ldots \ldots \ldots \ldots \ldots \ldots \ldots \ldots$

3-3 Distribution of the transformed spatial Ks data $\quad \ldots \ldots \ldots \ldots \ldots \ldots \ldots 2$

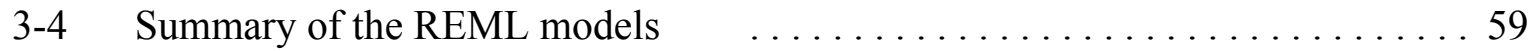

4-1 Rainfall characteristics of selected rainforest sites $\ldots \ldots \ldots \ldots \ldots \ldots \ldots$. . . . . 74

4-2 Rainfall characteristics of the montane and the lowland rainforest . . . . . . 86 


\section{$\underline{1 .}$}

\section{Introduction}

\subsection{The montane rainforest ecosystem in southern Ecuador}

With increasing elevation in wet tropical mountains, montane rainforests gradually displace the tall trees of the multi-storied lowland rainforest. This change seems to be largely controlled by temperature as it is normally observed at the elevation where the average minimum temperature drops below $18^{\circ} \mathrm{C}$ (Bruijnzeel, 2001). On large equatorial inland mountains the transition occurs at an altitude of 1200-1500 m (Bruijnzeel, 2001). Main floristic changes of montane forests compared to the lowland forests involve the mean canopy height (maximal $35 \mathrm{~m}$ ), the existence of two rather than three main canopy layers, and the high abundance of epiphytes.

In our study area, which is part of the south Ecuadorian Andes, "Lower Montane Rainforest" gradually changes to "Lower Montane Cloud Forest" on higher ground (Bruijnzeel and Hamilton, 2000). Not only the forest type but also other biotic and abiotic properties show a trend with increasing altitude, e.g. an increase of rain intensity of 35\% from 1800-3200 m and a vertical gradient in atmospheric water input as rainfall increases by $250 \mathrm{~mm} / 100 \mathrm{~m}$ up to $2600 \mathrm{~m}$ (Rollenbeck, 2007); a decreasing number of roots penetrating the mineral soil (Soethe et al., 2006); a decreasing density of oribatid mites (Maraun et al., 2008). This possible dependence of the ecosystems components on altitude was one of the restrictions regarding the site selection of this thesis. An old landslide, which we originally wanted to include into our study, had to be excluded afterwards because it appeared to be an outlier due to its location at a higher altitude compared to the other plots.

The other gradient, which characterizes our study area, arises from the fact that it extends over both valley sides of the Rio San Francisco (see pictures in the middle section). The most obvious difference between them is the human influence at the south-facing valley side, which resulted in a mosaic of pastures, fallows after pasture abandonment of different age and forests remnants, mainly on the steepest slopes. Signs of human interference at the northfacing valley side are restricted to the lowest parts. 


\subsection{Disturbances in the study area}

Due to climatic and topographic effects, the south Ecuadorian montane forest is frequently subject to shallow landslides. The triggering of these regional landslides is still insufficiently understood, which is why a recent project has been initiated that aims to understand their driving factors. In my thesis, I consider them as representatives of the intrinsic dynamics in the study area; hence, together with the mature forest they constitute a natural disturbance sequence.

For about 60 years, the south facing valley side has been greatly modified due to land-cover conversion. These activities resulted in the land-cover mosaic mentioned above (see pictures in the middle of the thesis). The regional pastures have a low carrying capacity and are frequently abandoned due to the invasion of bracken (Pteridium arachnoideum). I give a more detailed description of this human disturbance sequence in the introduction of chapter 3 (pp. $39-41)$.

\subsection{Hydrological flowpaths in soils of undisturbed tropical forests}

Our study addresses the part of the hydrological cycle, which starts when rain water, or in case of forest cover throughfall and stemflow, infiltrates into the soil. After a considerable portion of the infiltrated water is taken up by the vegetation and returned to the atmosphere, the remaining water flows through the soil profile to the stream. Its partitioning into various flowpaths is determined by topography, soil hydraulic properties and initial soil water conditions. With some exceptions, e.g. particularly clayey soils (Bell, 1973), infiltration excess overland flow (Hortonian overland flow) does not occur on undisturbed forest soils. More common, also under undisturbed conditions, is overland flow due to precipitation on previously saturated soils (saturation excess overland flow), which can be either topographydependent, i.e. in areas with wide valley bottoms, concave slopes and shallow soils (Dunne, 1978) or soil-dependent, in case of an impermeable horizon close to the surface (Bonell and Gilmour, 1978; Zimmermann et al., 2006). In the latter case, saturation develops above a layer with reduced hydraulic conductivity, which results in a perched water table. In landscapes with steep, straight slopes, which have conductive topsoil, storm flow is most likely composed of subsurface stormflow. This implies anisotropy of soil properties, i.e. the vertical decrease of macroporosity, which coincides with a decrease of the hydraulic conductivity. The latter is true because the permeability depends on the effective porosity 
according to the generalized Kozeny-Carman equation (Ahuja et al., 1984). If subsurface stormflow is forced back to the soil surface (return flow), e.g. due to microtopography, it can become a point source for overland flow (e.g. Elsenbeer and Vertessy, 2000).

In the humid tropics, the whole spectrum of these hydrological flowpaths can be found under natural conditions (Elsenbeer, 2001). One aim of my thesis was to integrate the tropical montane forest into this spectrum.

\subsection{Influence of disturbances on hydrological flowpaths}

The link between hydraulic conductivity and macroporosity provides the basis for the assumption that disturbances potentially impact on hydrological flowpaths. That is to say, the hydraulic conductivity is subject to all influences that change the macroporosity. In the humid tropics, the most common human impact is land-cover conversion from primary forests to pastures or other agricultural land. The resulting decrease of macroporosity is caused by compaction and changes in soil fauna and root systems; an involved change in hydrological flowpaths has been shown in a number of studies (Ziegler et al., 2004; Zimmermann et al., 2006). A possible relevance of those changes at the small catchment scale has recently been presented by Germer et al. (submitted), who found an increase in storm flow discharge of 17 $\%$ under pasture compared to primary forest in the Brazilian Amazon.

The still incomplete knowledge of the hydrological consequences of the land-cover change is even more fragmentary when considering the inverse process, which starts when secondary vegetation takes over after pasture abandonment. The importance of these fallows becomes clear when considering their dimensions in our study area: though deforestation claimed between $8-9 \%$ of an investigation area including the ECSF reserve and large parts of the Podocarpus national park, reforestation accounted for $4-7 \%$ in the same region spanning the period from 1986 to 2001 (Görner, 2006). A few studies in the humid tropics, restricted to lowland rainforest regions, provided evidence for a decades-requiring regeneration of soil hydrology following the obvious vegetation succession on the abandoned land (Godsey and Elsenbeer, 2001; Ziegler et al., 2004; Zimmermann et al., 2006).

To my knowledge, investigations on the soil-hydraulic regeneration after land-sliding are currently extremely sparse; an exception is the study of Vieira and Fernandes (2004). 


\subsection{General objective}

The overall aim of this work was to quantify the effects of the natural and human disturbances on the saturated hydraulic conductivity (Ks hereafter) and to describe the resulting spatialtemporal patterns. Both the documented sensitivity to disturbances (chapter 1.4.) and the central role in the regional water cycle (chapter 1.3.) substantiate the special suitability of this property when assessing the regional soil-landscape dynamics.

The following hypotheses summarize the general objective of the study:

1) Disturbances cause an apparent displacement of the less permeable soil layer towards the surface, either due to a loss of the permeable surface soil after land-sliding, or as a consequence of the surface soil compaction under cattle pastures.

2) 'Recovery' from disturbance, either because of landslide re-vegetation or because of secondary succession after pasture abandonment, involves an apparent displacement of the less permeable layer back towards the original depth.

3) Disturbances cause a simplification of the Ks spatial structure, i.e. the spatially dependent random variation diminishes. The subsequent recovery entails the re-establishment of the original structure.

In order to address these hypotheses, I used both statistical and geostatistical approaches. I estimated the implications for the plot-scale runoff generation by means of the regional rainfall regime.

\subsection{Chapter overview}

The thesis essentially consists of three papers, which address both the problems concerning the hypotheses above and the theoretical background regarding the spatial analysis of environmental data. Dealing with the latter arose from the sometimes confusing wealth of actual research regarding geostatistical data analysis, which seems to spill over to practical soil science to a limited extend only. After I spent considerable time on struggling through the recent geostatistical research, I decided to summarize my considerations in a separate paper, which is chapter 2 of this thesis. It is an attempted synthesis of the appropriateness of recent research results for all steps in geostatistical data analysis. Those included exploratory data analysis (check of uni- and bivariate distributions, decision of stationarity) and variogram estimation techniques (robust estimation requirements; correlation functions; estimation 
techniques); I subsequently evaluated the results in terms of spatial prediction uncertainty. At the end I summarize the results in a flowchart, which proposes a guideline for geostatistical data analysis.

Chapter 3 addresses the hypotheses of the research project, i.e. the spatial-temporal pattern of the saturated hydraulic conductivity in the sequences of natural and man-made disturbances (chapter 1.2.).

In the fourth chapter, I used the spatial-temporal information of saturated hydraulic conductivity in combination with local rain intensities to assess if the disturbance-effects impact on hydrological flowpaths, i.e. the partitioning of rainfall into vertical and lateral flowpaths. In chapter 5 I conclude with a summary of the research results and implications for future work. 


\title{
$\underline{2}$.
}

\section{Analyzing spatial data: an assessment of assumptions, new methods, and uncertainty using soil hydraulic data}

\begin{abstract}
Environmental scientists today enjoy an ever increasing array of geostatistical methods to analyze spatial data. Our objective was to evaluate several of these recent developments in terms of their applicability to real-world datasets of the soil field-saturated hydraulic conductivity $(\mathrm{Ks})$. The intended synthesis comprises exploratory data analyses to check for Gaussian data distribution and stationarity; evaluation of robust variogram estimation requirements; estimation of the covariance parameters by least-squares procedures and (restricted) maximum likelihood; use of the Matérn correlation function. We furthermore discussed the spatial prediction uncertainty resulting from the different methods.

The log-transformed data showed Gaussian uni- and bivariate distributions, and significant local trends. Robust estimation techniques were not required, and anisotropic variation was not evident. Restricted maximum likelihood estimation versus the method-of-moments variogram of the residuals accounted for partly considerable differences in covariance parameters, whereas the Matérn and standard models gave very similar results. In the framework of spatial prediction, the parameter differences were mainly reflected in the spatial connectivity of the Ks-field. Ignoring the trend component and an arbitrary use of robust estimators would have the most severe consequences in this respect. Our results highlight the superior importance of a thorough exploratory data analysis and proper variogram modeling, and prompt us to encourage restricted maximum likelihood estimation, which is accurate in estimating fixed and random effects.
\end{abstract}

\footnotetext{
With: Erwin Zehe, Niklas Hartmann \& Helmut Elsenbeer; an edited version is currently under review with Water Resources Research
} 


\subsection{Introduction}

Environmental scientists today enjoy an ever increasing array of methods to choose from to analyze spatial data. New techniques are constantly developed that aim to combine physical laws, observations and process knowledge for modeling the variability of environmental variables, both in space and time (Heuvelink and Webster, 2001). Geostatistics, which predominantly uses observations to describe the spatial variability of, for instance, soil properties, has come a long way since its introduction to soil science in the 1980s. Improvements relevant to soil hydrology include: new variogram estimation techniques (Pardo-Igúzquiza, 1998; Lark, 2000b; Minasny and McBratney, 2005), robust estimation (Cressie and Hawkins, 1980; Dowd, 1984; Watson, 1997; Genton, 1998; Lark, 2000a), scale effects in variogram estimation (Skøien and Bloeschl, 2006), trend modeling (Leuangthong and Deutsch, 2004; Lark et al., 2006), model selection (Geiler et al., 1997; Lark, 2000a; Lark, 2000b), sample size requirements for estimating variograms (Webster and Oliver, 1992; Gascuel-Odoux and Boivin, 1994), and variogram uncertainty for the method-of-moments variogram (Marchant and Lark, 2004). Although incomplete, this list hints at the considerable number of aspects the user of geostatistics - e.g., the soil hydrologist - should consider. By implication, this short list also hints at various pitfalls the unsuspecting user of geostatistics may encounter. To our knowledge, however, there has been no soil-hydrological study that evaluates in a comparative manner at least several of those new developments within a geostatistical framework. This lack prompted us to attempt such a comparison, using realworld datasets of soil field-saturated hydraulic conductivity (Ks from here on). We measured Ks under different land covers to characterize its spatial and temporal variation in the tropical montane rainforest of southern Ecuador. For this study, we selected three datasets, which comprise measurements at three soil depths under an old fallow regenerating from antecedent pasture use. Our comparison is based on the following research questions:

1) Do soil hydraulic data satisfy the assumption of stationarity?

2) Do we need robust estimation techniques?

3) Do we have to account for anisotropic variation?

4) In which manner do different variogram estimation techniques, e.g. restricted maximum likelihood versus method-of-moments estimation, contribute to variations in the estimated covariance parameters?

5) Should we use the "novel" Matérn function?

6) How can we get a reasonable estimate of the nugget variance? 
7) In which manner do the variations in the estimated covariance parameters (items 4-6) influence spatial predictions?

8) Does the existing literature regarding Ks spatial variability allow for any general statements, e.g. a dependence on certain environmental conditions?

The results of the comparison are the basis for recommendations regarding the geostatistical analysis of soil hydraulic properties in particular, and environmental data in general.

\subsection{Study area}

Embedded in the Eastern Cordillera of the Andes of south Ecuador, our study area (Figure 21) is located in the Reserva Biósfera de San Francisco around the Estación Científica San Francisco (ECSF) $\left(3^{\circ} 58^{\prime} 18^{\prime \prime} \mathrm{S}, 79^{\circ} 4^{\prime} 45^{\prime \prime} \mathrm{W}, 1860 \mathrm{~m}\right.$ a.s.1.). Steep slopes (30-50 $)$ covered with "Lower Montane Rain Forest", which gradually changes to "Lower Montane Cloud Forest" on higher ground (Bruijnzeel and Hamilton, 2000), characterize the north - facing slopes, where there are no signs of recent human intervention in the ECSF reserve. In contrast, the south - facing slopes have been subject to human influence for decades. Mean annual precipitation (1998-2005) amounts to $2273 \mathrm{~mm}$ (Rollenbeck et al., 2007), and mean annual (1999-2002) air temperature is $15.5^{\circ} \mathrm{C}$ (Motzer et al., 2005). A drier period is between November and January, and May and June are the wettest months (Motzer et al., 2005).

The bedrock consists mainly of weakly metamorphosed Palaeozoic schists and sandstones with some quartz veins (Wilcke et al., 2003), which belong to the Chiguinda unit (Mapa geológico del Ecuador; Instituto Geográfico de Militar y Ministerio de Energía y Minas). Soils are classified as Inceptisols and Histosols (Schrumpf et al., 2001; Soil Survey Staff, 1999) with a high percentage of silt.

For this study, we selected a plot of 50 times 70 meters in an old fallow situated at the southfacing valley side such that the $\mathrm{x}$-coordinate approximately follows the contour line. Main elevation differences occur in main slope direction (i.e. in direction of increasing ycoordinate), but there is also a topography gradient following the contour line, as the left side of the plot is located near a gully and the right side on a ridge. After a recovery of at least 10 years from antecedent pasture use, the fallow is covered by bracken (Pteridium aquilinum), which is very abundant in the pasture areas of this region, and succession vegetation. Among the most abundant succession plant families are Orchidaceae, Asteraceae, Ericaceae, 
Melastomataceae, Poaceae, Rosaceae, Gleicheniaceae, Lycopodiaceae, Bromeliaceae, and Myrsinaceae.

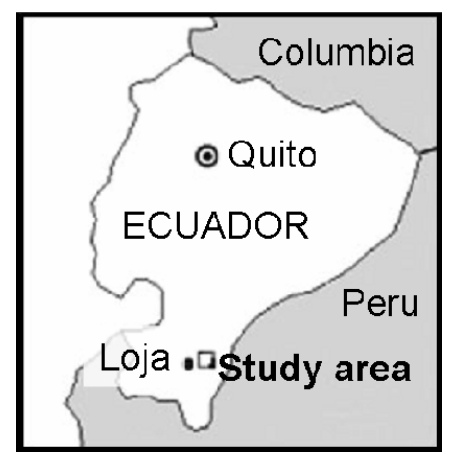

Figure 2-1. Location of the study area.

\subsection{Methods}

\subsubsection{Field measurements and sampling strategy}

We measured the field-saturated hydraulic conductivity in situ in the mineral soil at the depths of 12.5, $20 \mathrm{~cm}$ and $50 \mathrm{~cm}$ with an Amoozemeter, which is a Compact Constant-Head Permeameter (Ksat Inc., Raleigh; Amoozegar, 1989a). The procedure involved augering a cylindrical hole with radius $r$ to the desired depth, establishing a constant head $\mathrm{H}$ such that $\mathrm{H} / \mathrm{r}$ $\geq 5$ and monitoring the outflow from the device until a steady-state flow rate is attained; at which point $K s$ can be calculated via the Glover solution (Amoozegar, 1989b). This model deals only with one equation, based on gravitational flow and gravitational potential (Amoozegar, 1993). For a comparison of calculated $K s$ by the Glover equation with the calculated $K s$ using different Alpha parameter values (Elrick and Reynolds, 1992), the Glover equation gave results that were comparable to the results obtained by the fixed Alpha value approach (Amoozegar, pers. comm.).

We used a combined design- and model-based sampling design to satisfy the requirements both for the intra-site spatial analysis presented here, and for an inter-site comparisons to be published elsewhere. This design involved the random selection of 30 squares of $2 \mathrm{~m}^{2}$; the selection of 5 fixed measurement points, which resulted in a sample size of 150 per soil depth, and somewhat less at $50 \mathrm{~cm}$ depth where augering was not possible in all places due to high stoniness. We chose this sample size in reference to Webster and Oliver (1992) and GascuelOdoux and Boivin (1994) who recommended to sample at some 150 to 200 points in an area to estimate the variogram of that area. Since we had no information about the range of the 
spatial correlation, but knew from studies in the Brazilian Amazon that spatial patterns of $K s$ emerged only with a high sampling resolution (i.e., short lag distances) (Sobieraj et al., 2004), we emphasized small separation distances, starting with the smallest possible point distance of $0.25 \mathrm{~m}$. This distance emerged from field trials showed that yet smaller distances would cause prior measurements to interfere with subsequent ones. This procedure resulted in an irregular sampling scheme, which is illustrated in Figure 2-2.

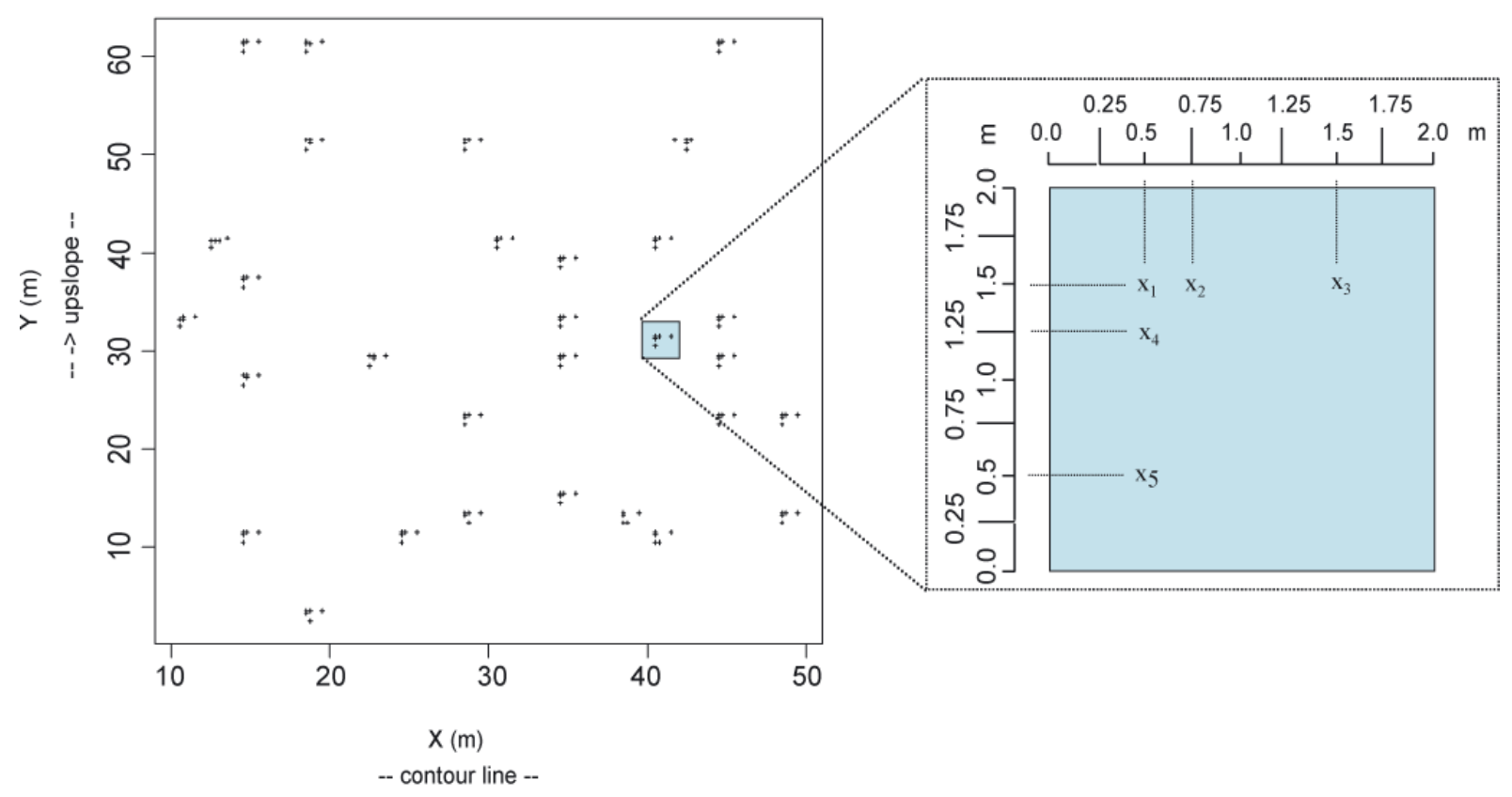

Figure 2-2. Sampling grid.

\subsubsection{Data analyses}

For all data analysis we used the language and environment of $R$, version 2.2.1. (R

Development Core Team, 2004); many of the geostatistical methods were implemented in the libraries geoR (Ribeiro and Diggle, 2001) and gstat (Pebesma, 2004).

\subsubsection{Exploratory data analysis}

We first checked the univariate distribution of the Ks-data by means of diagnostic plots (boxplots, quantile-quantile plots, histograms), and used the Box-Cox transformation (Box and Cox, 1964) to find the most appropriate transformation. We also produced $\mathrm{h}-$ scattergrams (Webster and Oliver, 2001a), which are scatterplots of point pairs separated by a fixed distance to scrutinize the data for possibly outlying values. 
We used diagnostic plots (dividing the data into quintiles; plots of the data versus the coordinates) to explore the data for non-stationarity that may be caused by local trends following the relation

$$
z(x)=\mu(x)+\varepsilon(x)
$$

where $z(x)$ is the observed variable at location $x, \mu(x)$ is a measure of central tendency, i.e., a deterministic drift of the variable at location $x$, and $\varepsilon(x)$ is the random component at location $x$ that should be normally distributed with zero mean and that satisfies the second-order stationarity required for spatial analysis. Hence, we calculated the residual values $\varepsilon(x)$ at every location $x$ and used them for the subsequent geostatistical analyses of the method-of-moments variogram if the F-test (Fisher, 1972) showed that $\mu(x)$ was significantly different from 0.

\subsubsection{Geostatistical analysis}

Experimental variogram estimation

As a first step in the variogram analysis, we calculated experimental variograms using the "classical" variogram estimator due to Matheron (1962)

$$
2 \hat{\gamma}_{M}(h)=\frac{1}{N(h)} \sum_{i=1}^{N(h)}\left\{z\left(x_{i}\right)-z\left(x_{i}+h\right)\right\}^{2},
$$

where $z\left(x_{i}\right)$ is the observed value at location $x_{i}, N(h)$ are the pairs of observations that are separated by lag $h$.

Since one cannot totally exclude the presence of extreme values by the inspection of diagnostic plots, we also produced robust experimental variograms with estimators proposed by Cressie \& Hawkins (1980), Dowd (1984), and Genton (1998). The Cressie - Hawkins' estimator is given by:

$$
2 \hat{\gamma}_{C H}(h)=\frac{\left\{\frac{1}{N(h)} \sum_{i=1}^{N(h)} \mid z\left(x_{i}-\left.z\left(x_{i}+h\right)\right|^{\frac{1}{2}}\right\}^{4}\right.}{0.457+\frac{0.494}{N(h)}+\frac{0.045}{N^{2}(h)}} .
$$


The Dowd estimator is

$$
2 \hat{\gamma}_{D}(h)=2.198\left\{\text { median }\left(\left|y_{i}(h)\right|\right)\right\}^{2}
$$

where $y_{i}(h)=z\left(x_{i}\right)-z\left(x_{i}+h\right), i=1,2, \ldots, N(h)$; and Genton's estimator is given by

$$
2 \hat{\gamma}_{G}(h)=\left(2.219\left\{\mid y_{i}(h)-y_{j}(h) ; ; i<j\right\}_{\left(\begin{array}{c}
H \\
2
\end{array}\right)}\right)^{2},
$$

with $y_{i}(h)$ defined as for Equation (3) and $H=$ integer part $(n / 2)+1, n=N(h)$.

For an in-depth discussion of the efficiency and robustness of the robust estimators we refer to Lark (2000a).

Since our sampling was highly irregular we had to define lag classes, which are groups of different individual lag distances between point pairs, such that every comparison constitutes one estimate only. This procedure is quite arbitrary, so we used different lag classes to compute the experimental variograms, and we then compared their influence on the theoretical variogram models. On the one hand, we calculated experimental variograms using lags in accordance with the unsystematic sampling design ("visually selected experimental variograms"). On the other hand, we chose the lags in a regular manner such that one lag was used every $25 \mathrm{~cm}$ if the minimum number of point pairs was at least 30 .

We also checked our data for anisotropy by calculating the experimental variograms in four different directions, one representing the contour line, one the slope and the other two are in between those two extremes.

Estimation of covariance parameters

First we had to decide if we needed robust estimation techniques. For this purpose, we fitted three standard theoretical variogram models (exponential, Gaussian, spherical) to visually selected experimental variograms derived from the "classical" Matheron and the three robust estimators by ordinary least squares. The "best" model was chosen by the minimum sum of squares from the fit, which is a conventional measure for the goodness-of-fit in a least squares fitting procedure. We then adopted the approach of Lark (2000a) who compared the 
variograms derived from all abovementioned estimators by cross - validation or with a validation subset using a statistics $\theta(\mathrm{x})$ defined as

$$
\theta(x)=\frac{\{z(x)-Z(x)\}^{2}}{\sigma_{K, x}^{2}}
$$

where $z(x)$ is the observed value at location $x, Z(x)$ is the kriged estimate and $\sigma_{K, x}^{2}$ the kriging variance. He argued that assuming normal kriging errors, $\theta(\mathrm{x})$ will be distributed as $\chi^{2}$ with one degree of freedom. Since the median of the standard $\chi^{2}$ distribution with one degree of freedom is 0.455 , the median of $\theta(\mathrm{x})$ is also 0.455 when a correct variogram is used to interpolate intrinsic data. A sample median significantly less than 0.455 suggests that kriging overestimates the variance whereas one which is greater than 0.455 underestimates the variance. In the former case, this may be due to the effects of outliers on the variogram, and in the latter case due to the effect of non-normality on a robust estimator. In order to compute confidence limits for the median of $\theta(\mathrm{x})$, Lark refers to standard text statements that the median of a large sample of $2 n+1$ data, which are random variables of median $\tilde{x}$ and probability density function $f(x)$, is a normally distributed variable drawn from a population with variance $\sigma_{\widetilde{x}}^{2}$ where

$$
\sigma_{\widetilde{x}}^{2}=\frac{1}{8 n * f(0.455)^{2}}
$$

where $f(0.455)$ is the value probability density function of 0.455 with one degree of freedom. At this point the confidence limits can be computed by

$$
0.455 \pm 1.96 * \sqrt{\sigma_{\widetilde{x}}^{2}}
$$

We used cross-validation to compare the classical and robust variogram estimators. For the soil depths of 12.5 and $20 \mathrm{~cm}(\mathrm{n}=150)$, the upper and lower $95 \%$ confidence limits for the median of $\theta(\mathrm{x})$ were calculated as 0.286 and 0.624 , respectively; for the $50 \mathrm{~cm}$ depth $(\mathrm{n}=105)$ they were 0.251 and 0.659 , respectively. Lark (2000a) proposed to select the estimator with the median value of $\theta(\mathrm{x})$ closest to 0.455 , if the median of $\theta(\mathrm{x})$ indicates that Matheron's estimator (which otherwise is the estimator of choice because of its efficiency) is significantly 
influenced by outliers. If all robust estimates are similar, then he recommended Genton's due to its efficiency.

If the median of $\theta(\mathrm{x})$ ruled out the presence of influential extreme values and hence supported using the Matheron estimator, we compared two lines of geostatistical analysis one of which is based on fitting a theoretical model to an experimental variogram whereas the other uses maximum likelihood, which estimates the covariance parameters directly from the data. In the former case, we fitted the model by least squares (LS) to the visually selected experimental variogram both over the whole (abbr. LS1) and over half the separation distance (abbr. LS2), and to the regular experimental variogram (abbr. LS3). We again used the abovementioned standard variogram models (exponential, Gaussian, spherical) and goodness-of-fit criterion, and two different weights: equal weights (ordinary least squares, abbr. OLS), and weights which correspond to the number of point pairs in each lag class (weighted least squares, abbr. WLS).

The principle of maximum likelihood estimation of variogram parameters is as follows: $n$ observed data are assumed to be from a multivariate Gaussian distribution with mean vector $m$ of length $n$ and covariance matrix $\Sigma$; the joint probability density of the data is

$$
f(z)=(2 \pi)^{-n / 2}|\Sigma|^{-1 / 2} \exp \left\{-\frac{1}{2}(z-m)^{T} \Sigma^{-1}(z-m)\right\}
$$

The vector $z$ contains the $\mathrm{n}$ data, and the vector $p$ contains the parameter of the covariance matrix. If the mean $m$ and the covariance $\Sigma$ are unknown and depend on parameter vectors $m$ and $p$, respectively, one can regard $z$ as fixed and $f(z)$ as a function of $m$ and $p$, which is called the likelihood function $L(m, p)$. Maximizing the likelihood, or minimizing the negative loglikelihood $-\log L(m, p)$ yields the parameter estimates. Restricted maximum likelihood treats the geostatistical model as a special case of a linear mixed model where the data are modeled as an additive combination of fixed effects (e.g. coefficients of a trend model), random effects (spatially dependent random variation) and independent random error (nugget variation). For a detailed mathematical description of the method we refer to Lark et al. (2006).

Within the framework of likelihood estimation, we also used the Matérn model in addition to the three standard correlation functions. The semivariance of this model is given by

$$
\gamma(h)=c_{0}+c_{1}\left(1-\frac{1}{2^{v-1} \Gamma(v)}\left(\frac{h}{r}\right)^{v} K_{v}\left(\frac{h}{r}\right)\right),
$$


where $c_{0}$ is the nugget variance, $c_{0}+c_{1}$ is the sill variance, $v$ is the smoothness parameter $(v>0), \Gamma$ is the gamma function, $r$ is the range parameter, and $K_{v}$ is a modified Bessel function of the second kind of order $v$. The great flexibility of the Matern model compared with standard models is based on its smoothness parameter $v$, which represents several theoretical models; examples are given in Minasny and McBratney (2005). They stated that $v$ implies the "roughness" or "smoothness" of the spatial process $(v \rightarrow 0$ : rough spatial process; $v \rightarrow \infty$ : smooth spatial process). They concluded that $v$ should be estimated by restricted maximum likelihood because a weighted nonlinear least squares estimation could give misleading results. Lark et al. (2006) stated that REML estimates are consistent as they converge in probability to the parameters to be estimated with less bias than both maximum likelihood estimates and method-of-moment estimates obtained from residuals of a fitted trend.

The ML method, however, has its own drawbacks; first, it lets the selection of parameters depend on sampling fluctuations and second, its explicit assumption of a multivariate normal distribution, which cannot be verified because we only have one realization of the full joint distribution of a variable (Pardo-Igúzquiza, 1998). Among others, Lark et al. (2006) discussed this problem in the context of spatial prediction of soil properties. Chilés and Delfiner (1999) suggested, in the framework of Gaussian simulation, that at least the bivariate distributions of the (transformed) data could be checked, e.g. those h-scattergrams which we already used for the outlier detection. These plots ought to be elliptical when the point pairs are autocorrelated, or circular in the uncorrelated case; deviations from the normal distribution can be easily detected (Figure 2-3).

Since we wanted to evaluate the parameters of the variogram models that were derived by the described methods, we calculated the effective range in each case to allow for comparability of the correlation lengths independent of the model type. The effective range for the spherical model coincides with the model range; for the exponential model, the effective range is approximately the model range times 3 , and for the Gaussian model it is estimated by the model range times the square root of 3 (Webster and Oliver, 2001b). For the Matérn model we visually established an effective range at $95 \%$ of the sill.

We also wanted to discuss the handling of the nugget value. Minasny and McBratney (2005) proposed to fix the nugget to the variance at the shortest possible separation distance (the smallest lag) due to difficulties to simultaneously estimate the nugget variance of the Matérn model with REML if the spatial process is rough. We adopted this proposal and tried both possibilities within the REML estimation framework: in one case we simultaneously 
estimated the nugget, and in the other case we fixed it to the semivariance at our shortest lag of $0.25 \mathrm{~cm}$, which was calculated using the above-mentioned formula of Matheron (1962).
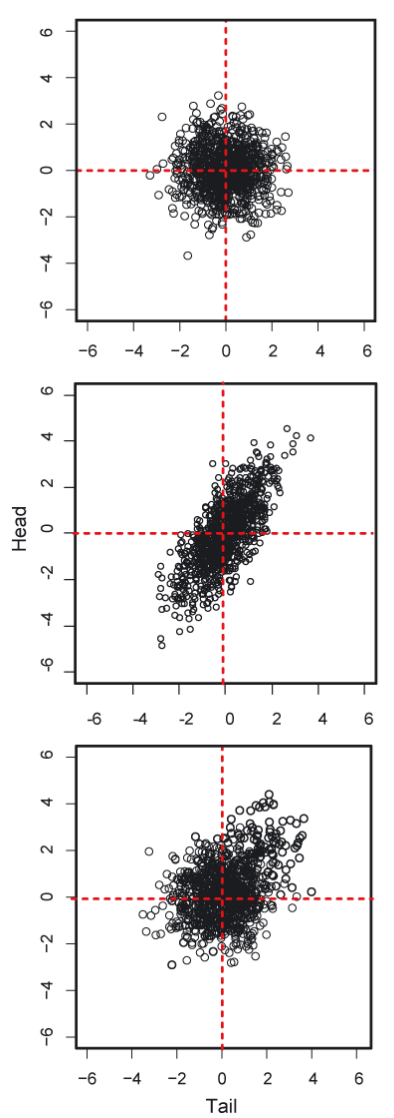

Figure 2-3. Examples of h-scattergrams. The vertical and horizontal red lines correspond to the population mean. A: Uncorrelated point pairs of a population that consists of two sets of randomly generated data of distribution $\mathrm{N}(0,1)$, where $\mathrm{N}\left(\mu, \sigma^{2}\right)$ denotes a normal distribution of mean $\mu$ and variance $\sigma^{2}$; B: Correlated point pairs of a population that consists of two sets of randomly generated data, one of which is set 1 from $A$ and the other is the sum of the two sets of $A ; C$ : Uncorrelated point pairs of a population that consists of two sets of randomly generated data of distribution $\mathrm{N}(0,1)$, each of which comprises a $10 \%$ contamination of a population with distribution $\mathrm{N}(2,1)$.

Spatial prediction

In order to evaluate the influence of the differences in variogram parameters involved in the described estimation techniques on spatial prediction, we first produced kriging maps. We therefore interpolated the residual values via simple kriging and then added the trend coefficients back to the interpolated residuals (Goovaerts, 1997a). We furthermore calculated the deviations of the kriged Ks-values that arose due to two different input models. For this purpose, we chose one covariance model as the reference against which the other models are compared.

We then performed 100 conditional sequential Gaussian simulations again using all different variogram models. For every input model, we post-processed the 100 simulations to summarize the spatial uncertainty information. We displayed the outcome in probability maps: at each simulated grid node, the probability of exceeding a given threshold is evaluated as the proportion of the 100 simulated values that exceed that threshold (Goovaerts, 1997b). 
To assess the hydrological consequences of the spatial structure of $K s$, e.g. the spatial distribution of possible impeding layers, we calculated for every grid node the probability that $\mathrm{Ks}$ is exceeded by some location estimate of local rainfall intensities. We extracted these intensities from ten-minute rainfall records for the period October 2005 to September 2006 (unpublished data T. Peters, Erlangen) of a climate station which is located some 100 meters away from our plot. From this data set, we calculated maximum 30-minute rainfall intensities of rainfall events that were separated from each another by a dry period of at least $2 \mathrm{~h}$. Location estimates of those intensities (e.g., median, upper quartile, maximum) can serve as 'thresholds': where they exceed simulated Ks values, impeding layers are likely to exist.

\subsection{Results}

\subsubsection{Exploratory data analysis}

The Box - Cox transformations revealed that taking logarithms is the most appropriate transformation for the right-skewed Ks - data, which corresponds to a multitude of other studies of Ks (see Table 2-1 for examples from the literature).

Significant trends exist for the log-transformed data at the three soil depths, which appear to be a first order polynomial on the $\mathrm{x}-(12.5,20 \mathrm{~cm}$ depth $)$ or the $y$-coordinate $(50 \mathrm{~cm}$ depth, respectively (Figure 2-4). Thus, they can easily be removed by linear regression. At the shallow soil depths, Ks decreases from the left to the right side of the plot (i.e. from gully to ridge), which we attribute to topography-dependent differences in soil depth and vegetation cover. At the $50 \mathrm{~cm}$ depth, higher Ks characterizes the lower parts of the plot; however, this trend is not as consistent for the topsoil. In summary, trend denotes a local feature of our data and may be an effect of either selecting too small an extent (Skøien and Blöschl, 2006) or structured variability that in turn is a fingerprint of the landscape organization, in our case slope affecting soil formation. 


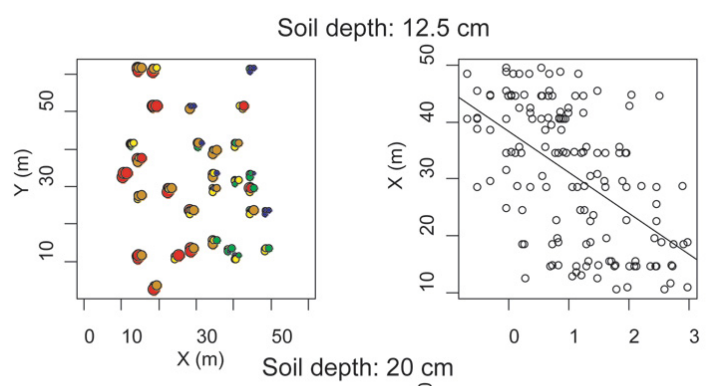

Figure 2-4. Plots of the log-transformed data divided into quintiles (greater point sizes indicate higher Ks; left side), and linear regression of the transformed data with the respective coordinate as the independent variable (right side).
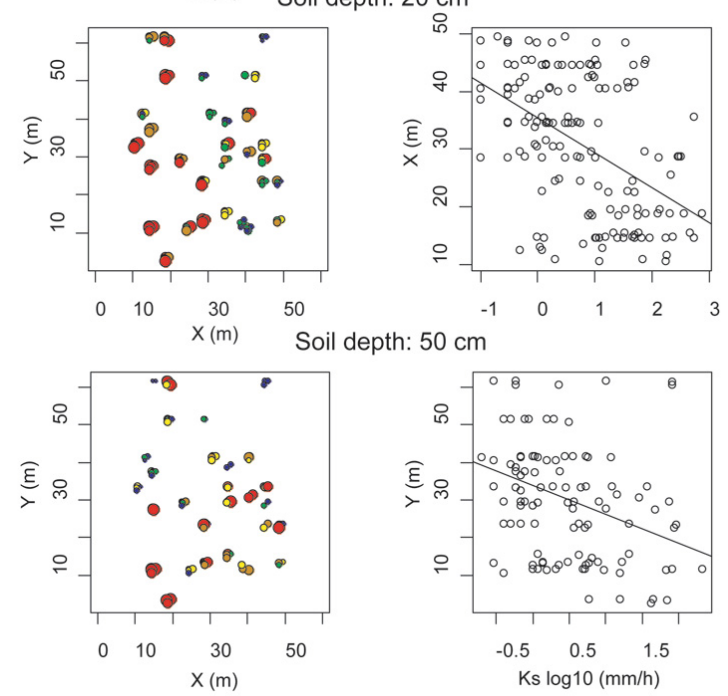

Consequently we performed all subsequent analyses with the residuals of the linear regression or estimated the trend coefficients as fixed effects within the REML estimation of the covariance function, respectively. The univariate distribution of the residuals appears approximately Gaussian with a higher skewness at $50 \mathrm{~cm}$ soil depth (Figure 2-5). H scattergrams display bivariate normal distributions and do not reveal any outlying values (Figure 2-6). They also indicate weak and very short autocorrelations at $12.5 \mathrm{~cm}$ depth, which are somewhat stronger at $20 \mathrm{~cm}$ depth vanishing after a few meters and strongest at $50 \mathrm{~cm}$ depth, but again not exceeding some meters.

We did not encounter problems in trend decomposition as heteroscedastic variance of residuals or linear constraints on the residuals (Leuangthong and Deutsch, 2004). 

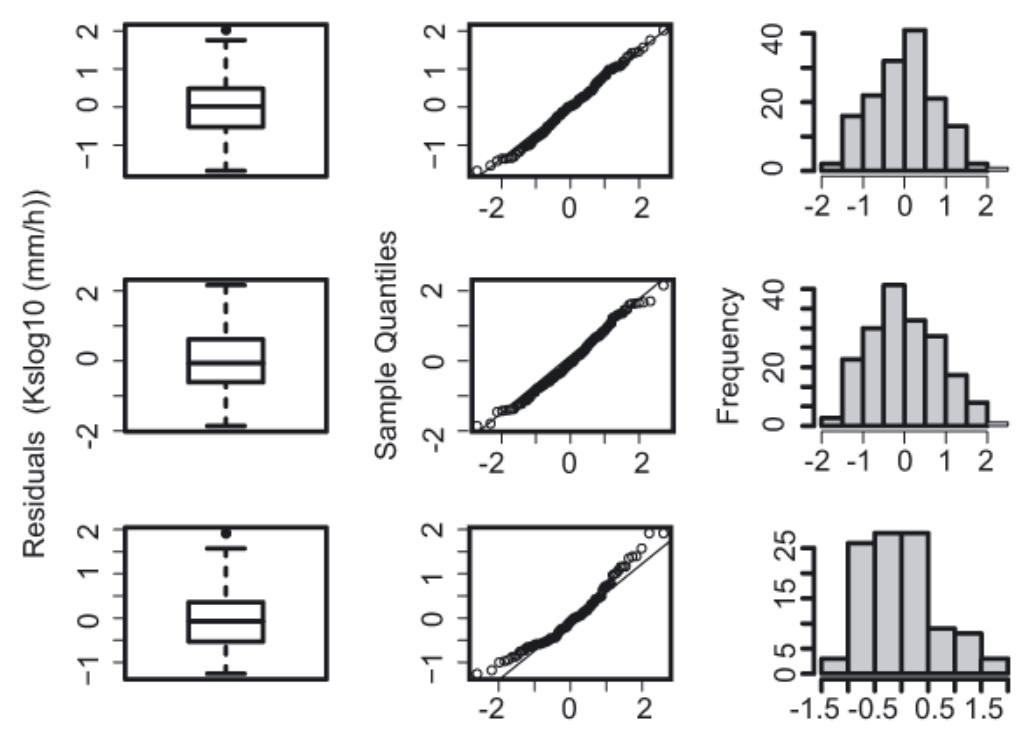

Theoretical Quantiles Residuals (Kslog10 (mm/h))

Figure 2-5. Univariate distribution of the residuals from regression for the $12.5 \mathrm{~cm}$ (top), $20 \mathrm{~cm}$ (middle), and 50 $\mathrm{cm}$ (bottom) soil depth.
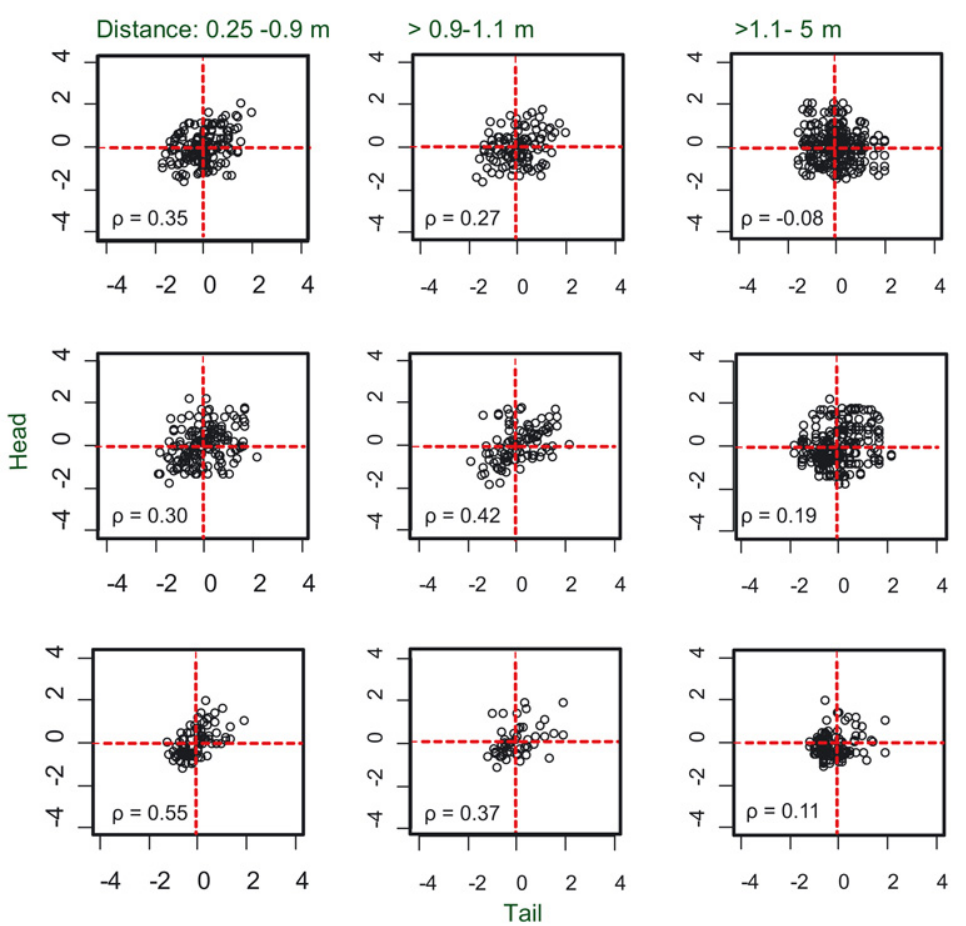

Figure 2-6. Bivariate distribution of the residuals for the $12.5 \mathrm{~cm}$ (top), $20 \mathrm{~cm}$ (middle), and $50 \mathrm{~cm}$ (bottom) soil depth; $\rho$ is the Pearson correlation coefficient.

\subsubsection{Geostatistical analysis}

Experimental variogram estimation 
The results for robust variogram estimation compared to classical estimation with the Matheron estimator revealed considerable differences between them related both to the selected model and the theoretical variogram parameters nugget, sill and range at all depths (Table 2-2). Since the variograms depend strongly on the selected lag classes, we were not able to delineate any systematic features of the several estimators. In spite of those differences, the median of $\theta(\mathrm{x})$ is rather insensitive and always remains within the confidence limits when using the Matheron estimator, and likewise for the robust estimators in most instances. Thus, the Matheron estimator can be used for all datasets, and robust estimation is not required at all.

Table 2-2. Results of robust estimation

\begin{tabular}{|c|c|c|c|c|c|c|c|c|c|}
\hline $\begin{array}{l}\text { Soil depth } \\
\text { (cm) }\end{array}$ & $\begin{array}{l}\text { Esti- } \\
\text { mator }^{a}\end{array}$ & Model $^{b}$ & Nugget & $\begin{array}{l}\text { Partial } \\
\text { sill }^{c}\end{array}$ & Sill & Range & 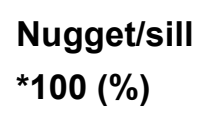 & $\begin{array}{l}\text { Median of } \\
\theta(x)\end{array}$ & $\begin{array}{l}\text { Mean of } \\
\theta(x)\end{array}$ \\
\hline \multirow[t]{4}{*}{12.5} & $M$ & Exp & 0.43 & 0.16 & 0.58 & 3.24 & 72.83 & 0.457 & 1.00 \\
\hline & $D$ & Exp & 0.36 & 0.29 & 0.64 & 3.24 & 55.53 & 0.535 & 1.08 \\
\hline & $\mathrm{CH}$ & Exp & 0.45 & 0.16 & 0.61 & 3.24 & 73.68 & 0.433 & 0.97 \\
\hline & G & Exp & 0.53 & 0.07 & 0.60 & 17.82 & 88.32 & 0.505 & 1.03 \\
\hline \multirow[t]{4}{*}{20} & $M$ & Gau & 0.40 & 0.34 & 0.75 & 8.10 & 54.05 & 0.483 & 1.15 \\
\hline & $\mathrm{D}$ & Exp & 0.33 & 0.50 & 0.83 & 6.48 & 39.85 & 0.534 & 1.19 \\
\hline & $\mathrm{CH}$ & Exp & 0.40 & 0.40 & 0.81 & 4.86 & 50.02 & 0.477 & 1.00 \\
\hline & G & Exp & 0.46 & 0.22 & 0.68 & 4.86 & 68.29 & 0.423 & 0.97 \\
\hline \multirow[t]{4}{*}{50} & $M$ & Exp & 0.23 & 0.27 & 0.49 & 9.72 & 45.56 & 0.426 & 1.04 \\
\hline & $\mathrm{D}$ & Gau & 0.17 & 0.28 & 0.45 & 11.34 & 37.11 & 0.755 & 1.75 \\
\hline & $\mathrm{CH}$ & Exp & 0.26 & 0.30 & 0.56 & 21.05 & 46.70 & 0.445 & 1.06 \\
\hline & $\mathrm{G}$ & Exp & 0.36 & 0.16 & 0.52 & 6.48 & 68.60 & 0.350 & 0.77 \\
\hline
\end{tabular}

${ }^{a}$ experimental variogram estimators proposed by Matheron (M), Dowd (D), Cressie-Hawkins $(C H)$, and Genton (G)

${ }^{\mathrm{b}}$ selected theoretical variogram model, Exp: exponential; Sph: spherical; Gau: Gaussian

${ }^{\mathrm{c}}$ sill variance less the nugget variance

Anisotropic behavior is not evident (Figure 2-7). Interestingly, if calculating directional variograms for the log-transformed data containing the trend component one could assume zonal anisotropy (Figure 2-8); this is particularly conspicuous at the shallow soil depths, where the strongest spatial correlation (without reaching a sill due to the unbounded variance) coincides with the direction of the trend component. 

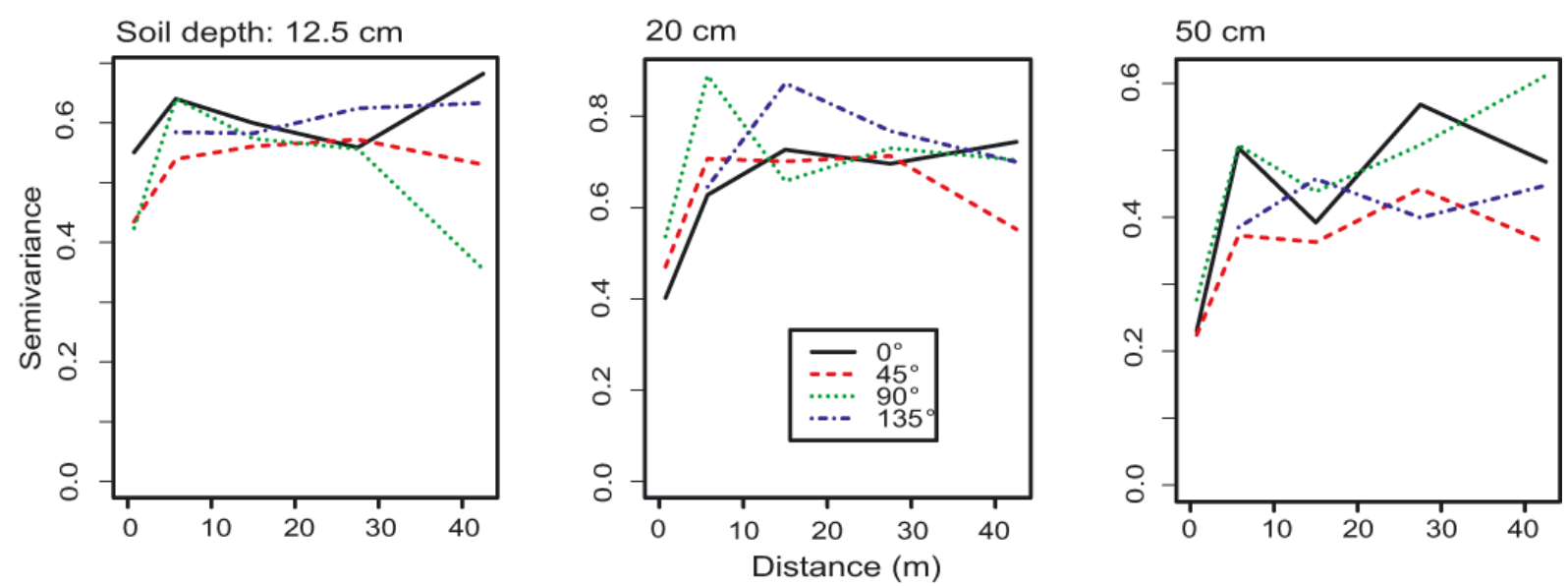

Figure 2-7. Directional variograms of the residuals. $90^{\circ}$ follows the direction of the contour line (i.e. the $x$ coordinate), and $0^{\circ}$ is the direction of the slope. Angle tolerance is $22.5^{\circ}$.
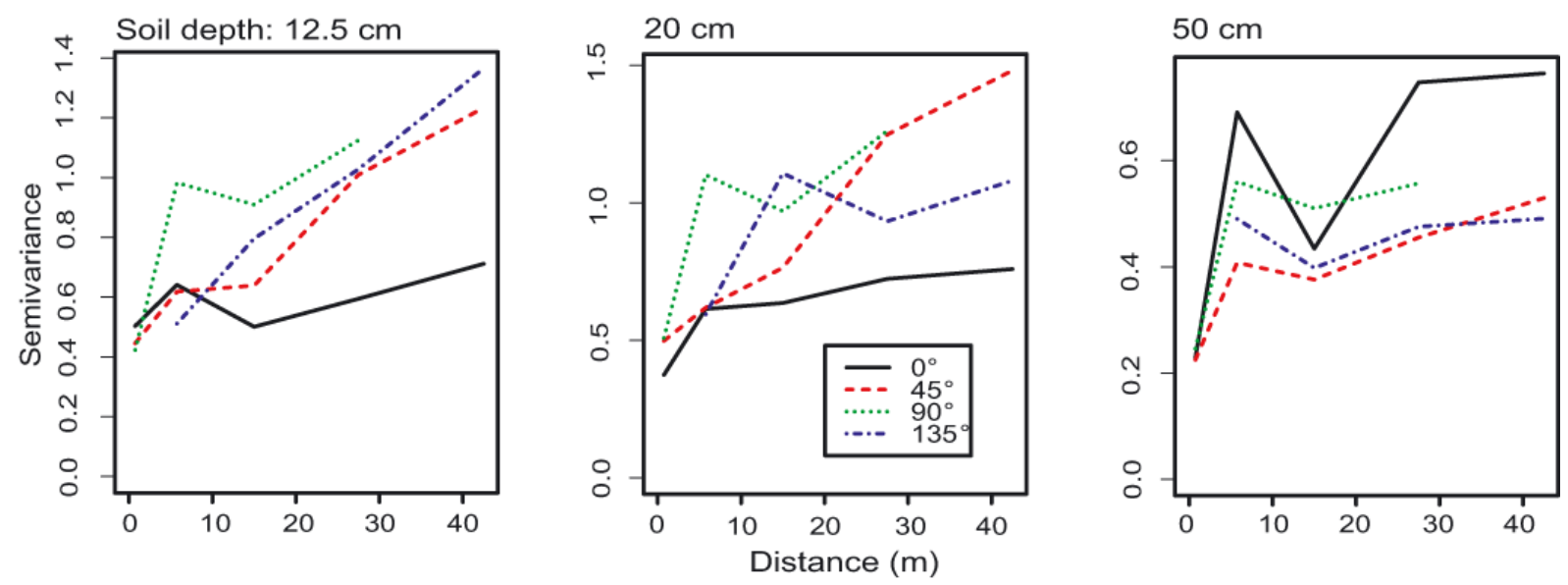

Figure 2-8. Directional variograms of the log-transformed data before trend decomposition. $90^{\circ}$ follows the direction of the contour line (i.e. the x-coordinate), and $0^{\circ}$ is the direction of the slope. Angle tolerance is $22.5^{\circ}$.

Estimation of covariance parameters

Greatest differences characterize the $50 \mathrm{~cm}$ depth, where the spatial autocorrelation is strongest, in contrast to the other soil depths where all models suggest a very short correlation (Table 2-3, Figure 2-9). At the $20 \mathrm{~cm}$ depth, the models of the regular experimental variograms have shorter ranges, and only the model fitted by weighted least squares over half the separation distance appears out of range compared to the bulk of models. At this depth, it was impossible to fit the Matérn model, possibly because of a flat likelihood function that does not reach a distinctive maximum. The most pronounced features at the $50 \mathrm{~cm}$ depth include the somewhat higher sill of the REML models, which is certainly due to the different estimate of the trend coefficients compared to those of the linear regression; the similarity 
between the Matérn and the respective standard model; and the similarity of the ML models of the residual data with the LS models of the regular experimental variograms. The greatest deviation from the bulk of models is associated with the OLS1 estimate, which comprises a comparatively large range and sill. This is due to the fact that this model fits with equal weights to all points of the visually selected experimental variogram (Figure 2-9); i.e. the high semivariance at the largest lag (possibly an edge effect) has to be incorporated in the estimate. The median of $\theta(\mathrm{x})$ appears to be not a sensitive indicator to assess those differences since it shows only small and insignificant variation; moreover, its optimum in the sense of being closest to the expectation does not correspond to the model which gives the minimum sum of squares or the highest likelihood, respectively (Table 2-3). When considering the mean of $\theta(\mathrm{x})$, however, a somewhat clearer picture emerges since it is always very close to the expectation for the likelihood models (Table 2-3), and there appears to exist some systematic behavior at least at $50 \mathrm{~cm}$ depth, where it exceeds the expectation for the models of the visually selected experimental variograms and falls below it for those of the regular experimental variograms (not shown). 

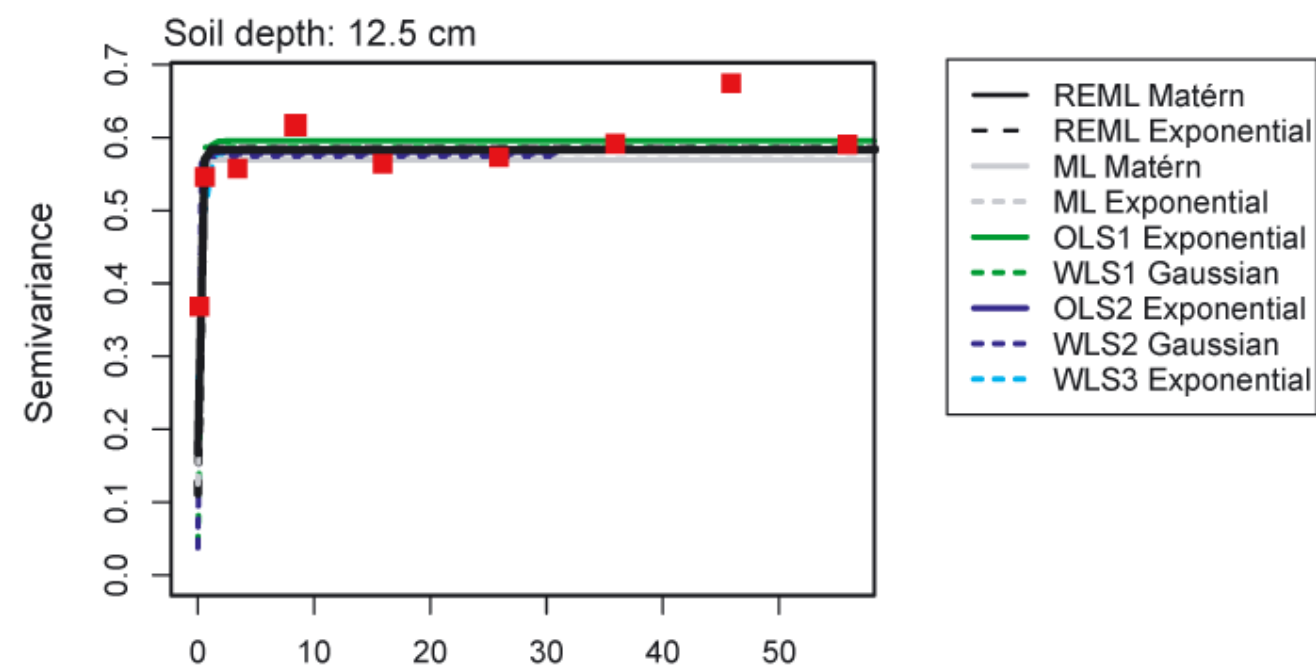

Soil depth: $20 \mathrm{~cm}$
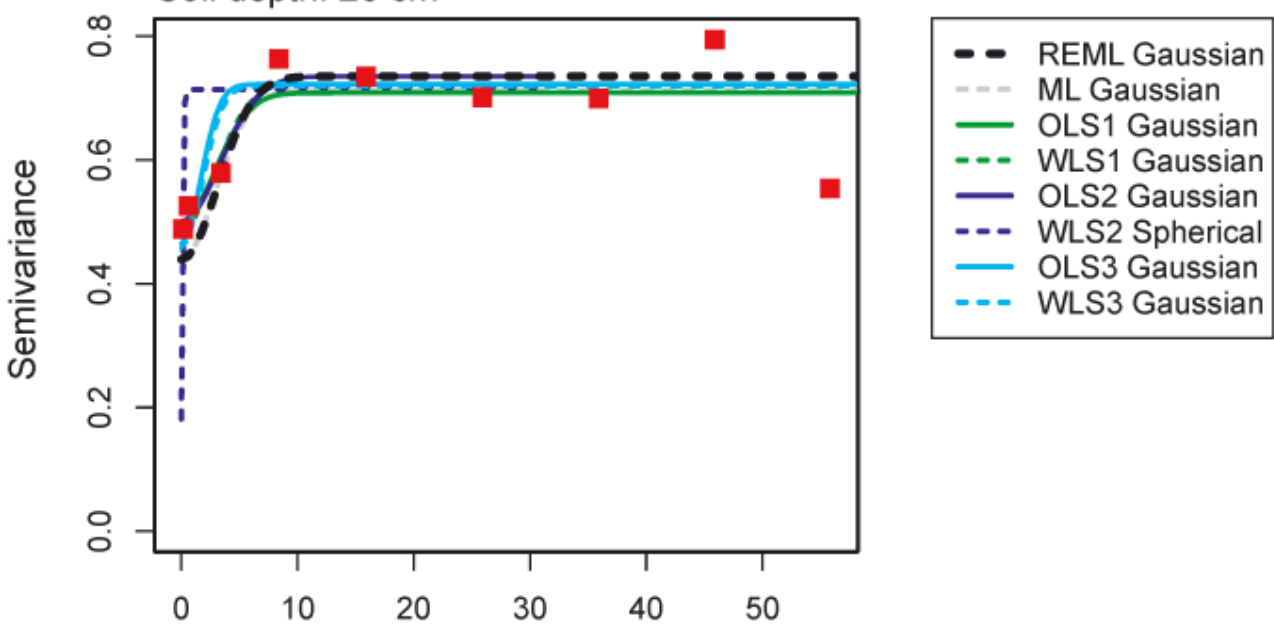

Soil depth: $50 \mathrm{~cm}$
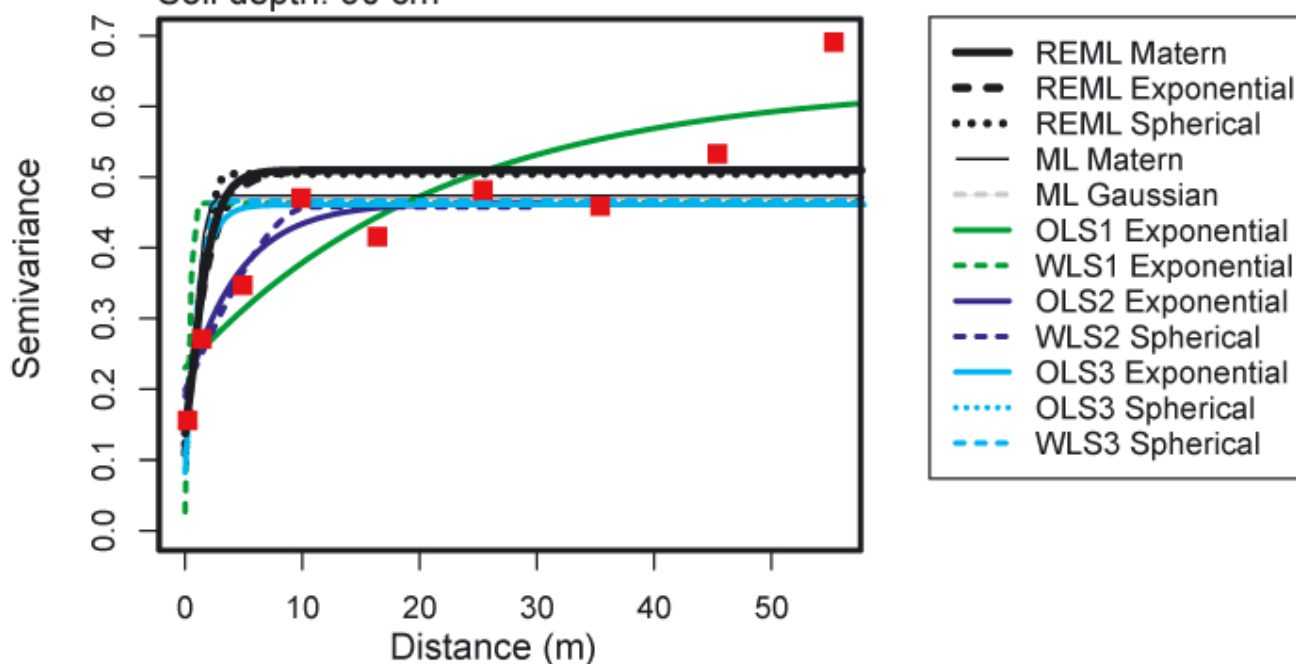

Figure 2-9. Fitted variogram models. Estimation methods are restricted maximum likelihood (REML), maximum likelihood (ML), ordinary least squares (OLS) and weighted least squares. OLS1 and WLS1 were fitted to a visually (i.e. according to the sampling design) selected experimental variogram over the whole separation distance, OLS2 and WLS2 are based on the same experimental variogram fitted over half the separation distance, and OLS3/WLS3 are fitted to the regular experimental variograms (one lag every $25 \mathrm{~cm}$ ). Red squares show the visually selected experimental variogram. 


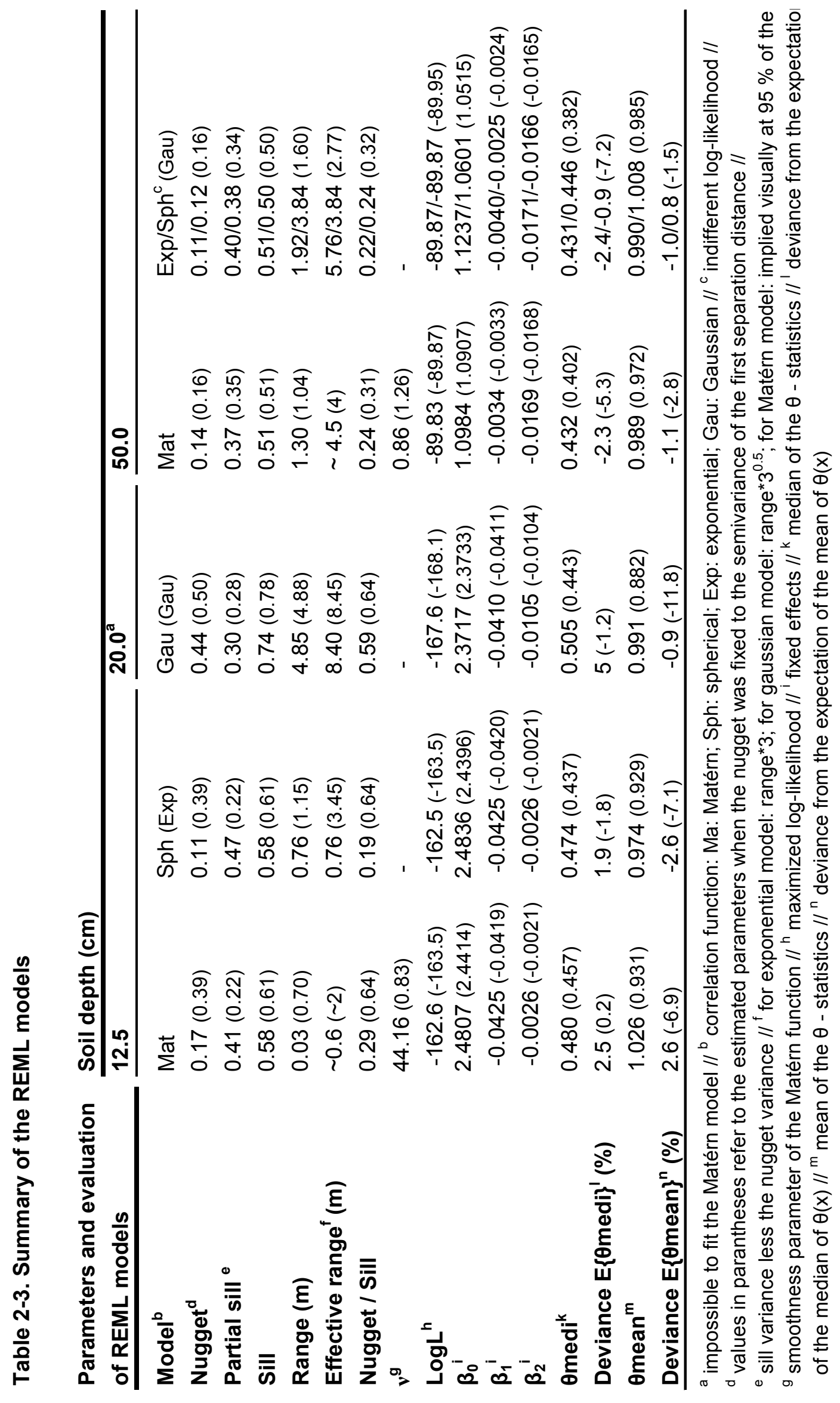


Spatial prediction

Because of the rather weak spatial structure at the shallow soil depths, we focus on the prediction for the $50 \mathrm{~cm}$ soil depth.

In general, the deviations between the kriged maps are restricted to certain locations within the plot, that is to say, to the left-lower corner and a cluster near the right upper corner (Figure 2-10). Due to the similarity of the Matern and the standard REML models, the kriging predictions do not differ much, with some locally higher deviations for the spherical model. The latter is also true for the ML and the LS estimates of the regular experimental variogram but here some clusters exist with more severe over- or underestimation compared to the REML - Matérn reference model. Highest deviations are associated with the LS models of the visually selected experimental variograms both for those that were fitted over the whole as well as over half the separation distance. The kriging map produced with a model which contained the linear trend shows a completely different spatial pattern, in addition to the absolute deviations.
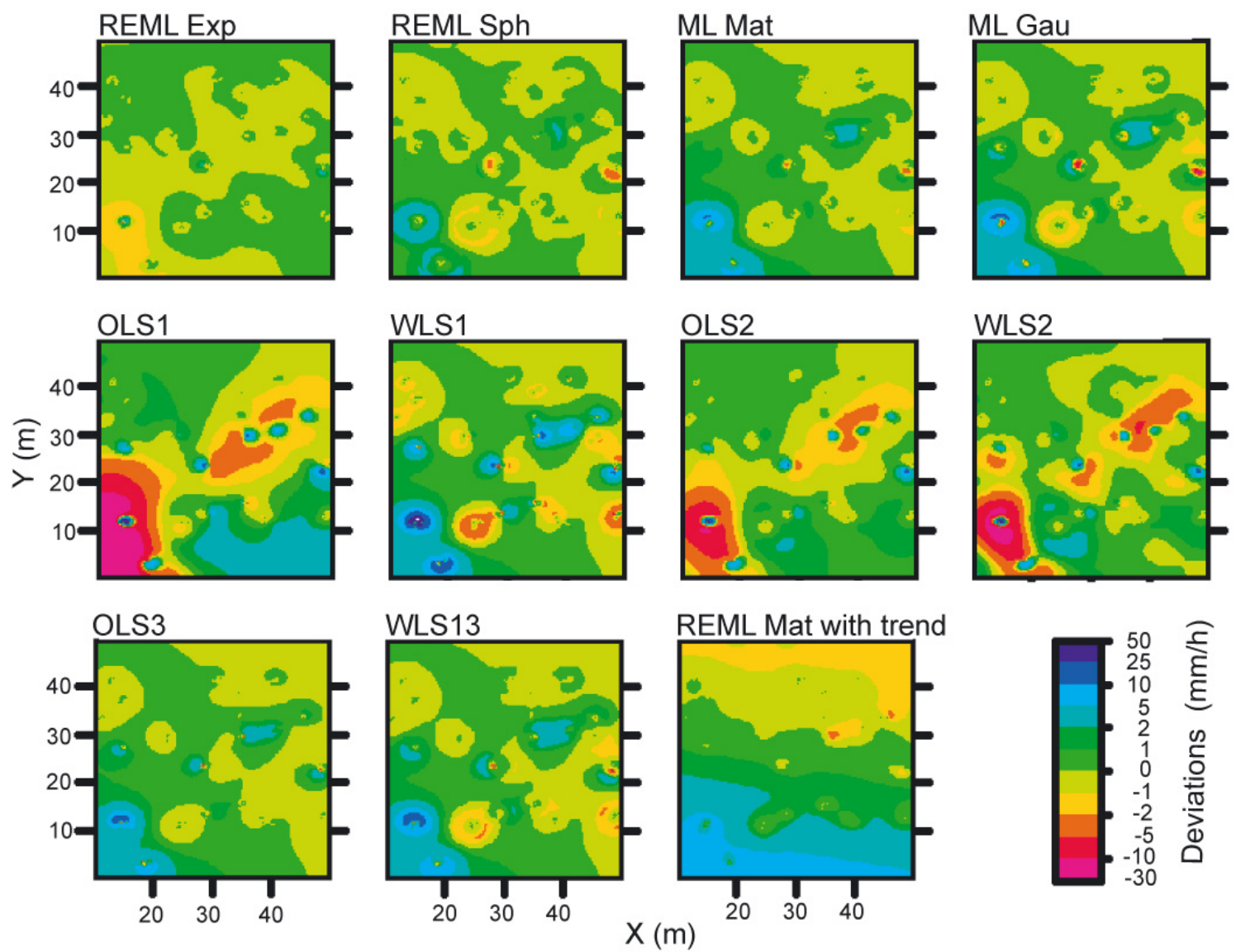
Figure 2-10. Deviations between kriged Ks-values due to differences between the estimated covariance parameters at $50 \mathrm{~cm}$ soil depth. We chose the REML-Matérn model as the reference against which the other models are compared. These are (from left to right and from top to bottom) the REML-exponential, the REMLspherical, the ML-Matérn, the ML-Gaussian, the OLS model fitted to a visually selected experimental variogram over the whole separation distance, the WLS model fitted to a visually selected experimental variogram over the whole separation distance, the OLS model fitted to a visually selected experimental variogram over half the separation distance, the WLS model fitted to a visually selected experimental variogram over half the separation distance, the OLS model fitted to the regular experimental variograms, the WLS model fitted to the regular experimental variograms, and a REML-Matérn model without fixed effects (i.e. no trend elimination).

The assessment of the spatial uncertainty revealed that the average number of Ks values in every of the 5 probability classes is quite similar regardless of the respective model (Table 24). E.g. between 25 and $32 \%$ of the simulated values are subject to a very small probability (i.e. below $20 \%$ ) of being exceeded by the median of the maximum 30-minute rainfall intensities. Hence, in our example model differences are insignificant for the mean probability. But the spatial arrangement, in particular the spatial connectivity, clearly depends on the covariance parameters used (Figure 2-11). Due to the comparatively long range of the OLS1 model, it simulated pronounced clusters of high or low probabilities, suggesting an impeding layer at the upper left corner and an area of unrestricted percolation in the lower left parts of the plot. Smaller but still pronounced clusters were produced by the LS2 models, whereas the WLS1 model resulted in a complete random pattern, which mainly characterizes the ML and LS3 estimates as well. The REML models take a middle position with some connected patches; in addition the probability map again mirrors the small differences between the Matérn and the standard covariance models.

Table 2-4. Probability that the median of the maximum 30-minute rain intensities exceeds Ks

Method $^{\mathrm{a}}$

Number of predicted Ks values / class (\%): mean \pm standard deviation

\begin{tabular}{|c|c|c|c|c|c|}
\hline & $\begin{array}{l}\text { Class }^{\mathrm{b}} 1 \\
\text { "very unlikely" }\end{array}$ & $\begin{array}{l}\text { Class } 2 \\
\text { "unlikely" }\end{array}$ & $\begin{array}{l}\text { Class } 3 \\
\text { "indifferent" }\end{array}$ & $\begin{array}{l}\text { Class } 4 \\
\text { "likely" }\end{array}$ & $\begin{array}{l}\text { Class } 5 \\
\text { "very likely" }\end{array}$ \\
\hline REMLMat/REMLSph & $25.8 \pm 0.7$ & $43.1 \pm 1.2$ & $28.2 \pm 0.8$ & $2.8 \pm 0.7$ & $0.1 \pm 0.1$ \\
\hline MLMat/MLGau & $24.1 \pm 0.3$ & $46.7 \pm 1.7$ & $27.5 \pm 1.1$ & $1.6 \pm 0.3$ & $0.1 \pm 0.0$ \\
\hline OLS1/WLS1 & $28.7 \pm 11.2$ & $43.7 \pm 11.1$ & $22.8 \pm 6.8$ & $4.9 \pm 6.6$ & $0.0 \pm 0.0$ \\
\hline OLS2/WLS2 & $32.3 \pm 1.3$ & $38.8 \pm 1.7$ & $23.3 \pm 0.1$ & $5.5 \pm 0.4$ & $0.1 \pm 0.1$ \\
\hline OLS3/WLS3 & $23.3 \pm 0.4$ & $48.0 \pm 0.7$ & $27.0 \pm 0.2$ & $1.7 \pm 0.1$ & $0.1 \pm 0.0$ \\
\hline
\end{tabular}

${ }^{a}$ model are summarized regarding the estimation method: REML/ML: Matérn and a standard model estimated by REML/ML; OLS1/WLS1 \& OLS2/WLS2: ordinary and weighted least squares models, whole and half distance fit, resp., of visually selected experimental variograms; LS3: LS models of regular exp. variograms ${ }^{b}$ probability classes: $1: 0-<2,2:>=2-<4,3:>=4-<6,4:>=6-<8,5:>=8-<10$ 
In summary, the predictions reproduced the differences in the covariance parameters. The visually selected experimental variogram where lag distance groups were used, and hence a smoothing effect occurred, resulted in a basically different pattern; in our case the existence of a spatially explicit impeding layer. The kriging maps (Figure 2-10) confirm the simulation results, and local deviations between them can be as high as $50 \mathrm{~mm} / \mathrm{h}$.
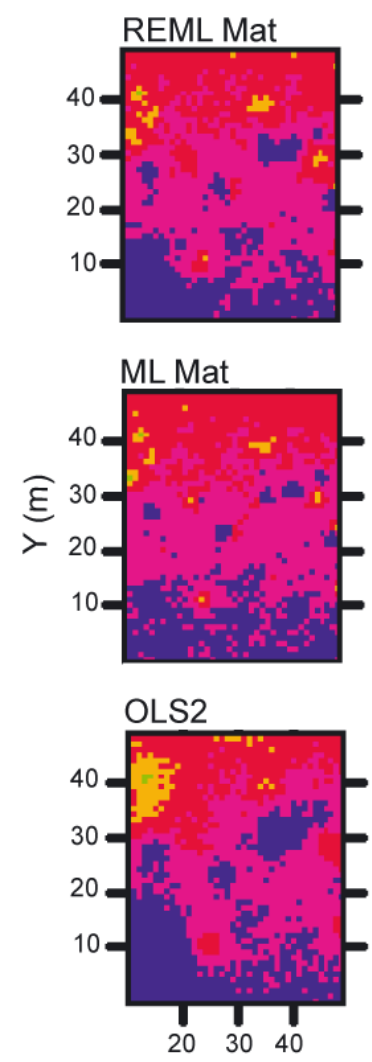
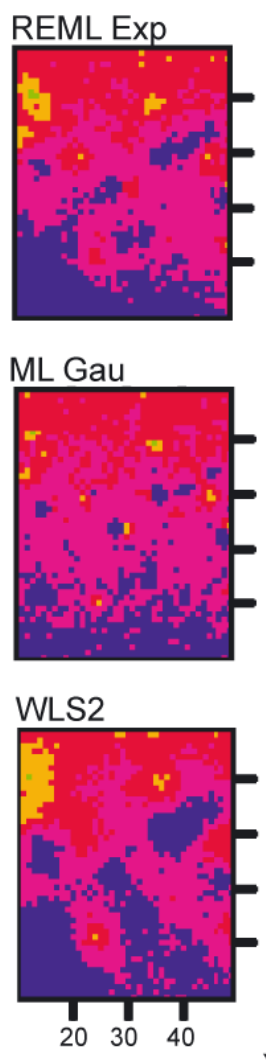
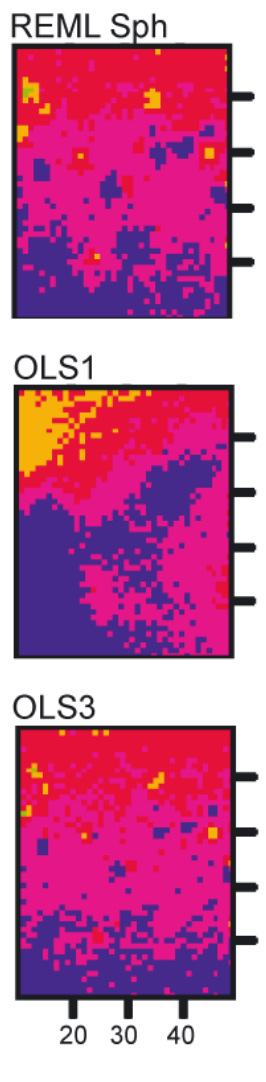
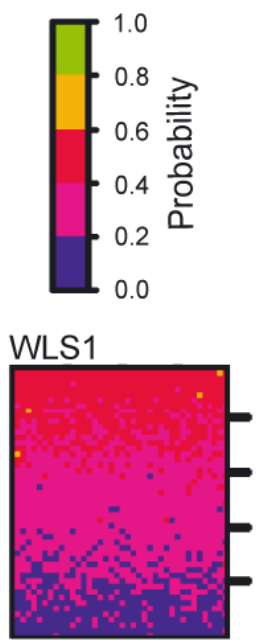

WLS3

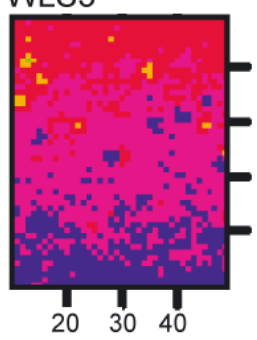

Figure 2-11. Probability maps displaying the probability that the median of the maximum 30-minute rain intensities exceeds the soil permeability at $50 \mathrm{~cm}$ soil depth. All fitted covariance models were used to run the conditional simulations. For abbreviations we refer to Figure 2-10.

Since we also wanted to assess which part of the variogram analysis is of major importance for application, we calculated, by way of one example, the deviations between kriging maps not only as a result of different model estimation but also for the hypothetical case of ignoring the trend component or of using the robust Cressie-Hawkins estimator (Figure 2-12). Not surprisingly, the violation of the intrinsic hypothesis is most crucial in the shallow soil, where the linear trend was particular strong. At $50 \mathrm{~cm}$ depth, using the robust estimator has the most severe consequences for kriging. This comparison highlights the outstanding importance of a 
thorough exploratory data analysis, and the risk of arbitrarily using robust estimation techniques.

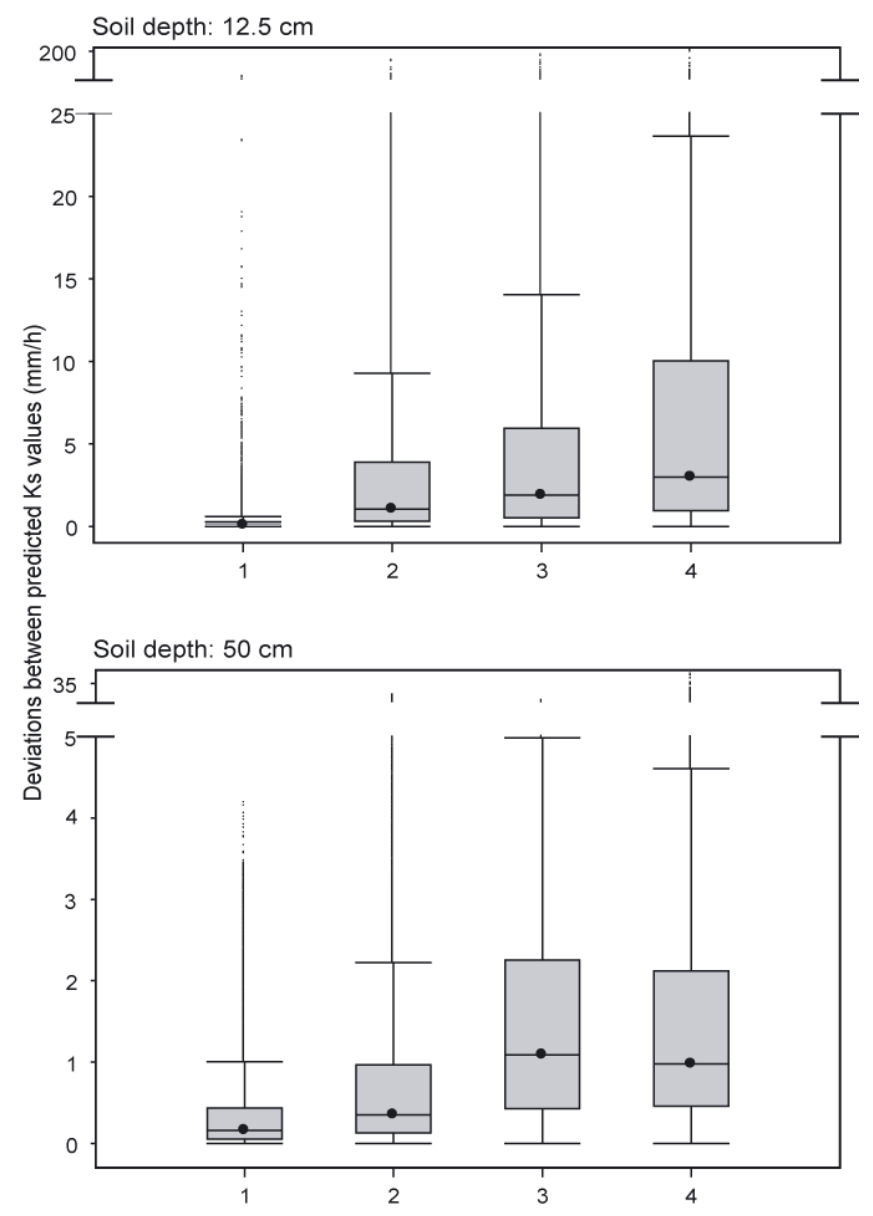

Figure 2-12. Boxplots of the absolute deviations between predicted Ks-values that are due to different aspects of the variogram analysis denoted by the numbers $1-4$ below the $\mathrm{x}$-axis. The REML-Matérn model serves as the reference, which is compared to 1: the best standard REML model (selection criterion: highest maximized likelihood); 2: the best least-squares model (selection criterion: median of $\theta(\mathrm{x})) ; 3$ : the best standard REML model without fixed effects (i.e. no trend elimination); 4: the ordinary least squares model for the experimental variogram of the Cressie Hawkins estimator (see Table 2-2 for parameters).

\subsection{Discussion}

\subsubsection{Exploratory data analysis}

There are several approaches to check the assumption of stationarity. We used diagnostic plots and evaluated apparent trends by testing the significance of the regression. Within the framework of REML estimation Lark et al. (2006) used the Wald statistics to test the null hypothesis that the fixed effects are zero. If the user chooses REML estimation, the latter approach can be adopted in addition to the visual diagnostics. Although it is a well-known fact that the sill variance should not be forced to the sample variance (e.g. Barnes, 1991), a comparison between these measures can be used as a control. The comparison depends on boundary conditions that Barnes (1991) summarized in a rule-of-thumb: the data must be somewhat evenly distributed over an area with dimensions greater than three times the range of the variogram. Since the rule-of-thumb is valid in our case, sill and sample variance of our 
data should approximately agree. Table 2-5 shows the exact match of those measures when the trend is taken into account, and the discrepancy between them when the trend is ignored. In the latter case, the continuously increasing semivariance with increasing lag in direction of the trend component (Figure 2-8) causes estimates of the sill variance that exceed the sample variance (Table 2-5).

Table 2-5. Comparison of sample variance and sill variance

\begin{tabular}{lllll}
$\begin{array}{l}\text { Soil depth } \\
\text { (cm) }\end{array}$ & $\begin{array}{l}\text { Variance }^{\mathrm{a}} \\
\text { of IgKs }\end{array}$ & $\begin{array}{l}\text { Variance }^{\mathrm{b}} \\
\text { of residuals }\end{array}$ & Sill $^{\mathrm{c}}$ & Sill $^{\mathrm{d}}$ \\
\hline 12.5 & 0.8 & 0.6 & 1.8 & 0.6 \\
20 & 0.9 & 0.7 & 1.2 & 0.7 \\
50 & 0.5 & 0.5 & 0.6 & 0.5 \\
\hline
\end{tabular}

${ }^{\text {a }}$ sample variance of the log-transformed Ks data

${ }^{b}$ sample variance of the residuals of the linear trend

${ }^{c}$ sill variance of REML model when trend is ignored

d sill variance of the REML-Matérn model

\subsubsection{Geostatistical analysis}

Experimental variogram estimation: robust estimation requirements

Robust estimation coincides with considerable differences in the covariance parameters nugget, sill, and range. In our case, the Matheron estimator shows both a median and a mean of the $\theta$ - statistics which are very close to the expectation. This is also true for the Cressie Hawkins estimator, whereas the other two robust estimators performed worse regarding this criterion, particularly the Genton estimator. The absences of extreme values that may negatively affect the classical estimator were confirmed by the univariate and bivariate distributions (Figures 2-5 and 2-6). Hence, our study corroborates the proposal by Lark (2000a) that the $\theta$ - statistics may qualify as a criterion to choose between classical and robust estimation. The risk of arbitrarily using a robust estimator instead of the classical one was quantified in a comparison study of the Matheron versus the Cressie-Hawkins estimator under normal conditions (Watson, 1997). She found that robust estimation yielded increasingly larger variance with increasing lag tolerance, and, up to the range of the spatial dependence, is increasingly negatively biased. Another drawback of robust estimation is the limitation of comparisons with other studies where the classical estimator has been used. 
In summary, our results approved the usefulness of the statistics $\theta(\mathrm{x})$. In this study, we used a rather rough approach because the confidence limits for the median of $\theta(\mathrm{x})$ ignore spatial dependence between the locations. For this reason Lark (2002) developed a method to compute Monte Carlo confidence intervals in the framework of modeling soil properties as contaminated regionalized variables.

\section{Estimation of covariance parameters}

Fitting parametric models to experimental variograms remains the widespread approach in studies dealing with the spatial variability of environmental variables (see Table 2-1 for examples concerning the saturated hydraulic conductivity) although some authors encourage estimation of the covariance model by restricted maximum likelihood (Pardo-Igúzquiza, 1998; Stein, 1999; Lophaven et al., 2002), especially for unsystematic sampling (Lark, 2000b). In the framework of hydrological modeling, Unlu et al. (1990) and Russo et al. (1997) used REML to estimate the covariance functions of parameters of some hydraulic properties including Ks (Table 2-1), and it was found in the former study that REML estimates of the sill and range were more accurate and consistent than those of OLS and ML. There is no objective "test" criterion that "proves" the advantage of the REML procedure (the $\theta$-statistics is a rather rough measure because it ignores correlation between the separate validation points), we discuss the basis for our preference in the spatial modeling of our Ks data in the following.

The first point refers to the influence of sampling scatter on the model parameters. This is a main criticism of maximum likelihood estimation as the scatter directly influences the parameter estimation whereas least - squares based techniques use the experimental variogram, which averages the semivariance for the selected lag classes. This "averaging effect" is of major importance when broader lag distance classes are used, which in our case is true for the visually selected experimental variograms that mirror the unsystematic sampling and hence use narrower lag classes for small compared to big separation distances. The dependence of the experimental variogram on the choice of the lag classes is a well-known fact; there is, however, no general rule for the choice of classes (except that they should not overlap). Hence, this step in the variogram analysis is always quite arbitrary, especially when the sampling is unsystematic as in our case. At any rate, it is questionable if point measurements should be summarized in classes which are then used for modeling even though the subsequent prediction or simulation is again based on very small units, e.g. a grid 
cell in a prediction grid. Another aspect is the generally greater number of point pairs in some - in our case the middle - lag classes, which leads to a monotonization of the semivariance; the importance of this effect could be checked by sampling in a simulated landscape.

The simultaneous estimation of the fixed effects is a further benefit of REML estimation since the variogram of the residuals of the linear regression is a biased estimate of the variogram of the random component of spatial variation (Cressie, 1993). Nevertheless, they should be computed for exploratory purposes, e.g. to check their bivariate distribution and to assess the plausibility of the effective range. The $\mathrm{h}$ - scattergrams (Figure 2-6) indicated that the correlation lengths are within the range of a few meters. Thus, the high and low effective ranges, respectively, of the LS - fitted models for the whole - distance variogram at $50 \mathrm{~cm}$ depth appear rather implausible regarding this criterion, in contrast to those of the REML models. That is to say, $\mathrm{h}$ - scattergrams help to at least roughly estimate the correlation length.

In summary, our results provide convincing evidence for the gains associated with the use of restricted maximum likelihood to estimate fixed and random effects in geostatistical modeling (referred to as the "REML-E-BLUP" approach by Lark et al. (2006)) at least when the bivariate distributions are approximately normal.

Role of the nugget value

Cambardella et al. (1994) proposed that the strength of spatial dependence can be characterized by the nugget to sill ratio, e.g. if it is $\leq 25 \%$, then the variable is considered to be strongly spatially dependent. Our criticism regarding this approach emerges from a theoretical point of view because the nugget is usually estimated by extrapolation of the used covariance model and hence can not be verified by the data. Our results for the REML models (Table 2-3) illustrate what this means practically: at $12.5 \mathrm{~cm}$ depth, the nugget-to-sill ratio indicates strong spatial dependence, whereas for the $20 \mathrm{~cm}$ depth one would claim at best a moderate spatial dependence. Since the h-scattergrams (Figure 2-6) did not reveal stronger correlations of point pairs separated by the smallest separation distance at the $12.5 \mathrm{~cm}$ compared to the $20 \mathrm{~cm}$ depth, it is questionable if the strength of the autocorrelation differs much between these depths. If we fixed the nugget to the semivariance at the shortest lag, the resulting nugget-to-sill ratios appear more plausible. The notion that it may be advantageous to fix the nugget instead of estimating it simultaneously was also put forward by Minasny and McBratney (2005) who reported difficulties regarding nugget estimation when using the 
Matérn model with a small smoothness parameter. In addition, our results (Table 2-3) showed that $v$ can heavily depend on the nugget value, as well as the other parameters of the covariance function. Due to the very short-ranging autocorrelation at the shallowest soil depth, where the difference between fixed and estimated nugget is most pronounced, the influence of those differences on spatial prediction cannot be investigated. In cases where the range allows for meaningful predictions and where the estimated nugget considerably differs from the fixed one, the decision as to which one to use may be difficult and depend on the user's experience. Uncertainty in the semivariance estimation at the shortest lag due to a small number of contributing point pairs may persuade the user the estimate the nugget by model extrapolation. A sampling design which allows for calculating the semivariance at short lags is highly advantageous in either case.

Spatial prediction

Goovaerts (1997c) argued that prior decisions, such as the assumption of stationarity and the random function model for modeling uncertainty, are far more consequential for interpolation results than the choice of a variogram model. This is particularly true in situations where, for instance, the intrinsic hypothesis is severely violated by the data (see, for example, Figure 212 for the $12.5 \mathrm{~cm}$ depth) or where the choice of a simulation algorithm is not appropriate for a specific problem (e.g. Gaussian versus indicator simulation). But our results also showed that the estimation method of the covariance parameters can become important as well; both the differences in spatial connectivity and the absolute deviations are likely to affect applications, e.g. the use of the interpolated permeability values as an input for hydrological models.

\subsubsection{Comparison with other studies of the spatial variability of $\mathrm{Ks}$}

It is currently impossible to relate the spatial structure of soil permeability to some predictable feature such as land use, soil texture, measuring method, or soil depth (Table 2-1). To make things even more complicated, the choice of a sample scale triplet (Bloeschl, 1999) relative to the scale of the underlying soil variability affect the estimates of the variogram parameters; e.g., apparent correlation lengths always increase when increasing spacing, extent or support (Western and Bloeschl, 1999). 
The comparison reveals that agriculture, for example, seems to promote spatial Ks patterns that are completely random, but also strong and extensive autocorrelations; in contrast, data from forested land are still too rudimentary to allow any conclusions (Table 2-1). Deviations from the intrinsic hypothesis are found in many cases; hence, special attention should be given to this part of the variogram analysis. For the majority of the studies, the sample sizes fall considerably below the recommended minimum of 150-200 for the method-of-moments variogram (Webster and Oliver, 1992), which certainly influences the results and hence this comparison. The required sample sizes for REML estimation may differ from this recommendation, or may even be lower but this has not yet been addressed adequately. Existing spatial structure is attributed to a well-developed and stable soil structure (Reynolds and Zebchuk, 1996), uniform texture and pore size distribution developed by long-term (notillage) agricultural practice (Mohanty and Mousli, 2000), or intrinsic variations in soil texture and mineralogy (Shukla et al., 2004). The absence of spatial predictability is assumed to be caused by biogenic macroporosity, which overrides possible texture and topography dependence (Sobieraj et al., 2002), uneven breaking of soil structure due to freezing and thawing (Mohanty et al., 1991), or surface tillage in the upper horizons (Bosch and West, 1998). Hence it appears that a rather uniform soil texture and a stable soil structure that does not undergo frequent disturbance may favor the development of a predictable spatial structure of saturated hydraulic conductivity. This assumption seems to be valid for our study as well, because the permeability of the surface horizons, which have experienced disturbances such as the compaction by cattle treading exhibit less spatial structure compared to the deeper soil. 


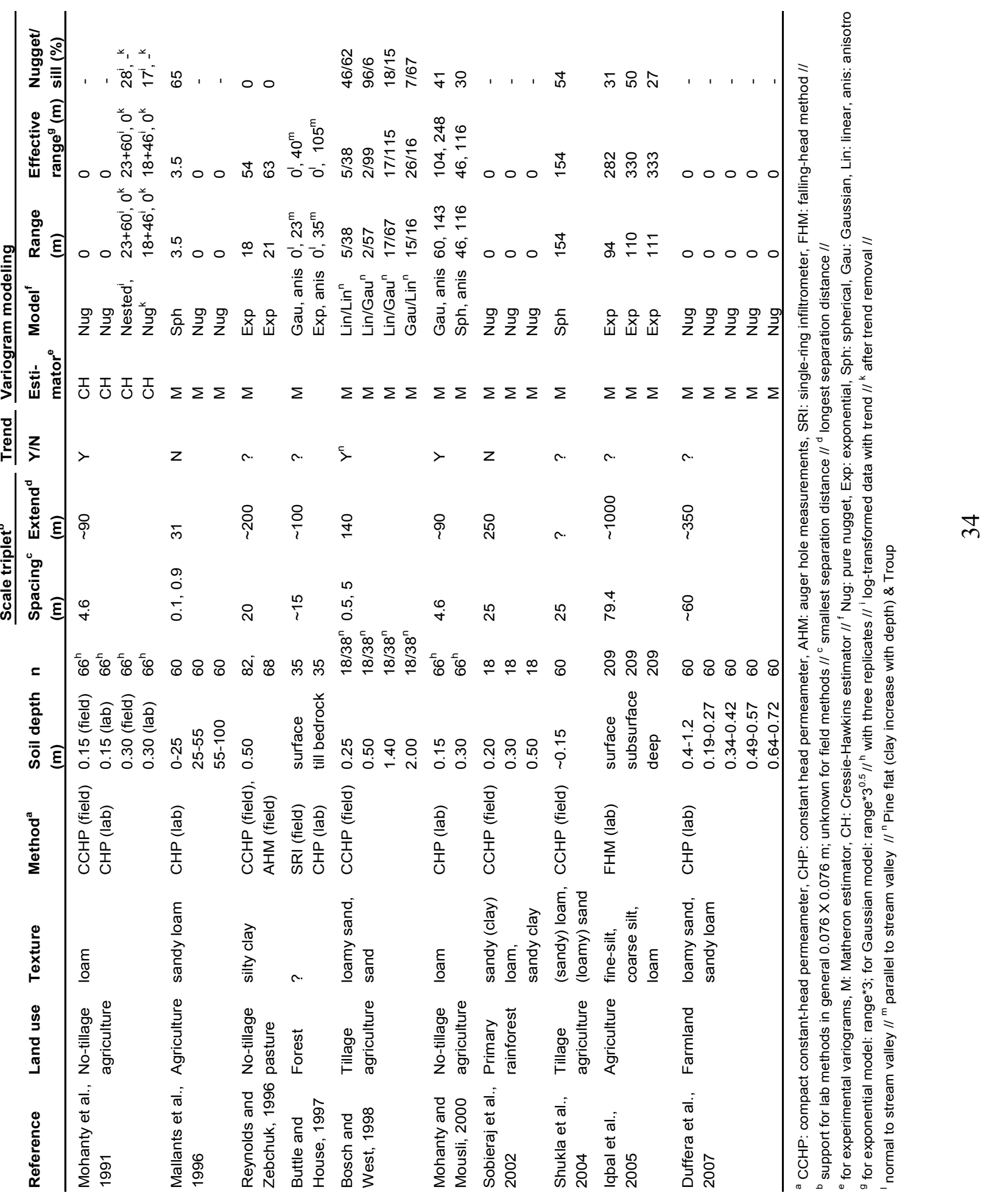




\subsection{Conclusions}

We first summarize our results in reference to the research issues we addressed in this study.

1) Significant trends of the mean permeability exist at every investigated soil depth, with particular importance for the shallow soil. Ignoring it would produce misleading results.

2) Robust estimation techniques are not required, since the log-transformed data does not exhibit extreme values in its univariate and bivariate distribution. This was further confirmed using the approach of the $\theta$ - statistics Lark (2000a) to assess the need for robust estimators. Arbitrary use of robust estimators is on risk of being less efficient.

3) Anisotropic variations are not evident. The anisotropic appearance of the trendcontaining data provides a link between the trend component and a seemingly direction - dependent spatial dependency.

4) The model comparison revealed that the estimated covariance parameters depend on the estimation method and on the experimental variograms used for the least - squares based model development, respectively.

5) We found rather small differences between the Matérn and standard models. It was not always possible to estimate the parameters of the Matérn function, but in one case this model was associated with a higher likelihood.

6) Fixing the nugget variance potentially modifies all parameters of the covariance function and may therefore have an impact on spatial prediction. This should be investigated further. In some cases, the estimated nugget variance appeared to be too small.

7) In the framework of prediction we showed that in our case the model differences do not influence average values, e.g. the average probability that rainfall intensities exceed the soil permeability. The spatial arrangement, particularly the connectivity of zones with high or low Ks, however, depends on the used model, and local deviations in kriging maps can be considerable.

8) General conclusions about the spatial structure of the saturated hydraulic conductivity in relation to attributes as e.g. soil type, land use, and measurement techniques are currently impossible on the basis of the literature reviewed. Some interpretations and the results of this study, however, may indicate a dependence of the spatial structure on soil conditions as a result of disturbances, i.e. a predictable structure has been associated with rather stable, undisturbed soils. 
Our results permit some general recommendations. First, the discussion of a plausible estimate of the nugget variance emphasizes the advantage of a sampling design which allows for calculating the semivariance at short lags. Second, under bivariate normal conditions we encourage estimation by restricted maximum likelihood which does not require the arbitrary selection of lag classes. The mean of the $\theta$ statistics for the REML models, which is very close to the expectation, and their plausible effective ranges further support their accuracy. If one decides for robust estimation techniques, the variogram model should only be fitted over half the separation distance to avoid edge effects. Third, in the framework of REML estimation we propose to use the Matérn correlation function when possible and to compare it to some standard models (e.g. the spherical one) by means of the maximized likelihoods. In summary, we propose a flowchart (Figure 2-13) for the geostatistical analysis of environmental data; the red boxes contain the inherent most critical decision points. This flowchart can be extended of course, and it should be continuously updated in the face of future developments. 


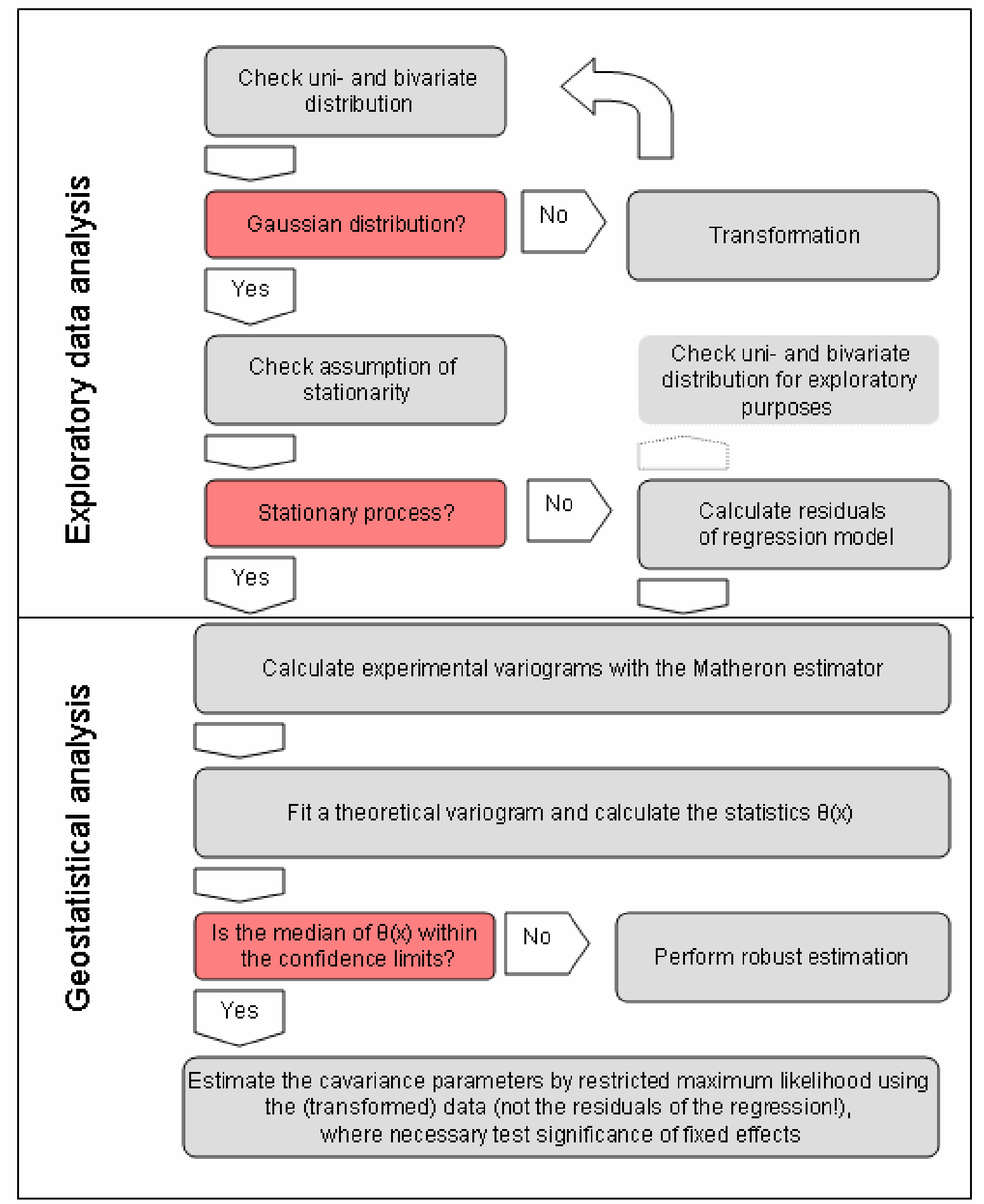

Figure 2-13. Proposed flowchart for spatial data analysis. 


\title{
3.
}

\section{The soil hydraulic response to disturbance and recovery. I. Spatial and temporal variability of the saturated hydraulic conductivity}

\begin{abstract}
Tropical montane rain forests are subject to both natural and anthropogenic disturbances, such as shallow landslides and forest-to-pasture conversion. In both cases, rapid vegetation succession occurs upon pasture abandonment and geomorphic stability.

Soil saturated hydraulic conductivity $(\mathrm{Ks})$ is a sensitive indicator to assess the influence of this landscape dynamics regarding soil hydrology. We investigated the disturbance effects both on global means and the spatial structure of this soil hydraulic property.

We measured Ks in situ at soil depths of 12.5, 20, and $50 \mathrm{~cm}(\mathrm{n}=30-150 /$ depth $)$ under landslides of different ages ( 2 and 8 years), under actively grazed pasture, fallows following pasture abandonment ( 2 to 25 years of age), and under natural forest.

Global means of the soil permeability generally decrease with increasing soil depth. Ks does not differ among landslides and in comparison to the natural forest which suggests a marginal effect of the regional landslide activity on soil hydrology. In contrast, results from the human - induced disturbance regime show an enormous permeability decrease of two orders of magnitude after forest conversion to pasture at shallow soil depths, and a slow regeneration after pasture abandonment that requires a recovery time of at least one decade.

Disturbances affect the Ks spatial structure, in particular the correlation length, in the topsoil. Spatial dependence is most pronounced under natural forest and under a regenerating fallow. The largest differences in spatial patterns are found in the subsoil permeability, where the spatial structure is site-specific and can be either stronger or less pronounced than in the topsoil. Apart from this dependence of the Ks spatial variability on land covers and soil depths, generally short correlation lengths in the range of a few meters suggest that other upscaling techniques than geostatistics may be more feasible in our study region.
\end{abstract}

With: Helmut Elsenbeer; we submitted an edited version to Journal of Hydrology 


\subsection{Introduction}

Disturbances are part of natural ecosystems dynamics. In forested regions, ecosystem-inherent disturbances include treefall, outbreak of herbivores, fires, floods, and mass movements, which take place over a wide range of spatial and temporal scales. Some disturbances do merely destroy the vegetation itself whereas others potentially impact abiotic components of the ecosystem. Landslides belong to the latter as they are initiated in the soil body and in return affect soil properties.

In humid tropical environments characterized by steep slopes, high rainfall, and frequent catastrophic events such as hurricanes or earthquakes, landslides are a common phenomenon (Terlien, 1997; Larsen et al., 1999; Vieira and Fernandes, 2004). In montane rainforests of the south Ecuadorian Andes, they are an intrinsic part of the natural disturbance regime. Because of their potentially devastating consequences for human life and local economies, the management of landslide risks and the prediction of landslide hazards have received considerable attention (e.g. Terlien, 1997; Zaitchik et al., 2003; Brenning, 2005). The few studies that dealt with the impact of landslide disturbance and recovery on soil properties in pristine ecosystems focused on soil fertility and soil organic matter (e.g., Walker et al., 1996; Singh et al., 2001; Wilcke et al., 2003). Larsen et al. (1999) and Hou et al. (2005) studied erosion processes and soil fauna, respectively, under undisturbed forest and on recent landslide scars. Regarding soil hydrology, Vieira and Fernandes (2004) investigated the saturated hydraulic conductivity on and next to landslide scars near Rio de Janeiro. To our knowledge, however, no study has yet attempted to quantify the soil hydraulic response to landsliding in tropical montane rainforests, though landslides figure prominently in this environment.

In addition to this ecosystem-inherent disturbance, forest conversion for pasture establishment has become a cause of disturbance in this region over the past 60 years. This development is a cause of concern, because tropical montane rainforests are the most endangered of tropical forest ecosystems, with an annual rate of deforestation of about 1.1 percent for 1981-1990, which is greater than the overall rate of deforestation in the tropics (Bruijnzeel, 2001). In the montane rainforest of south Ecuador, deforestation initiates a 'vicious circle' (Hartig and Beck, 2003):

After repeated burning of the natural forest, pasture grasses or short - term crops (beans and maize), which may precede pasture establishment, and bracken (Pteridium arachnoideum) develop simultaneously. Due to the widespread practice of frequently burning bracken - 
invaded pastures, the cycle of the concurrent bracken and pasture development is repeated several times. The increasing density of fern rhizomes, combined with an ongoing weakening of the grass tussocks, reduces the period of improved grass growth with every fire. After less than 10 years on average, bracken takes over completely and pastures are abandoned. The final succession stage consists of patches of bracken separated by $2-3 \mathrm{~m}-$ high bushes. The high potential of bushes and bracken to propagate from seeds and rhizomes, respectively, appears to ensure a high stability of this vegetative type and a long - lasting serial stage. Natural forest recovery is unlikely mainly because of restricted seed dispersal.

These human and natural disturbance regimes characteristic of our montane rainforest study site are summarized in Figure 3-1.

Soil degradation processes may also influence the natural succession (Guenther et al., 2006). Little is yet known, however, about the influence of land use and subsequent recovery on soil properties in tropical mountainous regions. McDonald and Healey (2000) and Bautista-Cruz and Del Castillo (2005) investigated soil fertility in second-growth forests of Jamaica and Mexico, respectively. Schrumpf et al. (2006) dealt with the influence of forest disturbance on organic nutrients by comparing mature forests, secondary forests and shrub vegetation in clearings in Tanzania. Changes in the soil hydrological behavior due to land use in a tropical mountainous rainforest region in Vietnam were studied by Ziegler et al. (2004). The influence of pasture establishment and subsequent fallows on soil hydrology is still poorly known despite the broad extension of those land cover types in tropical montane rainforest environments.

Our long-term objective is to quantify the influence of natural and man - made disturbances and the subsequent recovery on a key property of the hydrologic cycle - the soil saturated hydraulic conductivity - and to describe the resulting spatial-temporal pattern. We selected the saturated hydraulic conductivity (Ks from here on) because it has shown to be a sensitive indicator for soil disturbances (Ziegler et al., 2004; Zimmermann et al., 2006). The objective of this study was to test three hypotheses:

1) Disturbances cause an apparent displacement of the less permeable soil layer towards the surface, either due to a loss of the permeable surface soil after land-sliding, or as a consequence of the surface soil compaction under cattle pastures.

2) 'Recovery' from disturbance, either because of landslide re-vegetation or because of secondary succession after pasture abandonment, involves an apparent displacement of the less permeable layer back towards the original depth. 
3) Disturbances cause a simplification of the Ks spatial structure, i.e. the spatially dependent random variation diminishes. The subsequent recovery entails the reestablishment of the original structure.

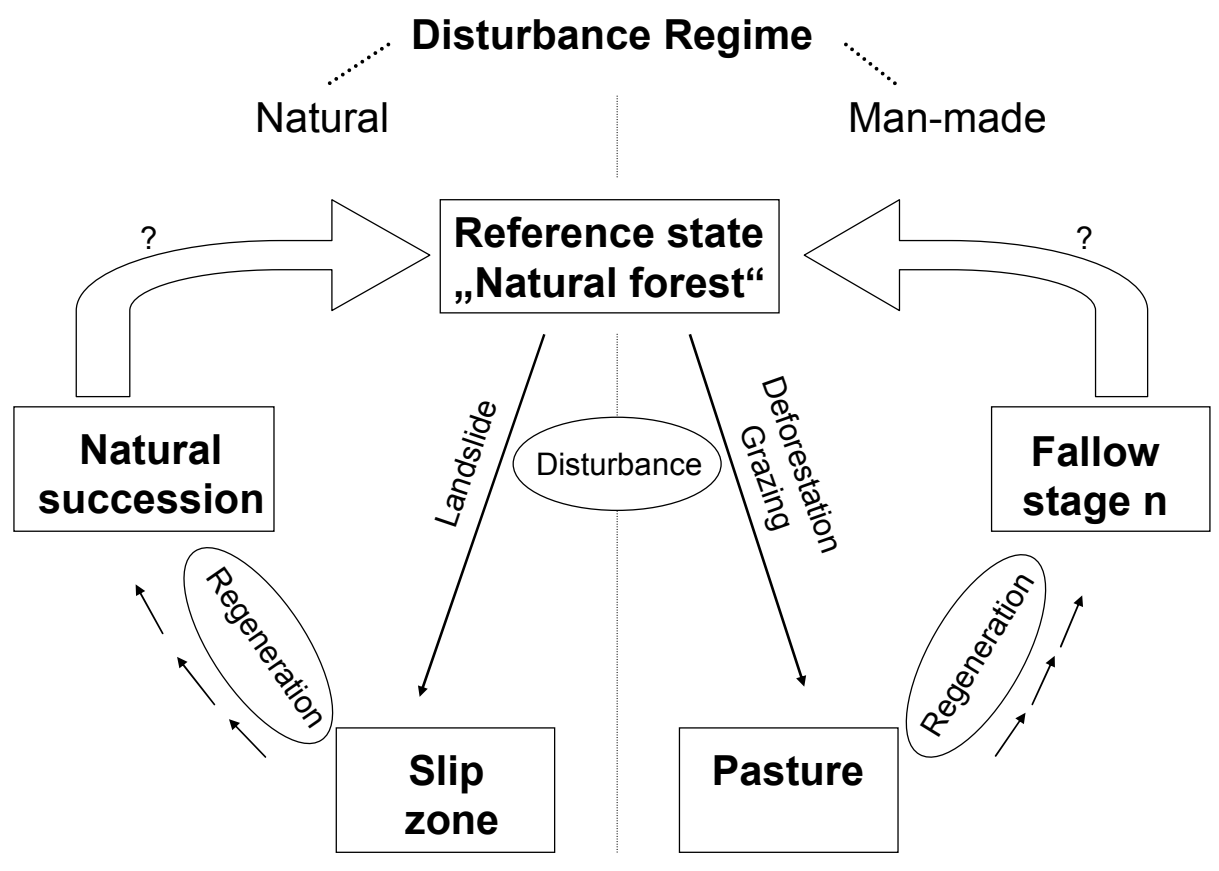

Figure 3-1. Conceptual framework of the study.

\subsection{Materials and methods}

\subsubsection{Study area}

Embedded in the Eastern Cordillera of the Andes of south Ecuador, our study area (Figure 32) is located in the Reserva Biósfera de San Francisco around the Estación Científica San Francisco (ECSF) (3 $3^{\circ} 58^{\prime} 18^{\prime \prime} \mathrm{S}, 79^{\circ} 4^{\prime} 45^{\prime \prime} \mathrm{W}, 1860 \mathrm{~m}$ a.s.1.). Steep slopes (30-50 $)$ covered by "Lower Montane Rain Forest", which gradually changes to "Lower Montane Cloud Forest" on higher ground (Bruijnzeel and Hamilton, 2000), characterize the north - facing valley side of the Rio San Francisco, where recent human intervention is virtually absent. By contrast, the south - facing valley side has been subject to human influence for decades. Shallow translational landslides are frequent throughout the study region, where $3.7 \%$ of an 1117-ha forested study area was covered by visible landslides in 1998 (Wilcke et al., 2003). We observed minor recent slip activity at pastures and on fallows potentially due to the 
absence of forest biomass, which is assumed to be of major importance for landslide initiation in this area.

Mean annual precipitation (1998-2005) amounts to $2273 \mathrm{~mm}$ (Rollenbeck et al., 2007), and mean annual (1999-2002) air temperature is $15.5^{\circ} \mathrm{C}$ (Motzer et al., 2005). A drier period is between November and January, and May and June are the wettest months (Motzer et al., 2005).

The bedrock consists mainly of weakly metamorphosed Palaeozoic schists and sandstones with some quartz veins (Wilcke et al., 2003), which belong to the Chiguinda unit (Mapa geológico del Ecuador; Instituto Geográfico de Militar y Ministerio de Energía y Minas). Soils are classified as Inceptisols and Histosols (Soil Survey Staff, 1999; Schrumpf et al., 2001) with a high percentage of silt.

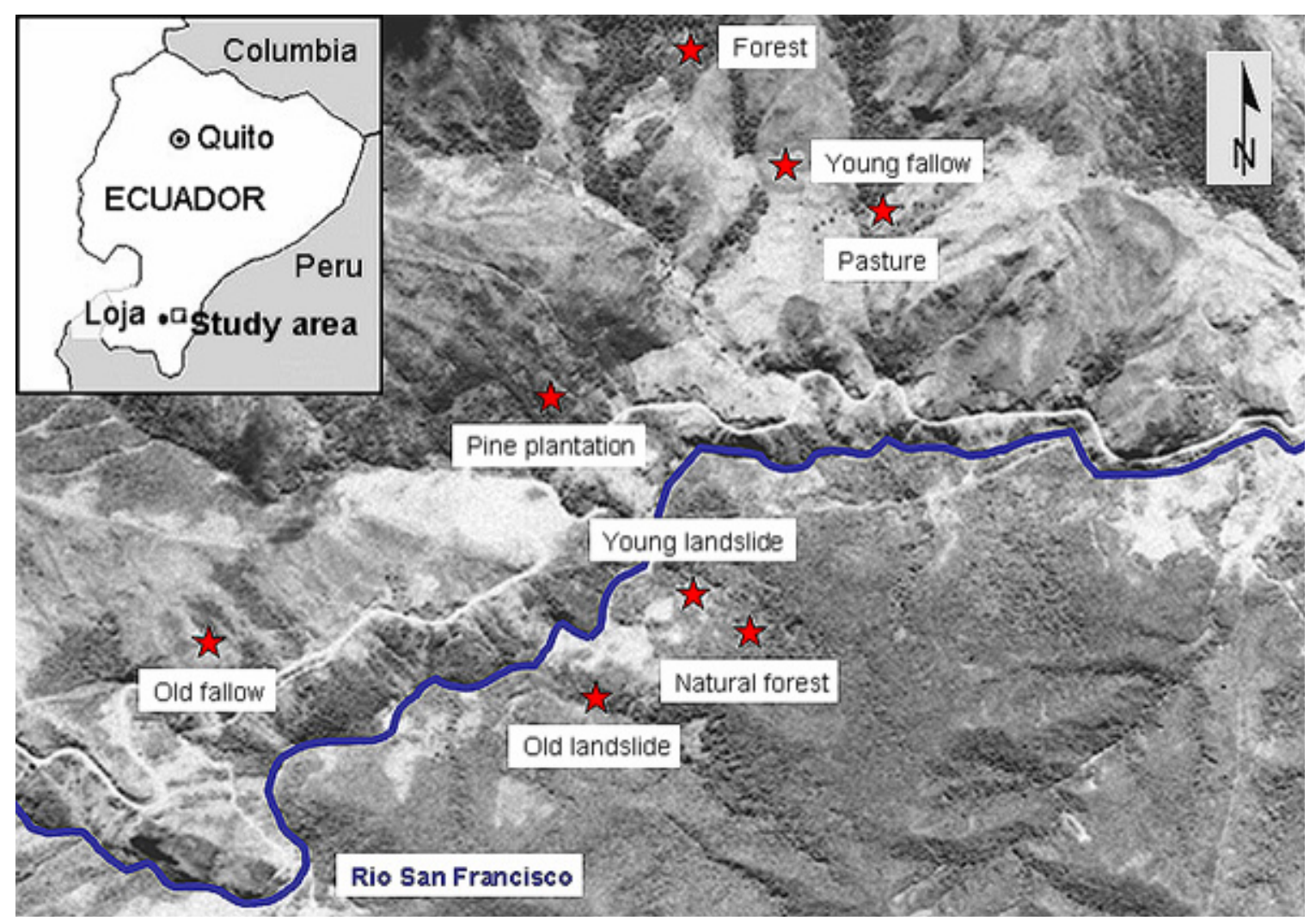

Figure 3-2. Map and aerial view of the research area.

\subsubsection{Site selection}

We selected four plots that represent the human disturbance and recovery sequence, and two landslides of increasing age. All plots are free of micro-topographic peculiarities such as big hollows, rills or gullies; slopes amounted to 30 till $40^{\circ}$, and aspects were similar. Both 
chronosequences have their old-growth forest reference since they are located on the two opposite valley sides (Figure 3-2). Hence, initial conditions may differ due to their distinct landscape history associated with e.g. higher frequencies of fires and the rareness of landslides in the areas influenced by human activities.

The reference site for the natural disturbance cycle is covered by "Lower Montane Rain Forest" (Bruijnzeel and Hamilton, 2000), underlain by a Humic Dystrudept (Goller et al., 2005 ) with a silt content of about $60 \%$ in all horizons (Schrumpf et al., 2001).

The young landslide (YS) occurred two years before our measurement campaign about onehundred meters to the northwest of the reference site. This slide consists of clearly distinguishable zones: below the scar is the slip zone, the zone of interest for the purposes of this study. This is followed downwards by a very steep and narrow depletion zone. At this position, a recently formed gully extends down to the accumulation zone at the foot of the landslide. Any successional vegetation is restricted to the accumulation zone. An older landslide (OS) is located in an adjacent catchment and was active about 7-8 years ago. Successional plants include mosses, grasses, ferns, and small shrubs, but also bigger shrubs and small trees that occur on "accumulation islands"; only the former slip zone is still bare of vegetation. This landslide is part of the landslide chronosequence whose soil properties were studied by Wilcke et al. (2003).

The reference forest (FO) on the south - facing valley side for the human disturbance cycle shows signs of interference, such as logs of cut trees and charcoal in the upper soil. Two soil profiles illustrated the high variability over very short distances: one showed an initial stage of soil development with an A - horizon overlying the parent material, whereas the other a well - defined B - horizon had already developed. At some measurement locations, a buried organic layer in about half a meter soil depth indicates former slide activities.

Our pasture plot (PA) has been grazed for about 20 years. Numerous narrow cattle trails are distributed along the contour lines. The dominant grass species are Setaria sphacelata on less inclined slope portions and Melinis minutiflora on steeper slopes. The low palatability of Setaria and the low biomass production of Melinis explain the low carrying capacity in the study region (Hartig and Beck, 2003).

The young fallow (YF) was abandoned from pasture use only two years before our measurements, which accounts for the rather unusual dominance of Setaria instead of bracken.

After a recovery of at least 10 years, succession vegetation covers the old fallow (OF), but bracken is still frequent. Among the most abundant families are Orchidaceae, Asteraceae, 
Ericaceae, Melastomataceae, Poaceae, Rosaceae, Gleicheniaceae, Lycopodiaceae, Bromeliaceae, and Myrsinaceae, which are the same pioneers as on the landslides. The pine plantation (PI) represents a special type of a secondary forest; pines (Pinus patula) were planted immediately after pasture abandonment 25 years ago. The space between the sparsely standing trees is almost completely covered by bracken, which in places grows taller than $2 \mathrm{~m}$.

Table 3-1 provides a summary of all plot descriptions and abbreviations of the plot names which will be used in the text from here on.

Table 3-1. Selected site properties

\begin{tabular}{|c|c|c|c|c|c|c|}
\hline $\begin{array}{l}\text { Land cover } \\
\text { type }\end{array}$ & Abbreviation & $\begin{array}{l}\text { Altitude } \\
\text { (m a.s.I.) }\end{array}$ & $\begin{array}{l}\text { Average } \\
\text { slope }\left({ }^{\circ}\right)\end{array}$ & Aspect & $\begin{array}{l}\text { Sampled } \\
\text { area/plot (ha) }\end{array}$ & $\begin{array}{l}\text { Recovery } \\
\text { time (years) }\end{array}$ \\
\hline Young landslide & YS & 2000 & 35 & W & --- (slip zone) & 2 \\
\hline Old landslide & OS & 1900 & 35 & $S$ & 0.06 (entire slide) & 7 to 8 \\
\hline Natural forest & NF & 2000 & 35 & NW & 0.4 & --- \\
\hline Pasture & PA & 2000 & 35 & SW & 0.5 & 0 \\
\hline Young fallow & YF & 2100 & 35 & SW & 0.4 & 2 \\
\hline Old fallow & OF & 2100 & 30 & SE & 0.35 & $\sim 10$ \\
\hline Pine plantation & PI & 1900 & 35 & $S$ & 0.1 & $\sim 25$ \\
\hline Forest & FO & 2200 & 35 & SW & 0.1 & --- \\
\hline
\end{tabular}

\subsubsection{Sampling}

We measured the field-saturated hydraulic conductivity in situ in the mineral soil at the depths of 12.5, $20 \mathrm{~cm}$ and $50 \mathrm{~cm}$ with an Amoozemeter (Ksat Inc., Raleigh; Amoozegar, 1989a), a compact, constant-head permeameter. The procedure involved augering a cylindrical hole with radius $r$ to the desired depth, establishing a constant head $\mathrm{H}$ such that $\mathrm{H} / \mathrm{r} \geq 5$, and monitoring the outflow from the device until a steady-state flow rate is attained; at which point $K s$ can be calculated via the Glover solution (Amoozegar, 1989b). This model deals only with one equation, based on gravitational flow and gravitational potential (Amoozegar, 1993). For a comparison of calculated $K s$ by the Glover equation with the calculated $K s$ using different Alpha parameter values (Elrick and Reynolds, 1992), the Glover equation gave results that were comparable to the results obtained by the fixed Alpha value approach (Amoozegar, pers. comm.).

For all land covers except the young landslide, the pine plantation, and the forest at the landuse side, we used a combined design- and model-based sampling approach to satisfy the preconditions both for inter-site comparisons and for the intra-site spatial analysis. The approach involved the random selection of 30 squares of $2 \mathrm{~m}^{2}$; every square included 5 fixed 
measuring points (Figure 2-2). Hence, we used $150 \mathrm{Ks}$ measurements per soil depth for the spatial analysis, which corresponds to the recommended sample size to estimate method-ofmoments variograms (Webster and Oliver, 1992). Since only the selection of the squares was design - based, we used only their first point for the global comparisons, which resulted in a sample size of 30 per land cover and soil depth.

At the young landslide, we measured $K s$ exclusively in the slip zone via a simple random selection of 30 measuring points. For the pine plantation and the forest we also took 30 sampling points randomly.

\subsubsection{Statistical and geostatistical analyses}

\subsubsection{Initial conditions}

A prerequisite for inter - site comparisons is the equality of initial conditions to ensure that the measured effects are solely a consequence of the "treatment". Since $K s$ is a function of the soil's macro-porosity (Carman, 1956; Ahuja et al., 1984) it is subject to all influences that change the macro-porosity. Apart from disturbance effects, macro-porosity may vary depending on soil texture, and, particularly in the topsoil, on soil structure. Soil texture of human-disturbed plots is comparable, i.e., the soils have a high silt content, between 20 and $35 \%$ sand, and a low clay content (Figure 3-3). Within the forested part of our study area, particle size distributions of the loamy soils are heterogeneous at a small scale due to the prevalent gravitational mass movements. For example., for 36 profiles in a $2500 \mathrm{~m}^{2}$ plot in the forest catchment where our natural forest plot is located (Muñoz, 2005), the coefficient of variation amounts to $25 \%$ for all particle sizes; this is in the same range as the particle size variations between the intermediate slide and another one far away from the former (data from Wilcke et al., 2003). Hence, particle size distributions are more scattered for the naturaldisturbed plots (Figure 3-3). The soil of the intermediate slide has a sand content of more than $50 \%$ in contrast to the natural forest, where sand amounts to less than $20 \%$ of the particle size classes.

Macrostructure is subangular to angular in soil profiles at both valley sides; regarding the microstructure, low contents of clay and crystalline oxides, especially in the topsoils (Schrumpf et al., 2001), do not promote structural macro-porosity (Ringrose-Voase, 1991). Non-structural porosity, i.e. biopore formation, depends on extrinsic factors; hence, variations 
in soil structure can be attributed to the vegetation and the corresponding edaphon. The same applies to carbon contents (Makeschin et al., 2007).

Within a given land cover, Ks may depend on topography (Huwe et al., 2007); therefore we based our plot selection on similar slopes and slope positions (Table 3-1).

To avoid spatial pseudoreplication we chose the greatest possible plot size; sampling of more than one plot per land cover was impossible due to the overall restricted accessibility and the precondition of similar slopes.
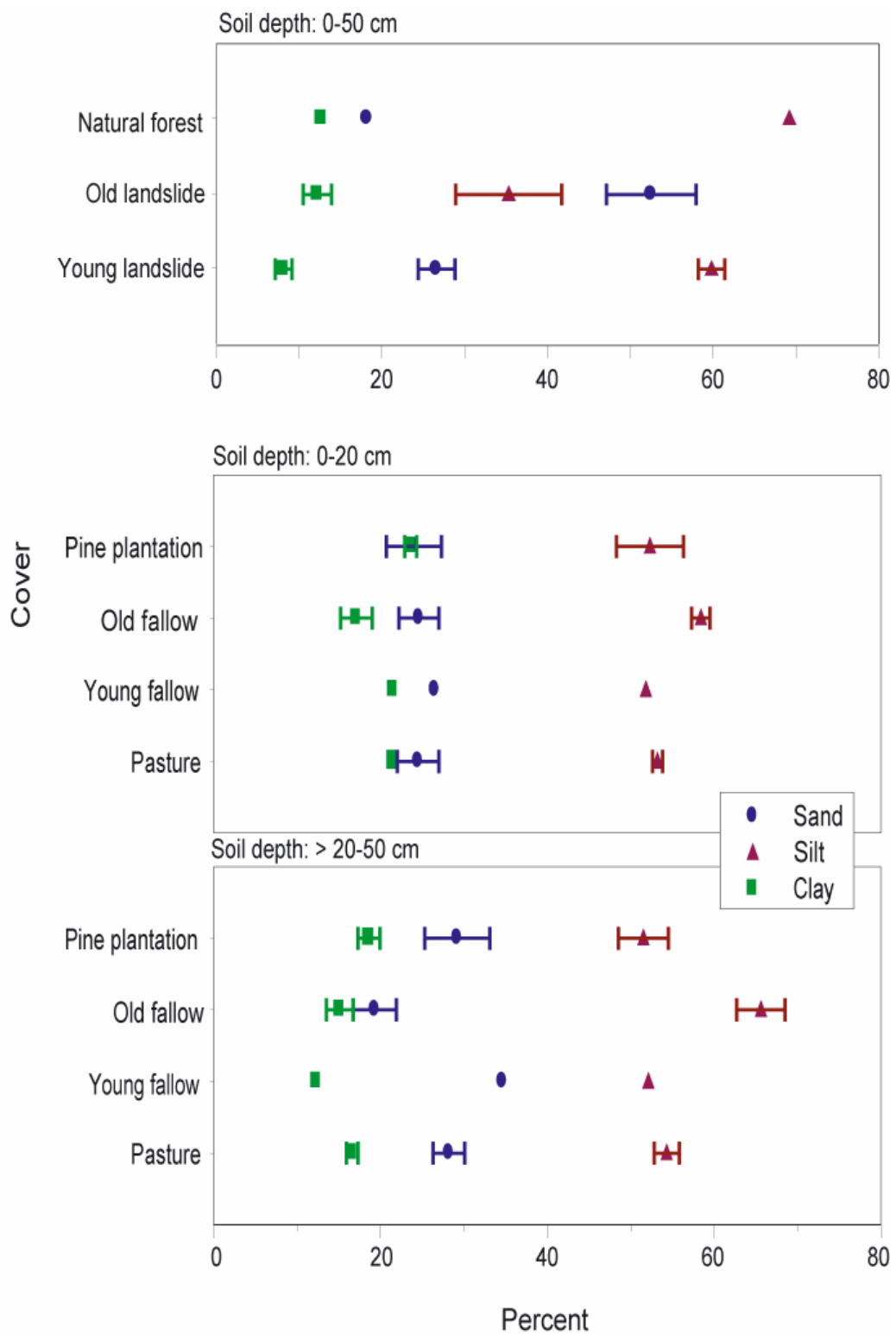

Figure 3-3. Mean particle size distributions (data from Wilcke et al., 2003; unpublished data from F. Makeschin, Dresden; unpublished data from B. Huwe, Bayreuth) for the investigated land covers. Bars represent the mean \pm standard errors when data of more than one profile was available. Profiles were located within the plots (PA, YF, OF, YS, OS, NF) or adjacent to the plots (PI). 


\subsubsection{Exploratory data analysis}

Since diagnostic plots indicated non-Gaussian behavior of the $K s$ distributions, we used BoxCox Transformation (Box and Cox, 1964) to find the most appropriate transformation. We then checked the univariate distribution of the (transformed) data, both for the global comparison datasets and for the spatial datasets. The latter were also checked for bivariate Gaussian distributions and outliers by means of h-scattergrams (Webster and Oliver, 2001a), which are scatterplots of point pairs separated by a fixed distance. We computed the Spearman rank correlation coefficient for the point pairs to get a first idea of the strength and the range of the spatial autocorrelations.

We used diagnostic plots (dividing the data into quintiles; plots of the data versus the coordinates) to explore the spatial data for non-stationarity that may be caused by local trends following the relation

$$
z(x)=\mu(x)+\varepsilon(x)
$$

where $z(x)$ is the observed variable at location $x, \mu(x)$ is a measure of central tendency, i.e., a deterministic drift of the variable at location $x$, and $\varepsilon(x)$ is the random component at location $x$ that should be normally distributed with zero mean and that satisfies the second-order stationarity required for spatial analysis. Hence, we calculated the residual values $\varepsilon(x)$ at every location $x$ and used the F-test (Fisher, 1972) to explore if $\mu(x)$ is significantly different from 0 . In case of a significant deterministic trend, we estimated the trend coefficients as fixed effects by restricted maximum likelihood (see below).

\subsubsection{Global comparisons}

We used the median as a resistant estimator of location with its $95 \%(\alpha=0.05)$ confidence interval calculated as follows:

$$
M \pm t_{n-1} * d_{F} /\left(1.075 * n^{\frac{1}{2}}\right)
$$

where $\mathrm{t}$ is the $\mathrm{t}$-statistic at the $95 \%$ confidence level for a given sample size, $\mathrm{n}$, and $\mathrm{d}_{\mathrm{F}}$ is the fourth spread (Iglewicz, 1983). Based on the confidence intervals we evaluated the 
differences between the land covers within the human and the natural disturbance sequence, respectively. In addition, we visually classified the different zones of the older landslide in the former slip and the non-active zone and compared their soil permeability.

\subsubsection{Spatial analysis}

As a first step in the variogram analysis, we calculated experimental variograms using the variogram estimator according to Matheron (1962)

$$
2 \hat{\gamma}(h)=\frac{1}{N(h)} \sum_{i=1}^{N(h)}\left\{z\left(x_{i}\right)-z\left(x_{i}+h\right)\right\}^{2},
$$

where $z\left(x_{i}\right)$ is the observed value at location $x_{i}, N(h)$ are the pairs of observations that are separated by lag $h$.

We next decided if we need robust estimation techniques. For this purpose, we fitted three standard theoretical variogram models (exponential, Gaussian, spherical) by ordinary least squares to the experimental variograms; the "best" model was chosen by the minimum sum of squares from the fit. We then adopted the approach of Lark (2000a) who compared the variograms derived from the Matheron estimator and three robust estimators by cross validation or with a validation subset using a statistics $\theta(\mathrm{x})$ defined as

$$
\theta(x)=\frac{\{z(x)-Z(x)\}^{2}}{\sigma_{K, x}^{2}}
$$

where $z(x)$ is the observed value at location $x, Z(x)$ is the kriged estimate and $\sigma_{K, x}^{2}$ the kriging variance. Lark (2000a) showed that $\mathrm{E}($ median $\theta(\mathrm{x}))$ is 0.455 when a correct variogram is used to interpolate intrinsic data. In order to compute confidence limits for the median of $\theta(\mathrm{x})$ Lark (2000a) argues in reference to standard texts that the median of a large sample of $2 n+1$ data, which are random variables of median $\tilde{x}$ and probability density function $f(x)$, is a normally distributed variable drawn from a population with variance ${\sigma_{\widetilde{x}}}^{2}$ where

$$
\sigma_{\widetilde{x}}^{2}=\frac{1}{8 n * f(0.455)^{2}}
$$


where $f(0.455)$ is the value probability density function of 0.455 with one degree of freedom. At this point the confidence limits can be computed by

$$
0.455 \pm 1.96 * \sigma_{\widetilde{x}}^{2 \frac{1}{2}}
$$

If the median of $\theta(\mathrm{x})$ indicates that Matheron's estimator is significantly influenced by outliers, robust estimation techniques should be used.

We also checked our data for anisotropy by calculating the experimental variograms in four different directions, one representing the contour line, one the slope and the other two are in between those two extremes.

If the median of $\theta(\mathrm{x})$ ruled out the presence of influential extreme values we estimated the covariance parameters nugget, sill, and range by restricted maximum likelihood as proposed by Lark et al. (2006). The principle of maximum likelihood estimation of variogram parameters is as follows: $n$ observed data are assumed to be from a multivariate Gaussian distribution with mean vector $m$ of length $n$ and covariance matrix $\Sigma$; the joint probability density of the data is

$$
f(z)=(2 \pi)^{-n / 2}|\Sigma|^{-1 / 2} \exp \left\{-\frac{1}{2}(z-m)^{T} \Sigma^{-1}(z-m)\right\}
$$

The vector $z$ contains the $\mathrm{n}$ data, and the vector $p$ contains the parameter of the covariance matrix. If the mean $m$ and the covariance $\Sigma$ are unknown and depend on parameter vectors $m$ and $p$, respectively, one can regard $z$ as fixed and $f(z)$ as a function of $m$ and $p$, which is called the likelihood function $L(m, p)$. Maximizing the likelihood, or minimizing the negative loglikelihood $-\log L(m, p)$ yields the parameter estimates. Restricted maximum likelihood treats the geostatistical model as a special case of a linear mixed model where the data are modeled as an additive combination of fixed effects (e.g. coefficients of a trend model), random effects (spatially dependent random variation) and independent random error (nugget variation). For a detailed mathematical description of the method we refer to Lark et al. (2006). We again used the three standard model types, because we could not fit the more flexible Matérn model (Whittle, 1954; Matérn, 1960) for a number of datasets. This impossibility was due to flat likelihood functions when we estimated the additional smoothness parameter of the Matérn function. 
Estimation by REML requires a multivariate Gaussian distribution, which cannot be verified (Pardo-Igúzquiza, 1998), which is why we scrutinized the h-scattergrams to at least check for bivariate Gaussian distributions. To rule out distortion of the REML-estimated covariance parameters due to skewness, we compared them with those of the least-squares models of the Matheron experimental variogram.

In order to compare the covariance parameters between cover types, we calculated the effective range to allow for comparability of the correlation lengths independent of the model type. The effective range for the spherical model coincides with the model range; for the exponential model, the effective range is approximately the model range times 3 , and for the Gaussian model it is estimated by the model range times the square root of 3 (Webster and Oliver, 2001b).

We also wanted to compare the strength of spatial autocorrelations. Cambardella et al. (1994) suggested using the ratio of the nugget-to-sill-variance for this purpose, and this approach has been widely adopted. If this ratio is $\leq 25 \%$, then the variable is considered to be strongly spatially dependent; a ratio of $25-75 \%$ indicates moderate dependence, and one of $75 \%$ and more suggests weak spatial autocorrelations. In an earlier study (Zimmermann et al., submitted) we proposed to fix the nugget to the semivariance at the smallest lag since estimating the nugget variance has to be done by model extrapolation, which may obscure the inter-site comparison of the autocorrelation strength. We therefore regarded the nugget variance as fixed, i.e. it corresponds to the semivariance calculated with the above-mentioned formula of Matheron (1962) at our smallest possible lag distance of $0.25 \mathrm{~m}$; for the $50 \mathrm{~cm}$ depth we averaged the semivariance over the first meter due to insufficient point pairs at the first lag.

In addition to the variogram analysis, we adopted an approach proposed by Bjørnstad and Falck (2001) that uses a nonparametric estimator (i.e. no a priori assumption of a functional form, e.g. Gaussian, exponential) of the covariance function, the spline correlogram, which is a generalization of the spatial correlogram. The assumptions which have to been satisfied are the same that we checked in the course of our analysis, i.e. second order stationarity, isotropy, and a Gaussian data distribution. The advantage of this method is the possibility to generate a confidence envelope for the covariance function by means of a bootstrap procedure. The correlation length is defined as the distance at which the covariance is not significantly different from 0 ; non-random local structures are indicated if the spatial autocorrelation at a separation distance of 0 (the y-intercept) is significantly positive. 


\subsection{Results}

\subsubsection{Exploratory data analysis}

Box-Cox transformation of the global comparison datasets showed that taking logarithms would be the most appropriate transformation in the majority of cases. There were, however, some exceptions, where the ladder of powers indicated square root transformation (pine plantation and forest at $12.5 \mathrm{~cm}$ depth), or transformation by the reciprocal of the square root (young fallow at 12.5 and $20 \mathrm{~cm}$ depth), respectively. Since it is impossible to compare differently transformed data, we used the untransformed data for the global comparisons, which reveal a high coefficient of skew in their univariate distribution (Table 3-2).

Table 3-2 Summary statistics of the Ks-data used for the global comparisons

\begin{tabular}{|c|c|c|c|c|c|c|}
\hline Cover & $\begin{array}{l}\text { Depth } \\
(\mathrm{cm})\end{array}$ & $\begin{array}{l}\text { Mean } \\
(\mathrm{mm} / \mathrm{h})\end{array}$ & $\begin{array}{l}\mathrm{LCL}^{\mathrm{a}} \\
(\mathrm{mm} / \mathrm{h})\end{array}$ & $\begin{array}{l}\text { Median } \\
(\mathrm{mm} / \mathrm{h})\end{array}$ & $\begin{array}{l}\mathbf{U C L}^{\mathbf{b}} \\
(\mathrm{mm} / \mathrm{h})\end{array}$ & Skewness \\
\hline \multirow{3}{*}{$\begin{array}{l}\text { Natural } \\
\text { forest }\end{array}$} & 12.5 & 135 & -32 & 25 & 81 & 2.17 \\
\hline & 20 & 92 & 5 & 22 & 39 & 2.48 \\
\hline & 50 & 11 & 0 & 3 & 5 & 4.19 \\
\hline \multirow{3}{*}{$\begin{array}{l}\text { Young } \\
\text { landslide }\end{array}$} & 12.5 & 53 & -7 & 12 & 30 & 3.35 \\
\hline & 20 & 80 & -5 & 23 & 50 & 1.96 \\
\hline & 50 & 11 & 5 & 7 & 10 & 4.20 \\
\hline \multirow{3}{*}{$\begin{array}{l}\text { Old } \\
\text { landslide }\end{array}$} & 12.5 & 189 & -29 & 55 & 139 & 4.35 \\
\hline & 20 & 101 & -1 & 20 & 41 & 2.46 \\
\hline & 50 & 19 & -6 & 6 & 18 & 1.81 \\
\hline \multirow[t]{3}{*}{ Pasture } & 12.5 & 14 & -2 & 3 & 9 & 3.04 \\
\hline & 20 & 17 & 1 & 2 & 4 & 3.55 \\
\hline & 50 & 130 & -11 & 11 & 32 & 2.21 \\
\hline \multirow{3}{*}{$\begin{array}{l}\text { Young } \\
\text { fallow }\end{array}$} & 12.5 & 7 & 1 & 1 & 2 & 5.04 \\
\hline & 20 & 10 & 0 & 1 & 2 & 3.38 \\
\hline & 50 & 10 & 0 & 1 & 2 & 5.23 \\
\hline \multirow[t]{3}{*}{ Old fallow } & 12.5 & 82 & 0 & 7 & 15 & 3.00 \\
\hline & 20 & 29 & 0 & 6 & 11 & 3.20 \\
\hline & 50 & 12 & 0 & 2 & 5 & 5.22 \\
\hline \multirow{3}{*}{$\begin{array}{l}\text { Pine } \\
\text { plantation }\end{array}$} & 12.5 & 514 & 217 & 429 & 641 & 0.62 \\
\hline & 20 & 125 & 6 & 50 & 94 & 2.38 \\
\hline & 50 & 12 & 1 & 3 & 5 & 4.24 \\
\hline \multirow[t]{3}{*}{ Forest } & 12.5 & 738 & 169 & 479 & 789 & 1.53 \\
\hline & 20 & 130 & -1 & 55 & 110 & 2.08 \\
\hline & 50 & 178 & -36 & 7 & 51 & 3.02 \\
\hline
\end{tabular}

a lower confidence limit of the median

${ }^{\mathrm{b}}$ upper confidence limit of the median

The spatial datasets had to be log-transformed except for the young fallow at 12.5 and $20 \mathrm{~cm}$ depth where we used the reciprocal of the square root for transformation. A Gaussian 
distribution could be achieved for half of the datasets, whereas for the others the distributions were still somewhat skewed (Table 3-3).

Table 3-3. Distribution of the transformed spatial Ks data

\begin{tabular}{|c|c|c|c|}
\hline $\begin{array}{l}\text { Cover } \\
\text { type }\end{array}$ & $\begin{array}{l}\text { Soil } \\
\text { depth }(\mathrm{cm})\end{array}$ & Skewness & $\begin{array}{l}\text { p-value }{ }^{a} \\
\text { (Shapiro) }\end{array}$ \\
\hline \multirow[t]{3}{*}{ Pasture } & 12.5 & 0.35 & 0.22 \\
\hline & 20.0 & 0.75 & 0.0001 \\
\hline & 50.0 & 0.59 & 0.0001 \\
\hline Young & 12.5 & 0.74 & 0.0005 \\
\hline \multirow[t]{2}{*}{ fallow } & 20.0 & 0.52 & 0.0003 \\
\hline & 50.0 & 0.04 & 0.51 \\
\hline Old & 12.5 & 0.09 & 0.58 \\
\hline \multirow[t]{2}{*}{ fallow } & 20.0 & 0.21 & 0.21 \\
\hline & 50.0 & 0.73 & 0.001 \\
\hline Old & 12.5 & -0.04 & 0.02 \\
\hline \multirow[t]{2}{*}{ landslide } & 20.0 & 0.08 & 0.13 \\
\hline & 50.0 & 0.45 & 0.12 \\
\hline \multirow{3}{*}{$\begin{array}{l}\text { Natural } \\
\text { forest }\end{array}$} & 12.5 & -0.39 & 0.005 \\
\hline & 20.0 & -0.14 & 0.42 \\
\hline & 50.0 & 0.05 & 0.89 \\
\hline
\end{tabular}

${ }^{a}$ p-value of the Shapiro-Wilk normality test

(Shapiro and Wilk, 1965)

At $12.5 \mathrm{~cm}$ depth, bivariate distributions as indicated by the h-scattergrams appear approximately Gaussian; i.e. the point cloud is not distorted; outlying values are also not highlighted (Figure 3-4). The same applies to the 20 and $50 \mathrm{~cm}$ depth except that pasture has some extreme values (Figure 3-5, Figure 3-6).

Significant linear trends characterize the log-transformed spatial data of the old fallow and the natural forest at all investigated soil depths. These local trends may be explained by the topography of those plots as their left sides were located near a small stream, and their right sides near a ridge, where Ks was comparatively low. Transformed Ks of the young fallow at $12.5 \mathrm{~cm}$ depth also shows a slight but significant linear trend. 

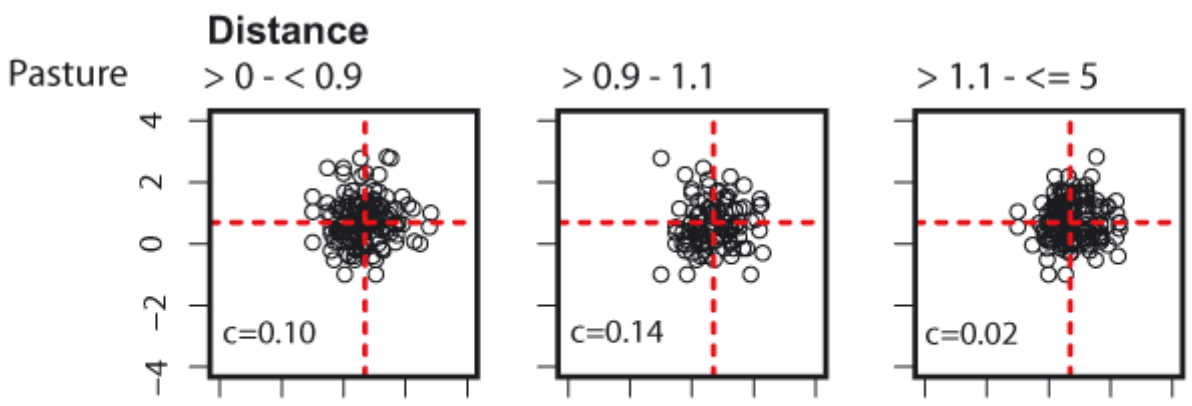

$>5-10$

Young fallow
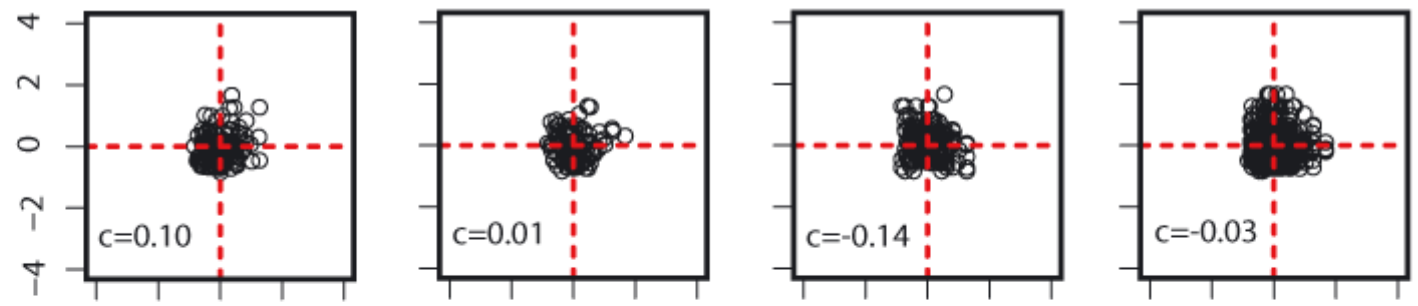

Old fallow
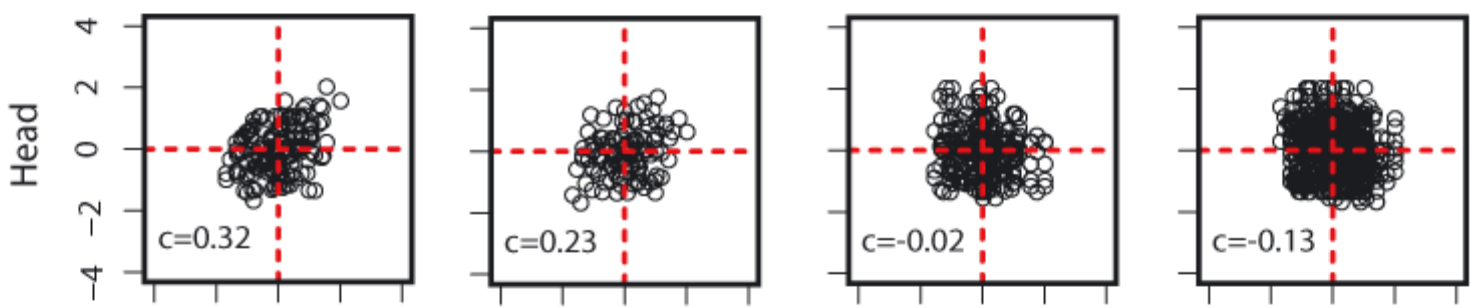

Old landslide
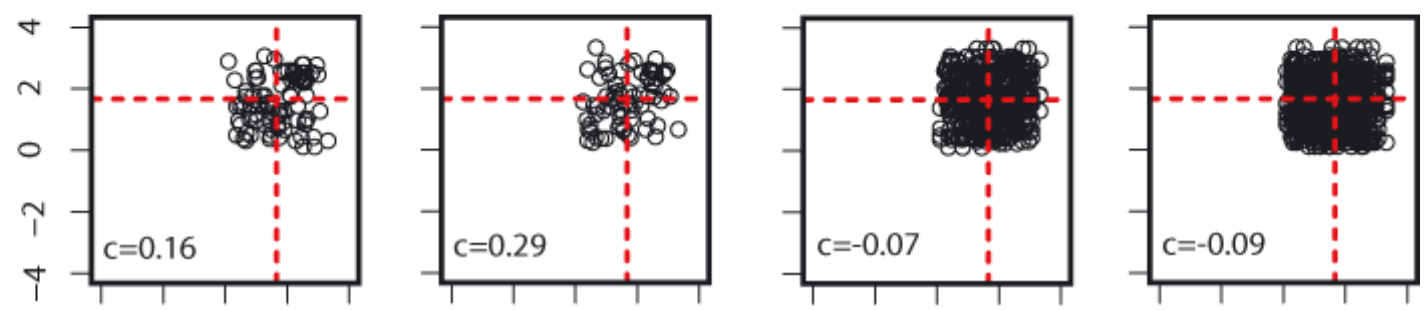

Natural forest
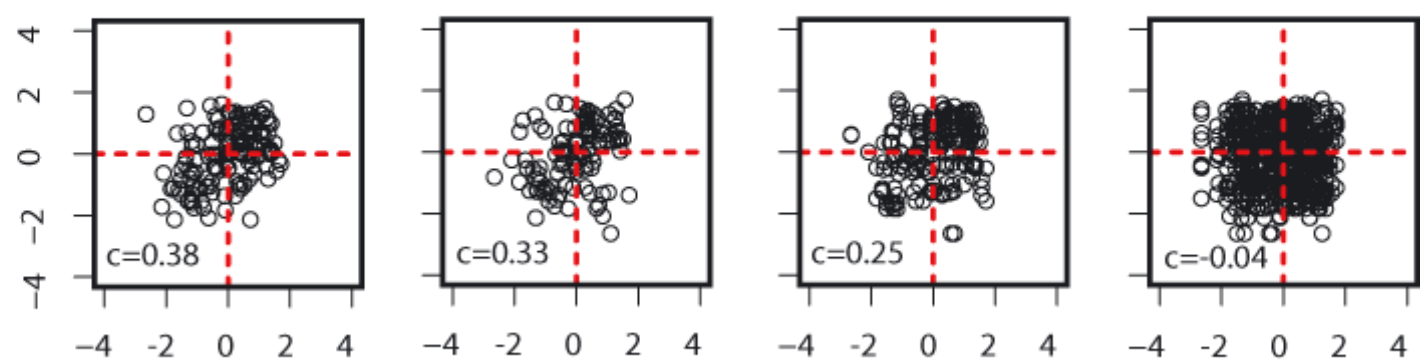

Tail

Figure 3-4. Bivariate distributions of the data or the residuals for the $12.5 \mathrm{~cm}$ soil depth; $\mathrm{c}$ is the Spearman rank correlation coefficient. 

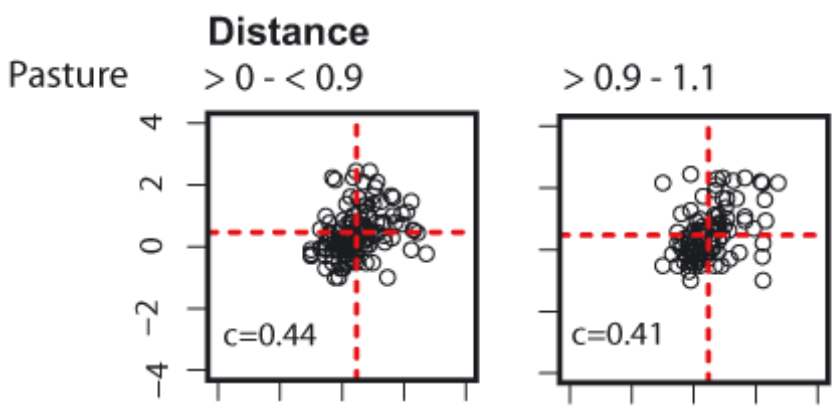

$>1.1-<=5$

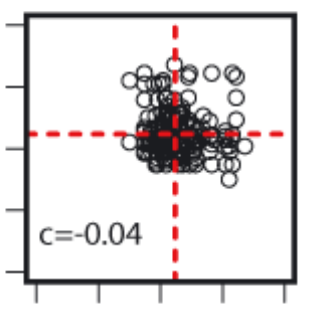

$>5-10$

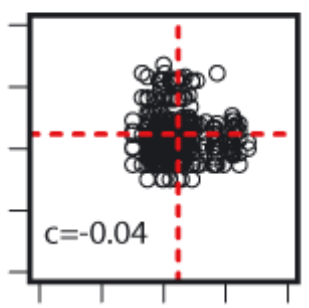

Young fallow
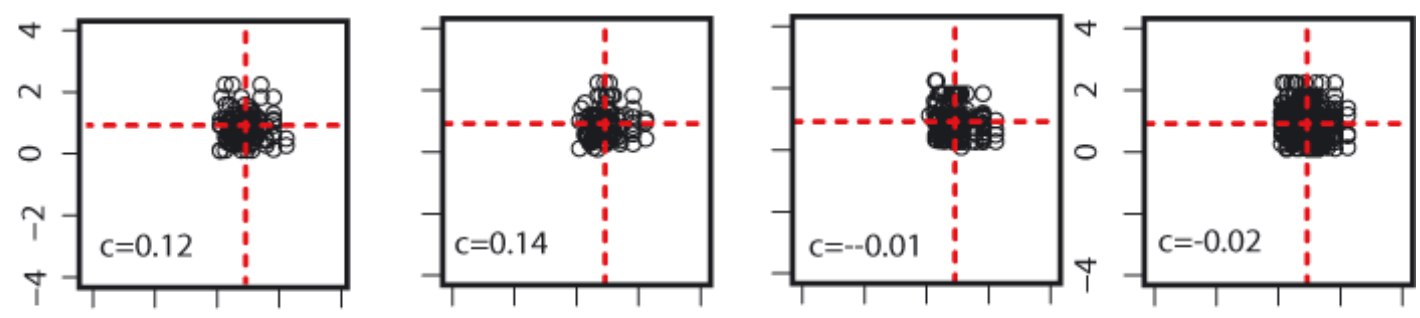

Old fallow
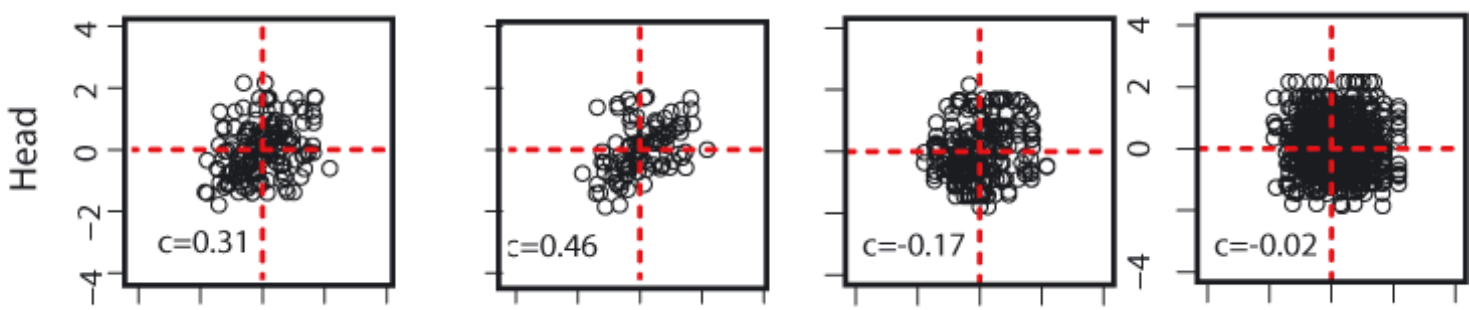

Old landslide
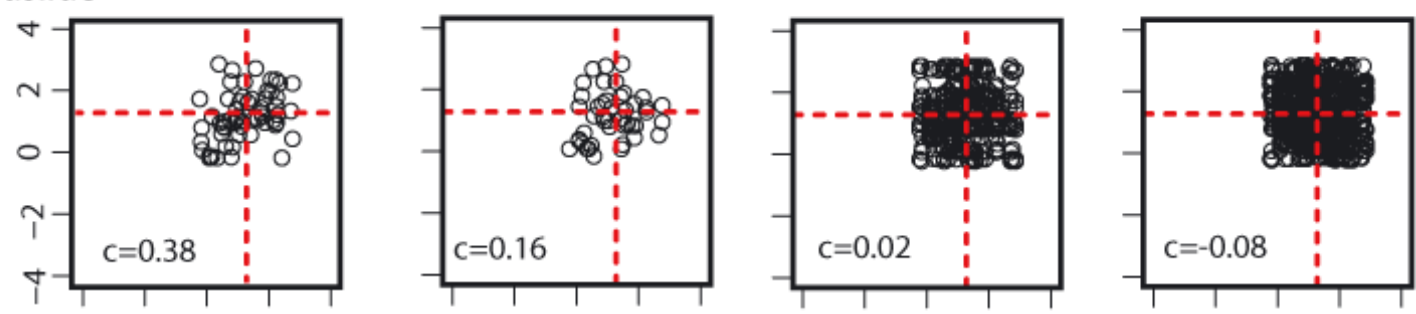

Natural forest
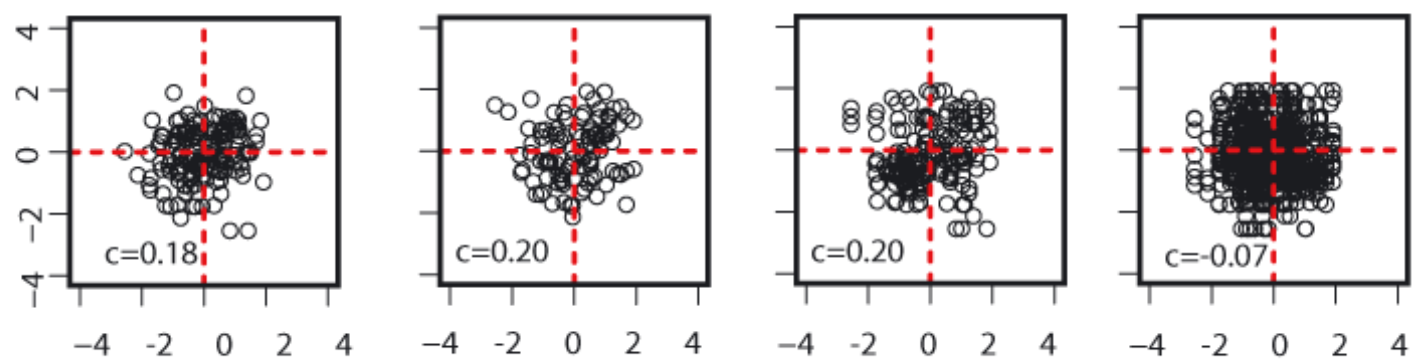

Tail

Figure 3-5. Bivariate distributions of the data or the residuals for the $20 \mathrm{~cm}$ soil depth; $\mathrm{c}$ is the Spearman rank correlation coefficient. 

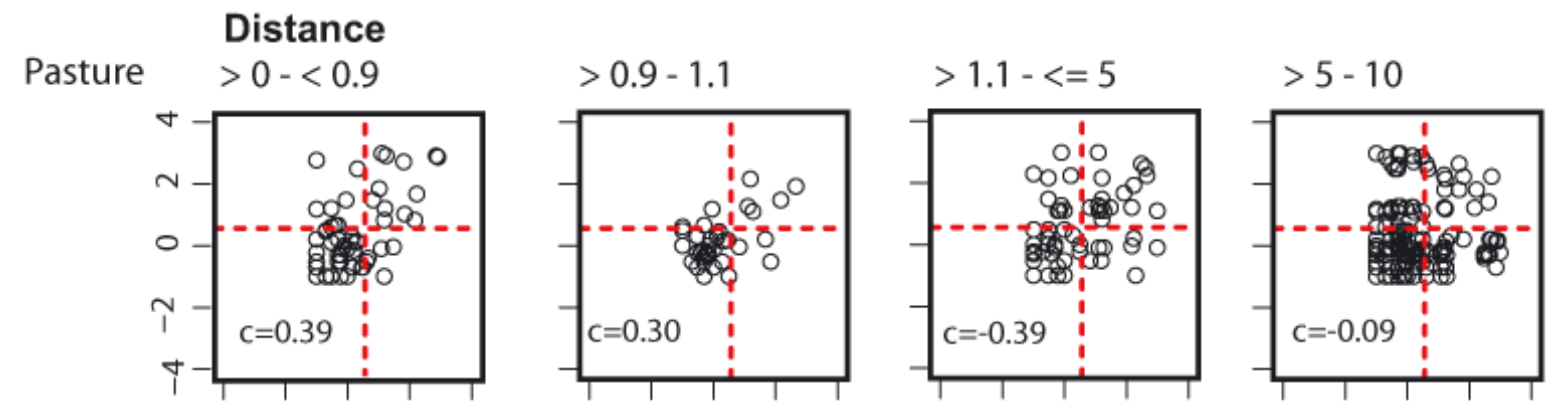

Young fallow
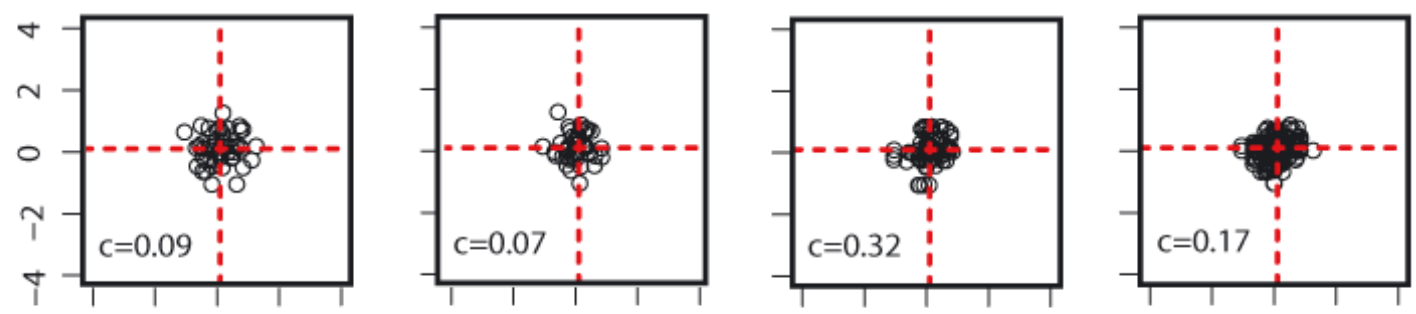

Old fallow
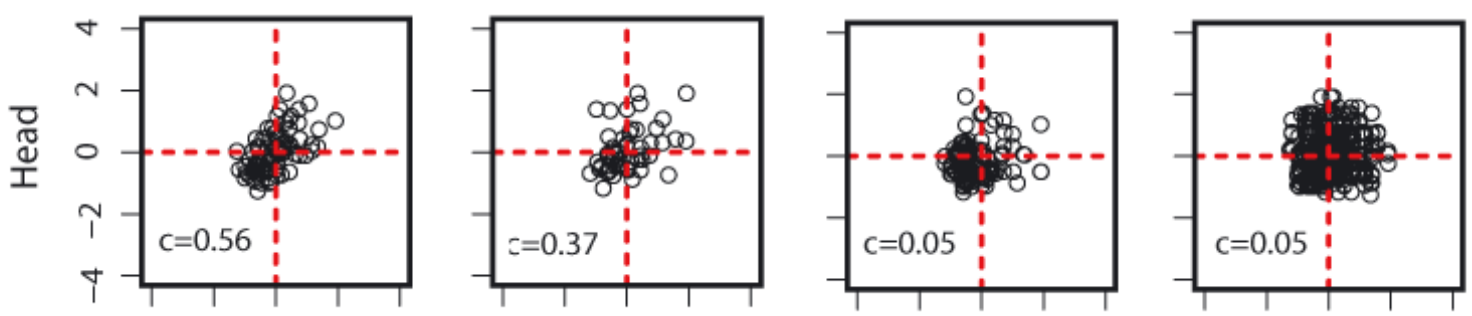

Old landslide
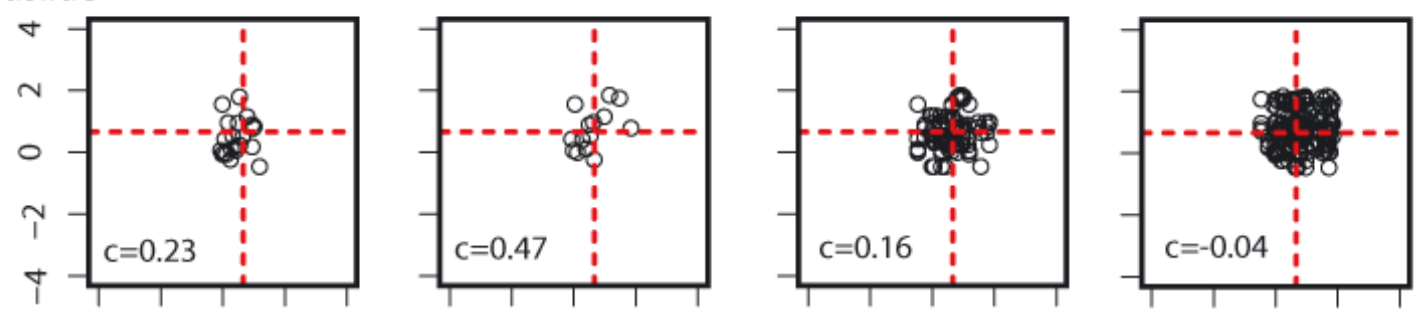

Natural forest
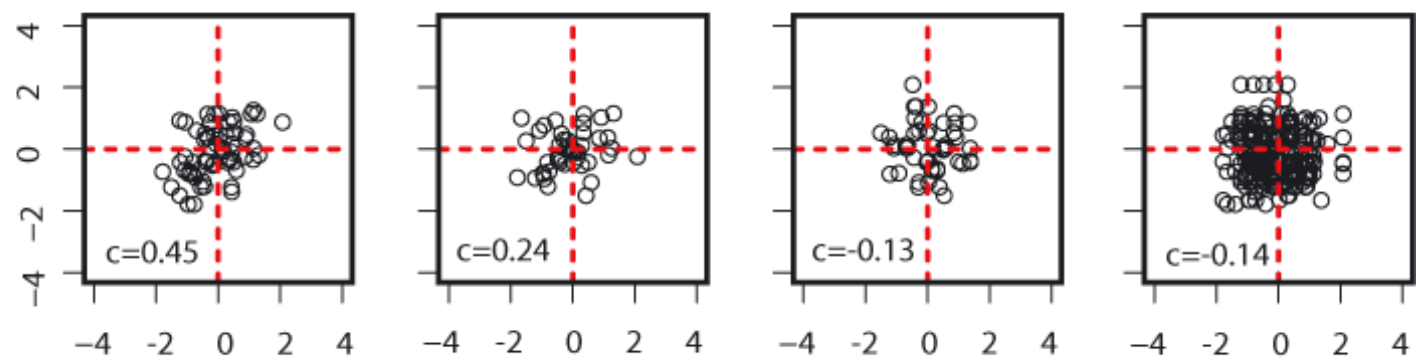

Tail

Figure 3-6. Bivariate distributions of the data or the residuals for the $50 \mathrm{~cm}$ soil depth; $\mathrm{c}$ is the Spearman rank correlation coefficient. 


\subsubsection{Global comparisons}

Depth gradient

Ks decreases with increasing depth under forest and on the old landslide. On the young landslide, $\mathrm{Ks}$ is somewhat higher at $20 \mathrm{~cm}$ compared to $12.5 \mathrm{~cm}$ soil depth, but also lowest at $50 \mathrm{~cm}$ depth (Figure 3-7, Table 3-2). In all cases, the decreasing trend is, however, not significant.
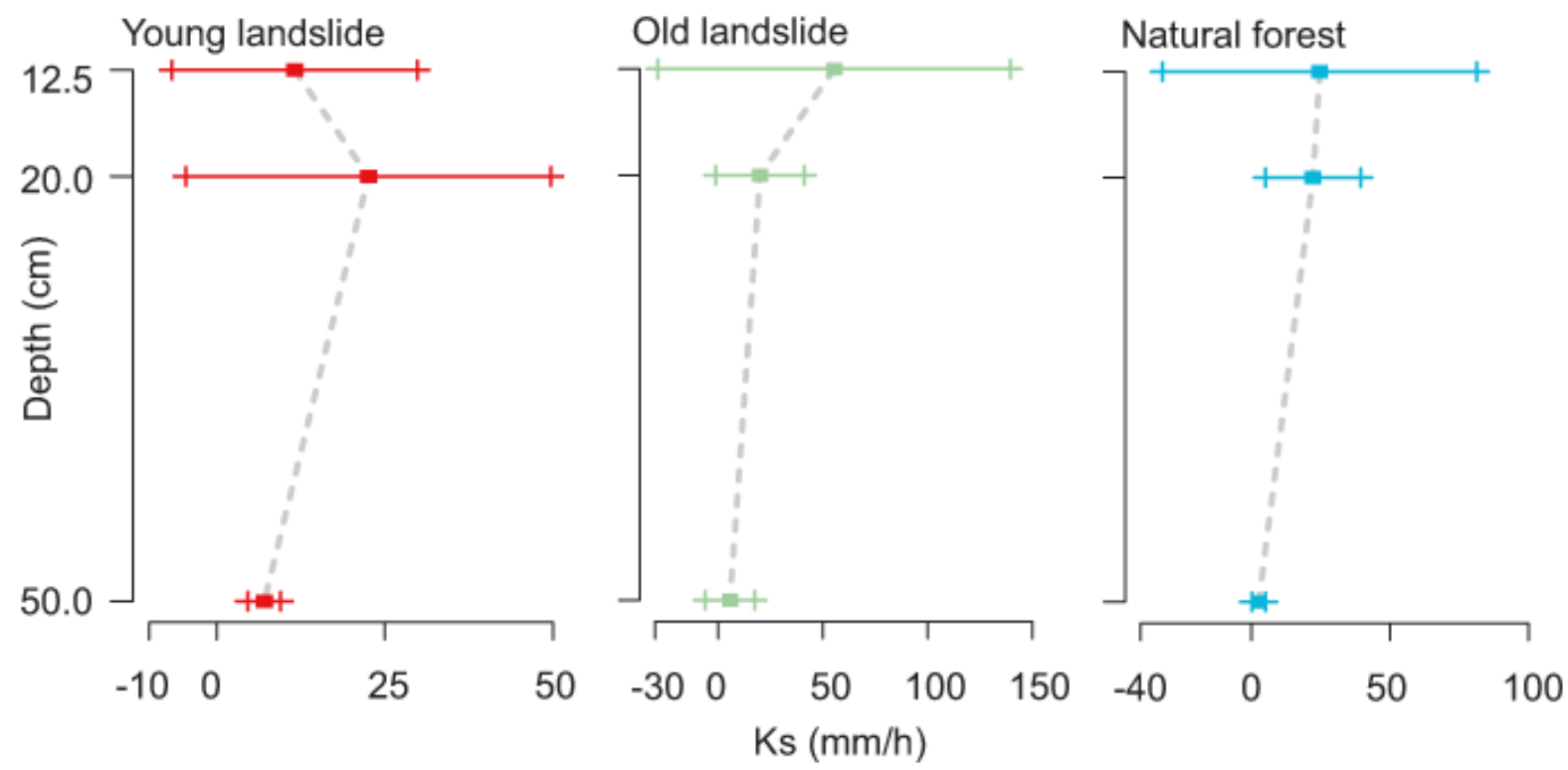

Figure 3-7. Depth gradient of Ks for the natural disturbance sequence. The boxes represent the median, and the bars encompass its $95 \%$ confidence interval.

At the human-influenced valley side, the drop of Ks with depth similarly occurs with the exception of pasture; here, Ks is highest at $50 \mathrm{~cm}$ soil depth (Figure 3-8, Table 3-2).
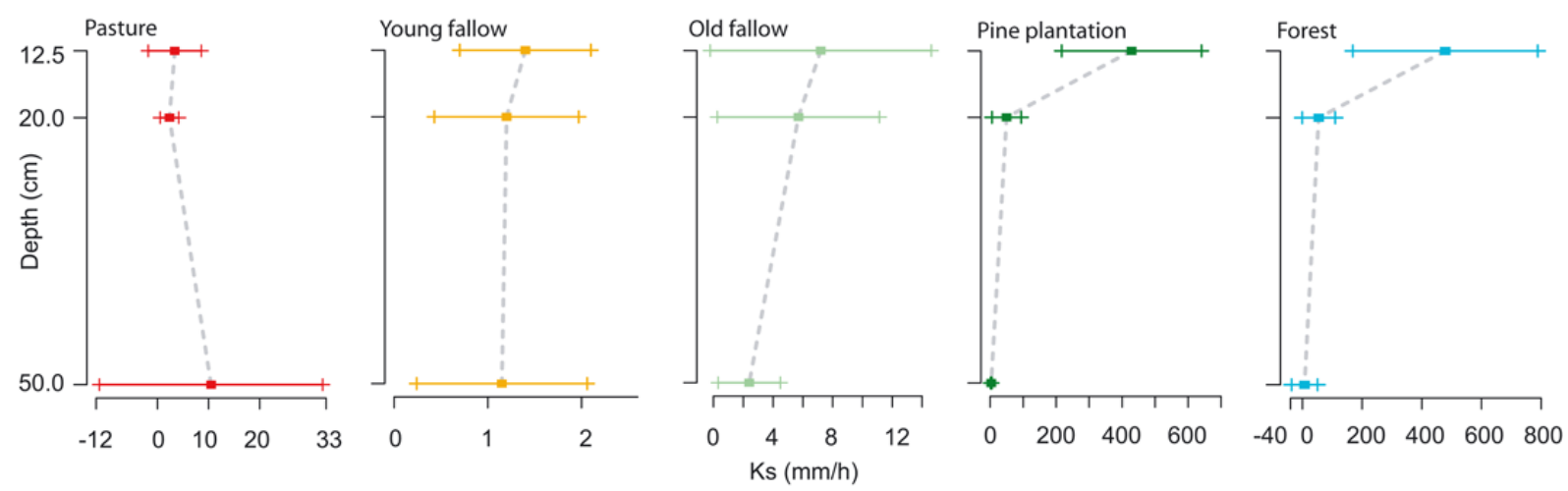

Figure 3-8. Depth gradient of Ks for the human disturbance sequence. The boxes represent the median, and the bars encompass its $95 \%$ confidence interval. 
Permeability under the young fallow decreases only very slightly between the topsoil and 50 cm depth. A somewhat more pronounced, but still insignificant drop characterizes Ks under the old fallow. In contrast, permeability of the soils under the pine plantation and the forest shows a significant depth gradient as it decreases by two orders of magnitude between the topsoil and $50 \mathrm{~cm}$ soil depth.

Inter-site comparison

The inter-site comparison for the natural disturbance sequence (Table 3-2) does not reveal significant changes of Ks along the pathway of recovery at any depth. Likewise the two different zones of a landslide slip zone and non-active zone do not differ significantly with respect to Ks at any depth (Figure 3-9).

Human disturbance affects Ks quite differently. The two forest types do not differ significantly at any depth, but their Ks exceeds that of pasture and the recovery stages by two orders of magnitude at the depths of 12.5 and $20 \mathrm{~cm}$, respectively (Table 3-2). That is to say, ten years of non-grazing and secondary succession have yet to produce a significant increase in Ks at the depths most affected by grazing. Permeability at $50 \mathrm{~cm}$ depth does not differ among land covers.

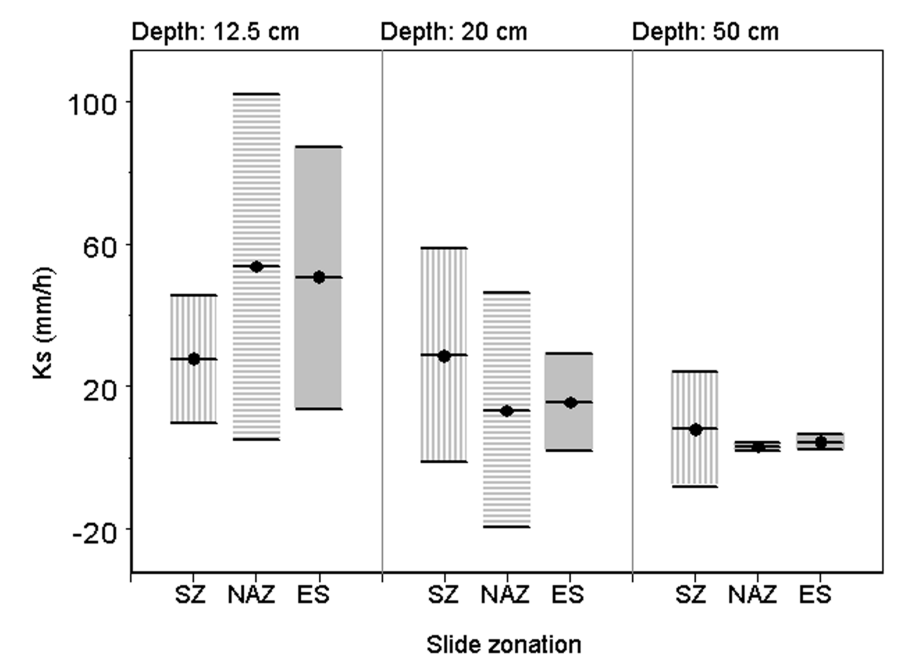

Figure 3-9. Ks under different zones on old landslide. SZ is the slip zone, NAZ the non-active zone, and ES the entire landslide. The line with the dot in the middle of the shaded rectangle represents the median, and the lines below and above the median show the calculated 95\% lower and upper confidence limits, respectively. 


\subsubsection{Spatial variability}

Robust estimation requirements and anisotropic variation

Although the univariate distribution is Gaussian for only half of the spatial datasets, the median of the $\theta$ statistics remains always within its confidence limits. These amount to 0.286 and 0.624 , respectively, for a sample size of 150 , and are somewhat wider for the partly smaller sample sizes at the $50 \mathrm{~cm}$ soil depth. Thus, we do not need robust estimation. There were only negligible differences in the sill variance between the least-squares models fitted to the experimental variogram and the restricted maximum likelihood estimates. We found partly greater differences between the models regarding the range, which is a result of the dependence of the least-squares model on the lag classes used for the experimental variogram (Zimmermann et al., submitted).

In summary, we decided to use REML for the estimation of the covariance parameters for all land covers and soil depths based on the h-scattergrams and the $\theta$ statistics.

Plots of the experimental variograms in four different directions of the transformed data or the residuals of the regression, respectively, did not indicate anisotropic variation.

Depth gradient of spatial patterns

An increase of both the strength of the autocorrelation and the correlation length characterizes a number of land covers. Under pasture, the effective range increases by one order of magnitude between 12.5 and 20 and $50 \mathrm{~cm}$ depth, respectively (Table 3-4). This trend is confirmed by the spline correlograms (Figure 3-10), which in addition indicate nonsignificant autocorrelation of the pasture topsoil permeability. The strength of the correlation similarly increases with depth under this land cover by about $20 \%$ (Table 3-4). A similar pattern characterizes the spatial depth gradient for the old fallow, though the effective range is shorter at 50 than at $20 \mathrm{~cm}$ soil depth (Table 3-4); it is the only land cover with significant autocorrelations at all soil depths (Figure 3-10). Ks under the young fallow exhibits only a weak spatial dependence in the topsoil, and complete spatial randomness in the subsoil. The old landslide also shows a depth-related pattern with a longer Ks correlation length in the subsoil (Table 3-4, Figure 3-10). Spatial correlations for Ks under the natural forest are only significant in the topsoil (Figure 3-10), but apart from this no clear depth-dependent pattern emerges (Table 3-4). 


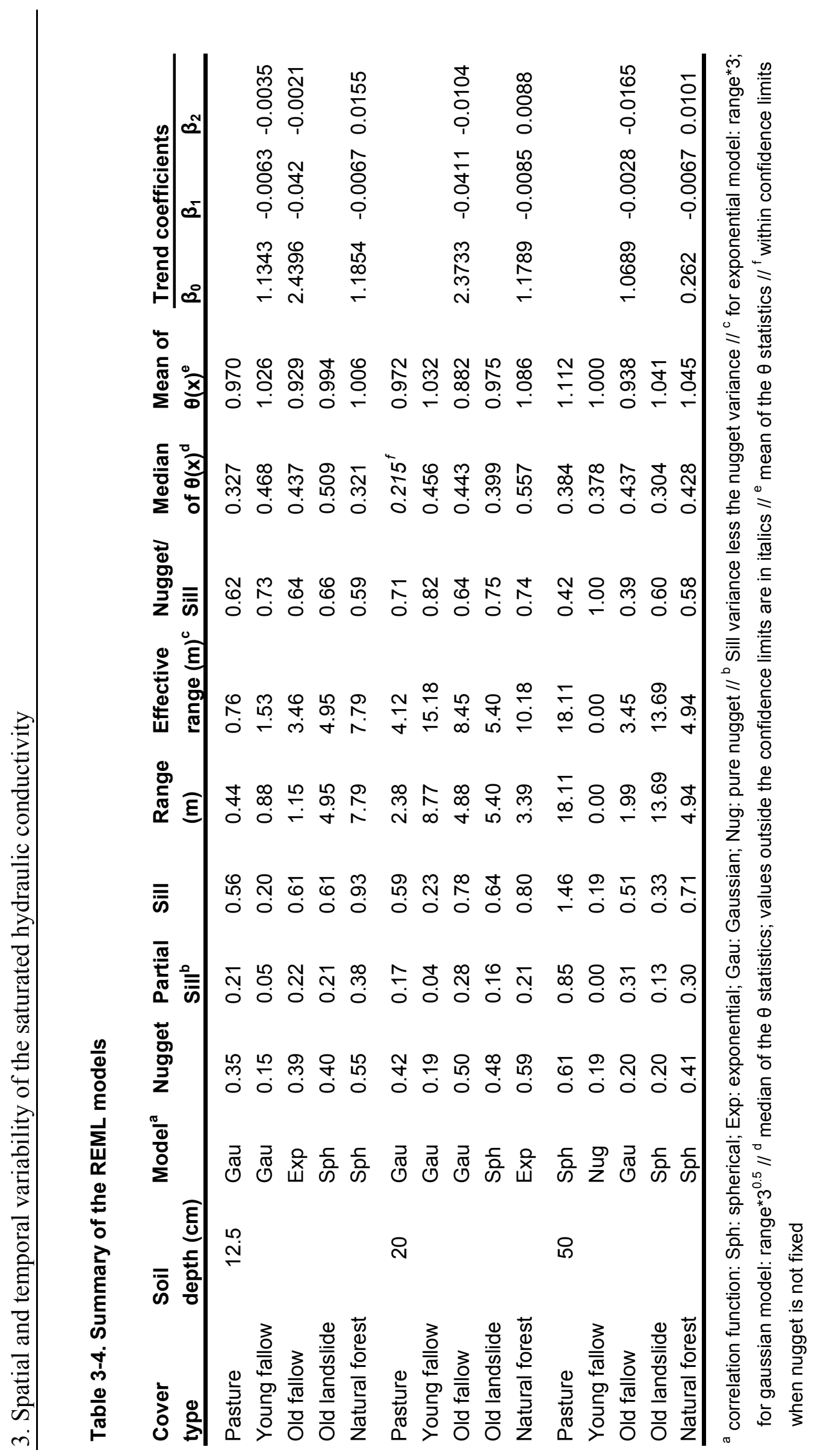


In summary, more or less pronounced and disparate spatial depth gradients characterize the permeability of all land covers.

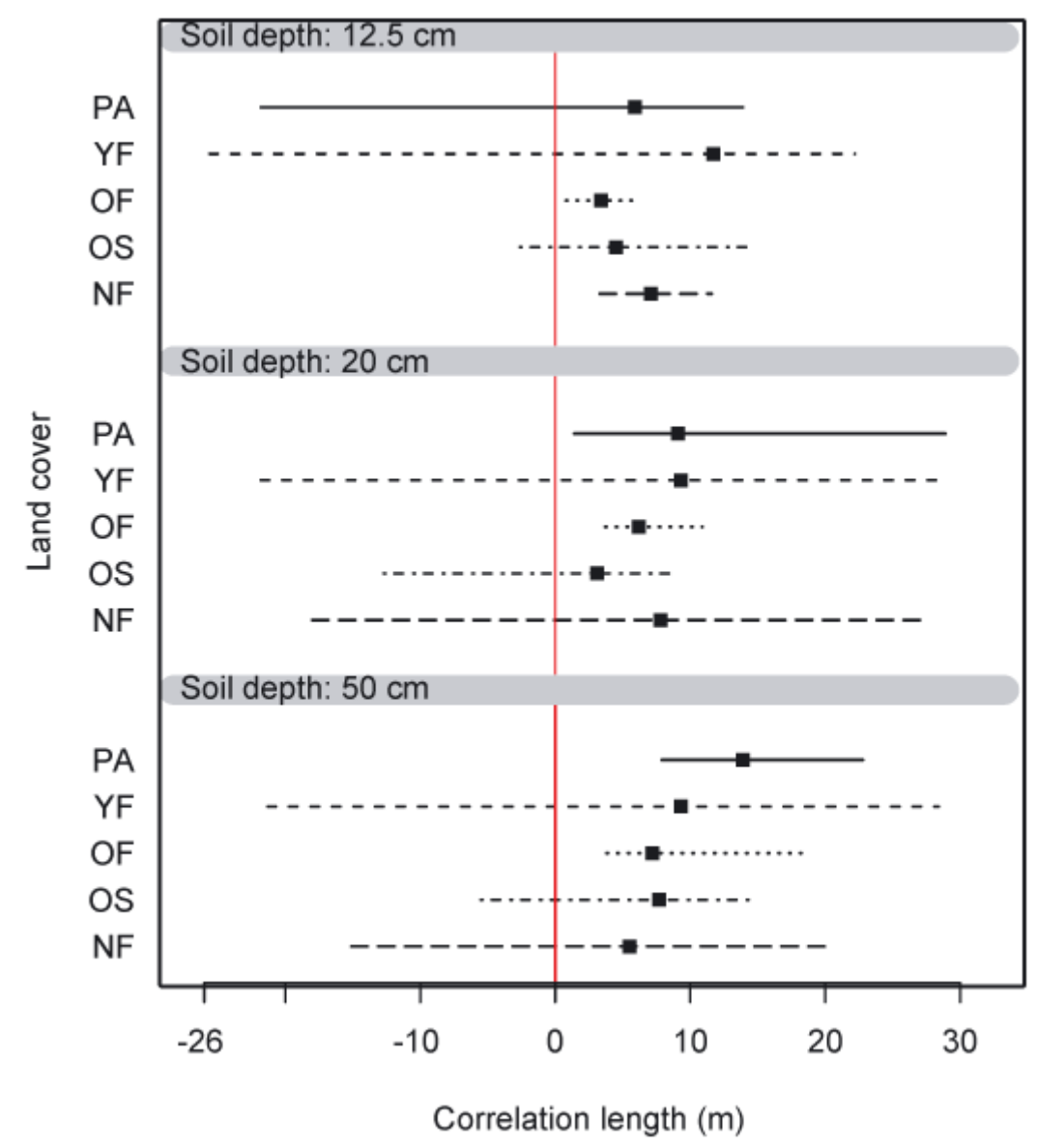

Figure 3-10. Correlation length estimated by the spline correlograms for the land covers pasture (PA), young fallow (YF), old fallow (OF), pine plantation (PI), and natural forest (NF). The square represents the estimate of the distance at which the similarity of two Ks values is not different of that expected by chance alone within the sample. The bars span the 95\% confidence intervals, which were estimated using bootstrapping based on 1000 bootstrap samples.

Spatial structure as a function of land use

In the topsoil, h-scattergrams (Figure 3-4) suggest similar weak spatial autocorrelations under pasture and the young fallow with a somewhat longer correlation length for the latter cover, whereas a stronger Ks spatial dependence is indicated for the old fallow. Ks of the natural forest topsoil shows both stronger and further-reaching autocorrelations compared to the landslide. The spline correlograms consistently indicate that only the old fallow and the natural forest exhibit significant Ks spatial autocorrelations, i.e. no spatial randomness (Figure 3-10). This coincides with the longer effective ranges of those land covers (Table 3-4). The 
nugget-to-sill ratios indicate, however, only moderate spatial dependence regardless of land cover.

At the $20 \mathrm{~cm}$ depth, permeability under pasture is stronger auto-correlated at the smallest separation distance than under either fallow, but the old fallow has again the longest correlation length (Figure 3-5). The Ks autocorrelation strength is similar for the forest and the landslide soil (Figure 3-5). The spline correlograms (Figure 3-10) indicate significant autocorrelation for pasture and the old fallow, but not for the other land covers. Although the longest effective range is associated with the young fallow (Table 3-4), this land cover has only a weak spatial structure compared to the other land covers, which at least show a moderate spatial dependence.

At $50 \mathrm{~cm}$ soil depth, complete spatial randomness characterizes the young fallow's permeability as indicated both by the spline correlograms and the variogram model. As at 20 $\mathrm{cm}$ depth, the spline correlograms (Figure 3-10) suggest significant autocorrelations only for pasture and the old fallow; pasture Ks has the longest effective range of all cover types. The forest-landslide comparison reveals a longer effective range of the landslide Ks (Table 3-4) but spatial autocorrelations of both covers are not significant as indicated by the spline correlograms (Figure 3-10).

\subsection{Discussion}

\subsubsection{Global comparisons}

The trend of decreasing Ks with increasing depth documented for all land covers except pasture (Figure 3-7, Figure 3-8) resembles that found for various soil types in many humid tropical regions (e.g., Malmer, 1996, Noguchi et al., 2003). Depending on precipitation characteristics, the hydraulic discontinuity with depth may be significant for shallow landslide initiation (Sidle and Ochiai, 2006). Vieira and Fernandes (2004), for instance, found a decrease by two orders of magnitude between the depths of $0.30 \mathrm{~m}$ and $0.60 \mathrm{~m}$ for a number of profiles close to the border and inside landslide scars in Rio de Janeiro.

The increase of Ks with depth under pasture was an exceptional case within the disturbancerecovery sequences. Several explanations might be proposed for this soil hydraulic behavior (e.g. high porosity in weathered sandstones; steeply inclined stone layers); the inter-site comparison, however, was not influenced in terms of a significant difference at the $50 \mathrm{~cm}$ soil depth. 
The remarkable lower surface soil permeability of pasture and the two fallow systems compared to the pine plantation and forest emphasizes the critical influence of land - cover change on soil hydrology. At the $50 \mathrm{~cm}$ depth, the disappearance of land - use effects on Ks matches observations from lowland Amazonia (Zimmermann et al., 2006) where Ks was independent of land cover at a depth of only $20 \mathrm{~cm}$.

Within the humid tropics, the impact of forest conversion or disturbance for timber harvesting or agricultural use on infiltrability has been shown in a number of studies (e.g., Malmer, 1996; Hanson et al., 2004). Ziegler et al. (2004) described the behavior of Ks in a land - use sequence including upland fields, fallows and secondary forests in mountainous Vietnam and reported a decline of Ks under the disturbed cover types compared to a reference forest as well as a regeneration of soil permeability some years after land-use abandonment. Alegre and Cassel (1996) and Martínez and Zinck (2004) found a decline of infiltrability after pasture establishment for an Ultisol in Peru and Colombia, respectively.

Lal (1996), working in western Nigeria, reported a decreased permeability under pasture, similar to that reported for Amazonia (Tomasella and Hodnett, 1996; Zimmermann et al., 2006). In a temperate rainforest region, McDowell et al. (2003) showed that simulated cattle treading indeed caused a decrease in surface permeability.

A recovery of Ks after pasture abandonment was observed in Amazonia (Godsey and Elsenbeer, 2002; Zimmermann et al., 2006). Comparing our results with the above mentioned lowland rainforest studies, it turns out that the decline of near - surface Ks after pasture establishment occurs in lowland as well as upland tropical regions. The recovery process is still insufficiently understood for general statements; the results from Amazonia and the montane rainforest in Ecuador, however, suggest that the deterioration of soil permeability under pasture is reversible after some time following abandonment. In Ecuador, we estimate this recovery time of surface Ks to exceed a decade since permeability under the old fallow still resembles that of pasture. After a quarter of a century, the former land use signal is likely to vanish, if the recovery documented for the pine plantation (Table 3-2) is any indication.

In order to explain the uniform permeability under the slides and the forest in the topsoil we propose that landslides in the study region basically remove biomass and the organic layer, but only a thin topsoil layer; thus, their impact on the mineral soil, and hence its Ks, is marginal. The soil hydraulic similarity of soil removal and accumulation zones of the old landslide and the rareness of actual landslides in the cleared areas also supports this hypothesis. 
Our results are in agreement with Wilcke et al. (2003) who concluded that the removal of the organic layer due to landslides is the most obvious change in soil properties regarding soil morphology and nutrient concentrations. Hou et al. (2005), working in a subtropical lowland forest, found in a study of litter decomposition by soil animals under undisturbed forest and recent landslide-disturbed sites that soil fauna recovers in very short periods of time after landslide disturbance. In our study region, soil fauna is not abundant; hence, only few macropores originate from animal activity. In this context, we found only very few visible macropores in soil clods and profile faces in the forest plot. Vieira and Fernandes (2004) investigated landslide scars along the Papagaio basin near Rio de Janeiro where they measured Ks at four slope positions on and next to the scars. At 30 and $60 \mathrm{~cm}$ soil depth, Ks hardly differed among those positions. This similarity of Ks between the upper soil layers of landslides and undisturbed areas is consistent with our observations.

\subsubsection{Spatial variability}

The spatial depth gradients highlight some special cases within the human disturbancerecovery cycle, which were also evident in the global comparisons. In the case of pasture, the high subsoil Ks coincides with a more pronounced spatial structure at $50 \mathrm{~cm}$ depth compared to the near-surface soil. That is to say, the unknown process which caused a number of unusual high permeability values is associated with a spatially dependent random variation. The young fallow is also exceptional in that the very low permeability throughout the investigated depth range is associated with a very weak or inexistent spatial structure. In summary we have to state that there is no generalizable depth-related spatial pattern: some land-cover types have a stronger Ks spatial dependence in the subsoil (pasture, old fallow), some are rather depth-independent (old landslide, natural forest), and the young fallow Ks exhibits spatial randomness in the subsoil. Hence, the evident depth gradient of average Ks has no analog in its spatial structure; e.g. lower subsoil permeability might on the one hand coincide with a more pronounced spatial dependence (e.g. old fallow), and can on the other hand be associated with a spatial pattern similar to the near-surface soil (i.e. natural forest). These variations in spatial depth gradients are reflected in the literature about Ks spatial variability of agricultural land. Mallants et al. (1996) reported a decrease of spatial dependence with increasing depth; Mohanty and Mousli (2000) found a decrease of correlation length, but increase of the correlation strength between 15 and $30 \mathrm{~cm}$ soil depth; 
Iqbal et al. (2005) also reported an increase of the correlation length moving from the surface to the deeper soil.

Some similarities characterize the spatial inter-site comparisons. First, the nugget-to-sill ratios indicate moderate spatial dependence in the topsoil; i.e. the partial sill contributes to about 30$40 \%$ to the total sill, which is therefore dominated by the nugget variance (Table 3-4). The high contribution of the nugget can be caused by high measurement errors (which we cannot quantify) or by a very small-scale variability. Since the measurement error should not vary much among the land covers, the small-scale variability seems to be of similar quantity for all of them. Some land-use related pattern regarding the strength of the spatial autocorrelation are indicated by the h-scattergrams for the topsoil (Figure 3-4, Figure 3-5), as the correlation is stronger for point pairs of the old fallow and forest Ks separated by small distances. Those differences, however, are not reflected in the variogram model one would use for spatial prediction (the sill variance is certainly somewhat biased due to departures from the Gaussian distribution for pasture and young fallow, but the models are adequate for kriging). Hence, from a practical point of view, the strength of Ks spatial dependence appears to be independent of land cover. In contrast, the correlation length seems to be a function of disturbance as the less disturbed soils of the old fallow and the natural forest have longer effective ranges than their disturbed counterparts. These land cover-related differences influence the spatial prediction; that is to say, exercises which require interpolated permeabilities, e.g. as an input in hydrological models, have to take into account the land-use effect.

The greatest variations both in the range and the strength of spatial autocorrelations are found at the depth of $50 \mathrm{~cm}$ (Table 3-4). The partial sill contributes between 0 (young fallow) and 60 $\%$ (old fallow) to the total sill variance, and the effective ranges encompasses 0 (young fallow) to 20 meters (pasture). As for average Ks values, land use is not an influential factor in the subsoil. But in contrast to simple location estimates, which at least do not differ significantly among the land covers, the covariance parameters are site-specific. That is to say, spatial interpolation is even more complicated than for the topsoil, where land use may be a proxy for the development of a predictable spatial structure. Hence, spatial interpolation is certainly inaccurate when taking the covariance parameters of maybe similar but not identical sites from the literature.

Inter-site comparisons of the Ks spatial structure are lacking in the literature. There are some indications, however, that a predictable spatial structure might be associated with stable soil conditions (Reynolds and Zebchuk, 1996, Mohanty and Mousli, 2000, Shukla, 2004). In 
contrast, a spatially independent random variation seems to originate from processes that interrupt the spatially-dependent intrinsic variations as e.g. biogenic macroporosity (Sobieraj et al., 2004), uneven breaking of soil structure due to freezing and thawing (Mohanty et al., 1991), or surface tillage in the upper horizons (Bosch and West, 1998). Our results for the topsoil spatial structure suggest that the impact of cattle treading and land-sliding might integrate into such processes. Figure 3-11 provides a conceptual framework, which proposes that even though the causes of disturbances are contrary (creation versus damage of macropores) their effect on the Ks spatial structure is similar, i.e. a loss of a spatially dependent random variation.

Figure 3-11. Possible effect of soil disturbances on $\mathrm{Ks}$ spatial structure. A: Soil column with intrinsic textural variation with alternating zones of high (where texture is coarse) and low (where texture is fine) $\mathrm{Ks}$, and the corresponding variogram. Spatially dependent random variation in permeability can also caused by intrinsic or extrinsic variations in soil structure, e.g. as a function of vegetation cover. B: The same soil column with biogenetic macropores (red entities), and the corresponding variogram. The spatially dependent random variation disappears or is very small-scale, which generates a flat or a pure-nugget variogram with a greater

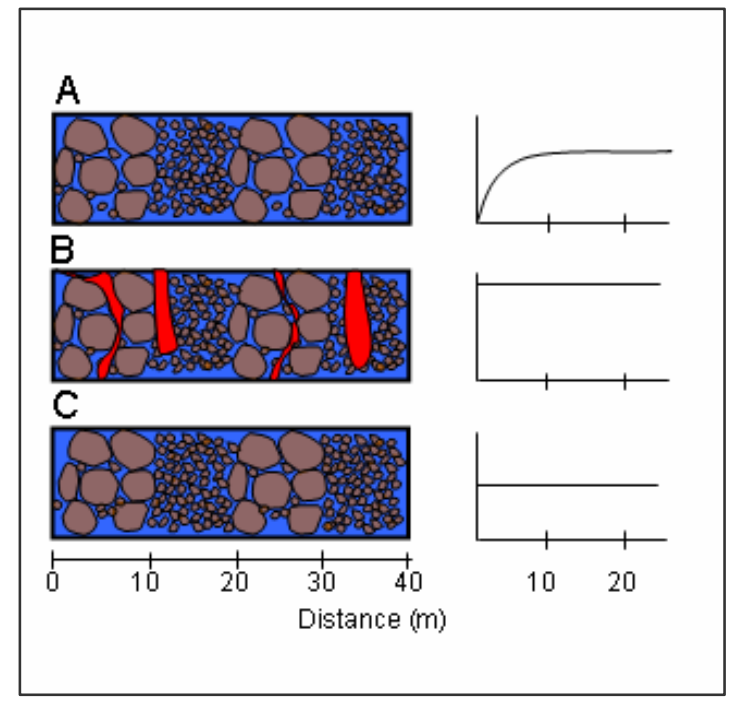
sill variance than that of A. Other examples of group B include soil cracks caused by freezing and thawing cycles. C: The same soil column which has undergone a compaction, e.g. by cattle treading. Permeabilities are generally low. The corresponding variograms tends to pure nugget solely comprising the random error; the sill variance is smaller compared to the variogram of A. Tillage operations are likely to have the same effect.

\subsection{Conclusions}

1) The soil hydraulic responses to disturbance and recovery are completely different for natural and man - made disturbance regimes in the tropical montane forest.

Landslides, which act as a natural disturbance in the study region, do not alter the saturated hydraulic conductivity with respect to the reference state. We therefore assume that landslides affect mainly organic horizons, but not the mineral soil. In contrast, forest conversion to pasture is accompanied by a reduction of surface Ks of two orders of magnitude. 
2) The reduction of the permeability under cattle pasture seems to be reversible, but the recovery after pasture abandonment requires at least one decade.

3) Disturbance effects on the Ks spatial structure are evident in the topsoil, where only the old fallow and the natural forest exhibit significant autocorrelations. However, greatest variations in the covariance parameters between the land covers are found in the subsoil, where the correlation length varies between 0 and $20 \mathrm{~m}$, and the portion of the nugget encompasses $30-100 \%$ of the total sill variance. These differences are sitespecific and cannot be explained by disturbance.

Consequently, practical applications requiring Ks input data, e.g. hydrological models, need to incorporate the land-use effect on average values. Spatial interpolation can only be done site-specific and would require a high sample size due to rather short-range autocorrelations. Hence, other upscaling techniques may be more appropriate in our study area. 


\title{
$\underline{4}$
}

\section{The soil hydraulic response to disturbance and recovery. II. Partitioning of rainfall in vertical and lateral flowpaths}

\begin{abstract}
Changes in soil hydraulic properties following ecosystem disturbances can become relevant for regional water cycles depending on the prevailing rainfall regime. In a tropical montane rainforest ecosystem, we showed that man-made disturbances were accompanied by a decrease in mean saturated hydraulic conductivity and a simplification of its spatial structure in the topsoil, whereas both mean permeability and spatial patterns were maintained after naturally occurring landslides. We used this spatial-temporal information combined with local rain intensities to assess the partitioning of rainfall into vertical and lateral flowpaths under undisturbed, disturbed, and regenerating land-cover types.

The studied montane rainforest is characterized by prevailing vertical flowpaths in the topsoil, which switch to lateral directions below $20 \mathrm{~cm}$ depth for less than one third of all rain events. In spite of the low frequency of such high-intensity rainstorms, the thereby activated lateral flow component transports a high portion of the annual runoff. Hydrological flowpaths under the landslides are similar to the natural forest except for a somewhat higher probability of impermeable layer formation in the topsoil of a two years old landslide.

In contrast, human disturbances involve pronounced differences in runoff components. In the topsoil to a depth of $20 \mathrm{~cm}$, we predicted the development of impeding layers for 24 and $44 \%$ of rain events for pasture and a two years old fallow, respectively. Using the natural forest as a reference we estimated the associated increase of the total rain amount in near-surface lateral runoff for the latter land-use types to be twofold and sixfold, respectively. An old fallow indicated regeneration towards the original vertical flowpaths in the topsoil, though the land use signal was still detectable as the predicted amount of near-surface lateral runoff was about 1.3 times higher compared to the reference state.

The consequences of land-cover change on hydrological flowpaths in the tropical montane rainforest region are of similar magnitude compared to a lowland rainforest in Brazil.
\end{abstract}


With: Helmut Elsenbeer; we submitted an edited version to Journal of Hydrology

\subsection{Introduction}

Soil-relevant disturbances, both man-made and natural, have the potential to affect ecosystem services of intact soils, such as water supply and purification or recycling of nutrients and organic wastes. These processes are strongly related to the movement of water and solutes between the soil-atmosphere boundary and within the soil; hence, they are often sensitive to changes in soil hydraulic properties, which can be initiated by disturbances. A key parameter in the hydrological cycle, the saturated hydraulic conductivity (synonym: soil permeability; Ks from here on), is sensitive to all disturbances that change a soil's macroporosity, because these two properties are functionally related (Ahuja et al., 1984). Examples of such disturbances are logging (e.g., Rab, 1996; Brooks and Spencer, 1997), tillage (e.g., Alakukku, 1998; Osunbitan et al., 2005), and cattle treading (e.g., Singleton and Addison, 1999; McDowell et al., 2003). Those changes will be relevant in the context of landscape hydrology if they involve a switch of hydrological flowpaths in the pedosphere, because these pathways control the partitioning of net precipitation into subsurface stormflow and overland flow. For instance, a shift to more lateral directions in the upper soil due to a decreased Ks after disturbances might increase the portion of near-surface or overland flow in runoff generation. If the latter is true, changes in the regional water cycle will follow with high probability, which can result in a decrease of dry season flow (Chandler, 2006), enhanced streamflow during the rainy season (Moraes et al., 2006), and an increased solute flux under stormflow conditions (Williams et al., 2004; Biggs et al., 2006).

In the humid tropics, hydrological flowpaths in undisturbed forests are predominantly vertical for soils with a weak anisotropy in the Ks-depth pattern, whereas near-surface lateral components are associated with soils that are characterized by a fast decrease of Ks with increasing depth (Elsenbeer, 2001). In both cases, several studies reported a decrease of the soil permeability at shallow soil depths after disturbances, which were mainly caused by forest conversion for agriculture (e.g., Ziegler et al., 2004), but also regeneration of Ks towards the original state can be observed, e.g. induced by the growth of secondary forests after land-use abandonment (Godsey and Elsenbeer, 2002; Zimmermann et al., 2006). One possibility to assess the potential impact of this Ks temporal variability on hydrological flowpaths is based on the interaction between soil hydraulic properties and the regional 
rainfall regime (Bonell and Gilmour, 1991; Elsenbeer and Vertessy, 2000). This approach requires the availability of both $\mathrm{Ks}$ and rainfall data with a high spatial (Ks) and temporal (rainfall) resolution. In this study, we evaluate changes in hydrological flowpaths after disturbances on the basis of spatial and temporal data sets of the soil permeability, which we collected under the land-cover types of natural and man-made disturbance sequences in a tropical montane rainforest ecosystem (Zimmermann and Elsenbeer, submitted). We showed that forest conversion to pasture is accompanied by a drop of Ks of two orders of magnitude, whereas soil permeability of forests remains unchanged after the naturally occurring landslides. In the topsoil, the spatial structure of Ks shows variations that could be attributed to the disturbances. We use this spatial-temporal information in combination with 10-minute rainfall records of two years to address the following research issues:

1) Which flowpaths prevail under undisturbed conditions in an montane rainforest ecosystem?

2) Are naturally occurring landslides associated with changes in flowpath behavior?

3) Do man-made disturbances alter hydrological pathways in the study area?

4) Do our site-specific results integrate into tropical standards?

To assess the latter, we directly compare the montane rainforest with a lowland rainforest in Brazil, where we measured Ks under a sequence of disturbed and regenerating landcover types (Zimmermann et al., 2006).

\subsection{Materials and methods}

\subsubsection{Study area}

Our study area is located in the south Ecuadorian Andes around the Estación Científica San Francisco (358 $18^{\prime \prime} \mathrm{S}, 79^{\circ} 4^{\prime} 45^{\prime \prime} \mathrm{W}, 1860 \mathrm{~m}$ a.s.1.). The north-facing valley side of the Rio San Francisco is covered by montane rainforest without human intervention, whereas the south - facing valley side has been subject to human influence for decades.

Shallow translational landslides are frequent throughout the study region, but we observed only minor recent slip activity at pastures and on fallows. Mean annual precipitation (19982005) amounts to $2273 \mathrm{~mm}$ (Rollenbeck et al., 2007), and mean annual (1999-2002) air temperature is $15.5^{\circ} \mathrm{C}$ (Motzer et al., 2005). The bedrock consists mainly of weakly metamorphosed Palaeozoic schists and sandstones with some quartz veins (Wilcke et al., 2003); soils are classified as Inceptisols and Histosols (Soil Survey Staff, 1999; Schrumpf et 
al., 2001) with a high percentage of silt. For more details, a map, and photos of the study sites we refer to the (Zimmermann and Elsenbeer, submitted).

\subsubsection{Site selection}

We selected four plots that represent the human disturbance and recovery sequence, and two landslides of increasing age. All plots are free of micro-topographic peculiarities such as big hollows, rills or gullies; slopes reached 30 till $40^{\circ}$, and aspects were similar. Both chronosequences have their old-growth forest reference plot since they are located on two opposite valley sides.

The reference site for the natural disturbance cycle is covered by "Lower Montane Rain Forest" (Bruijnzeel and Hamilton, 2000), underlain by a Humic Dystrudept (Goller et al., 2005 ) with a silt content of about $60 \%$ in all horizons (Schrumpf et al., 2001).

The young landslide (YS) occurred two years before our measurement campaign about onehundred meters to the northwest of the reference site. This slide consists of clearly distinguishable zones: below the scar is the slip zone, the zone of interest for the purposes of this study. This is followed downwards by a very steep and narrow depletion zone. At this position, a recently formed gully extends down to the accumulation zone at the foot of the landslide. Any successional vegetation is restricted to the accumulation zone.

An older landslide (OS) is located in an adjacent catchment and was active about 7-8 years ago. Successional plants include mosses, grasses, ferns, and small shrubs, but also bigger shrubs and small trees that occur on "accumulation islands"; only the former slip zone is still bare of vegetation.

The reference forest (FO) on the south - facing valley side for the human disturbance cycle shows signs of interference, such as logs of felled trees and charcoal in the upper soil. Two soil profiles illustrated the high variability over very short distances: one showed an initial stage of soil development with an A - horizon overlying the parent material, whereas the other a well defined B - horizon had already developed. At some measurement locations, a buried organic layer in about half a meter soil depth indicates former slide activities.

Our pasture plot (PA) has been grazed for about 20 years. Numerous narrow cattle trails are distributed along the contour lines. The dominant grass species are Setaria sphacelata on less inclined slope portions and Melinis minutiflora on steeper slopes. The low palatability of Setaria and the low biomass production of Melinis explain the low carrying capacity in the study region (Hartig and Beck, 2003). 
The young fallow (YF) was abandoned from pasture use only two years before our measurements, which accounts for the rather unusual dominance of Setaria instead of bracken.

After a recovery of at least 10 years, succession vegetation covers the old fallow (OF), but bracken is still frequent. Among the most abundant families are Orchidaceae, Asteraceae, Ericaceae, Melastomataceae, Poaceae, Rosaceae, Gleicheniaceae, Lycopodiaceae, Bromeliaceae, and Myrsinaceae, which are the same pioneers as on the landslides. The pine plantation (PI) represents a special type of a secondary forest: pines (Pinus patula) were planted immediately after pasture abandonment 25 years ago. The space between the sparsely standing trees is almost completely covered by bracken, which in places grows taller than $2 \mathrm{~m}$.

\subsubsection{Sampling}

We measured the field-saturated hydraulic conductivity in situ in the mineral soil at the depths of 12.5, $20 \mathrm{~cm}$ and $50 \mathrm{~cm}$ with an Amoozemeter (Ksat Inc., Raleigh; Amoozegar, 1989), a compact, constant-head permeameter. For all cover types except the young landslide, the pine plantation, and the forest at the land-use side, we used a combined design- and model-based sampling approach, which resulted in $150 \mathrm{Ks}$ measurements per soil depth. At the young landslide, we measured $K s$ exclusively in the slip zone via a simple random selection of 30 measuring points. For the pine plantation and the forest we also took 30 sampling points randomly.

For a detailed description of the measuring procedure and sampling strategy, we refer to (Zimmermann and Elsenbeer, submitted).

\subsubsection{Rainfall in the montane rainforest}

Hourly totals of rainfall are available since 1998 from astandard tipping bucket rain gauge with a minimum resolution of $0.1 \mathrm{~mm}$ (Richter, 2003). This rainfall measuring site is located on the north-facing valley side close to the ECSF research station. In order to avoid bias due to possibly different rainfall regimes at the two valley sides, we used rainfall records from two new, identically equipped climate stations for the flowpaths comparison, one of which is located next to the above-mentioned one, whereas the other is located on the opposite valley side. These new climate stations provide ten-minute rainfall records since September 2005 
(unpublished data T. Peters, Erlangen). Following Fleischbein et al. (2006), we separated events by a dry period of at least two hours.

\subsubsection{Partitioning of rain in hydrological flowpaths}

In the companion paper (Zimmermann and Elsenbeer, submitted) we estimated the parameters of spatial correlation functions for the cover types pasture, young fallow, old fallow, old landslide, and natural forest. For this study, we use these parameters to perform 100 conditional sequential Gaussian simulations, which we post-processed to summarize the spatial uncertainty information. We displayed the outcome in probability maps by the following procedure: at each simulated grid node, the probability that a variable of interest is exceeded by a given threshold is evaluated as the proportion of the 100 simulated values that exceed that threshold (Goovaerts, 1997). In our case we wanted to assess the hydrological consequences of the spatial and temporal variability of $K s$, i.e. the spatial distribution of possible impeding layers. We therefore calculated for every grid node the probability that Ks is exceeded by some location estimate of maximum 30-minute rainfall intensities, which we extracted from the rainfall records. The results can be interpreted as follows: if the rain intensities exceed most of the simulated Ks values, extensive impeding layers are likely to exist.

In order to assess the importance of impermeable layers for plot-scale hydrological flowpaths, we used the following classification: 1) if the probability of rain intensities exceeding Ks is generally low (probability $\leq 0.4$ ), we postulate prevailing vertical flowpaths; 2 ) if less than half of the plot area is assigned a high probability $(>0.6)$, we postulate a merely local formation of impeding layers with re-infiltration of possible overland flow at locations where those layers are absent; 3 ) if more than half of the plot area is assigned such a high probability, we postulate more extensive impeding layers involving a major contribution of near-surface lateral flowpaths to runoff. Since this framework ignores the correlation between the frequency of certain rain intensity classes and the associated portion of the annual precipitation within a class, we additionally summarized the quantity of rain associated with such a class. We therefore used all 10-minute rainfall records: rain amounts of those intensities which are associated with a high probability of exceeding simulated Ks area-wide (belonging to point 3 of the classification) are assumed to contribute to near-surface lateral flowpaths. It is certainly not possible to infer the true amount of near-surface runoff from this 
exercise, which is why we restrict our analysis to the relative increase of near-surface runoff under disturbed land-cover types compared to natural forest.

For a classification of the pine plantation, forest at the south-facing valley side, and the young landslide, where spatial data is not available, we compare the median Ks with the location estimates of the maximum 30-minute rain intensities. A potential for impeding layer formation is indicated if they exceed median Ks.

\subsubsection{Comparison with a lowland tropical rainforest}

The comparison with a tropical lowland rainforest is based on a site located in western Brazil, for which Ks measurements under a variety of man-made disturbance regimes and natural cover types were available (Zimmermann et al., 2006). The annual precipitation at the latter site is similar, although rain intensities are much higher (Table 4-1). We compared the following land-cover types regarding their topsoil permeability (12.5 and $20 \mathrm{~cm}$ soil depth): 1) a 20 year old pasture in Brazil with the Ecuadorian pasture; 2) a ten year old teak plantation regenerating from antecedent pasture use with the ten year old Ecuadorian fallow; 3 ) a 25 year old secondary forest with the pine plantation; 4) primary forest with the Ecuadorian forest. In order to allow comparability independent of varying event definitions, we use location estimates of 10-minute rain intensities, which are also available for the Brazilian site. At this site, a Campbell logger recorded 5-minute rainfall values from a tipping bucket rain gauge (Hydrological Services P/L, Liverpool, Australia) since 2002 with a resolution of $0.254 \mathrm{~mm}$. Since the time interval was longer (10 minutes) for the Ecuadorian study site, we aggregated the Brazilian records to 10 minutes. We assume the difference in minimal resolution to be negligible, since low-intensity events are unimportant in the tropical lowland study site. 


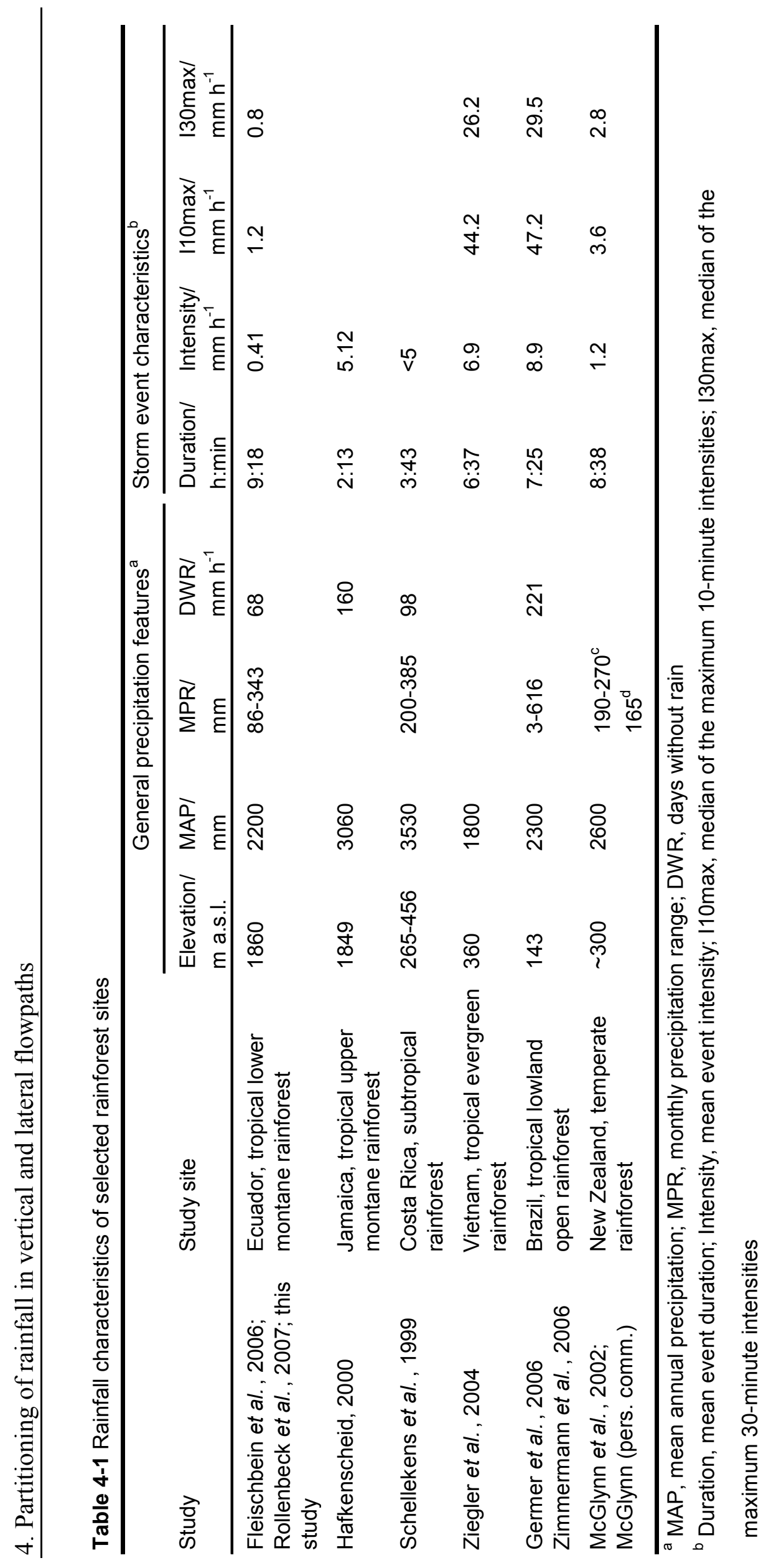




\subsection{Results}

\subsubsection{Rainfall in the montane rainforest}

Because precipitation derives mainly from advective clouds, rain intensities are generally low in our study (Rollenbeck et al., 2007). These low intensities distinguish the regional rainfall regime from that of other rainforests (Table 4-1). Although rainfall is dominated by light advective drizzle, our study region also experiences more intense convective events (Rollenbeck et al., 2007). Interannual variability of precipitation is low (Rollenbeck et al., 2007).

Maximum 30-minute rain intensities are similar for both valley sides, with respect to location estimates, the frequency of occurrence and the total rain amount (Figure 4-1). In accordance with the long-term observations, rainfall intensities are low for the majority of rainfall events occurring in the investigation period (Figure 4-1). More than $50 \%$ of all maximum 30 - minute rainfall intensities do not exceed $0.8 \mathrm{~mm} / \mathrm{h}$; however, events with those intensities contribute to only $5 \%$ of the annual rainfall (Figure $4-1$ ). High-intensity events contribute the bulk of the total rain amount. Events with 30-minute rain intensities between 2.8 and $7.4 \mathrm{~mm} / \mathrm{h}$ (i.e. between upper quartile and upper twentieths) contribute nearly half of the total rain amount, but those events comprise not even one fifth of all storms (Figure 4-1). As much as one third of the annual rainfall is associated with even higher intensities (upper twentieths till maximum of all 30-minute rainfall intensities), which occur only with a low frequency of about $5 \%$ of all rain events during the investigated years. During the period 1998 to 2004, the majority of the most intense rain events (i.e. the five most intensive storms within one year) took place in March, followed by December, April, May, and January. Hence, the months from December to May seem to be associated with intense rain storms. This period does not coincide with the unimodal distribution of the annual precipitation, which has a maximum between April and July (Rollenbeck et al., 2007). 


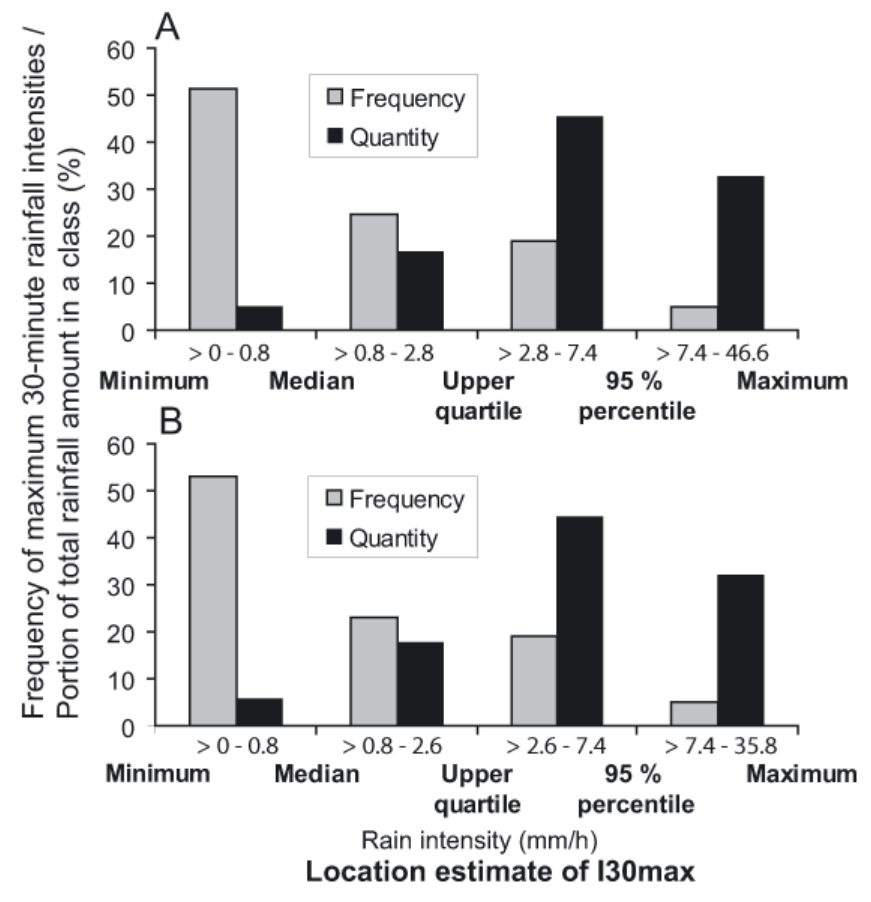

Figure 4-1. Frequency and quantity of the maximum 30-minute rain intensities in classes with intervals corresponding to location estimates of those intensities. A refers to the climate station at the south-facing valley side, and B to the north- facing valley side, where the rainforest reserve is located.

\subsubsection{Partitioning of rain in hydrological flowpaths as a function of disturbance}

\subsubsection{Probability of impeding layer formation}

Soil depth: $12.5 \mathrm{~cm}$

At the pasture, for at least half of the storms free percolation persists throughout the plot (Figure 4-2). Events with intensities that exceed the median are associated with a local occurrence of impeding layers, which have a patchy distribution due to the spatial random distribution of the pasture soil permeability at this depth. More extensive impeding layers with the potential to cause saturation excess overland flow likely develop during highintensity storms (Figure 4-2).

The very low Ks under the young fallow that can be already observed in the topsoil accompanies local impeding layers for all storms. For the low-intensity half of the events the trend of higher permeability at the right-hand plot side causes the non-random distribution of impeding layers, which are located in the lower left areas. At least one third of the storms are associated with extensive impermeable layers (Figure 4-2). 
Topography dependence of Ks involves localized ponding also in the old fallow's topsoil, but only the most intense storms (less than $5 \%$ ) are potentially associated with the occurrence of saturation excess overland flow.

Area-wide vertical percolation characterizes the topsoil hydrology under the old landslide and the natural forest for at least two third of all rain events, and merely local impermeable layers may develop during high intensity storms, which are location-dependent in the natural forest soil. Similar to the old fallow, the pronounced topography parallel to the slope is associated with higher Ks under the ridge and lower Ks in near-stream zones of the plot. 

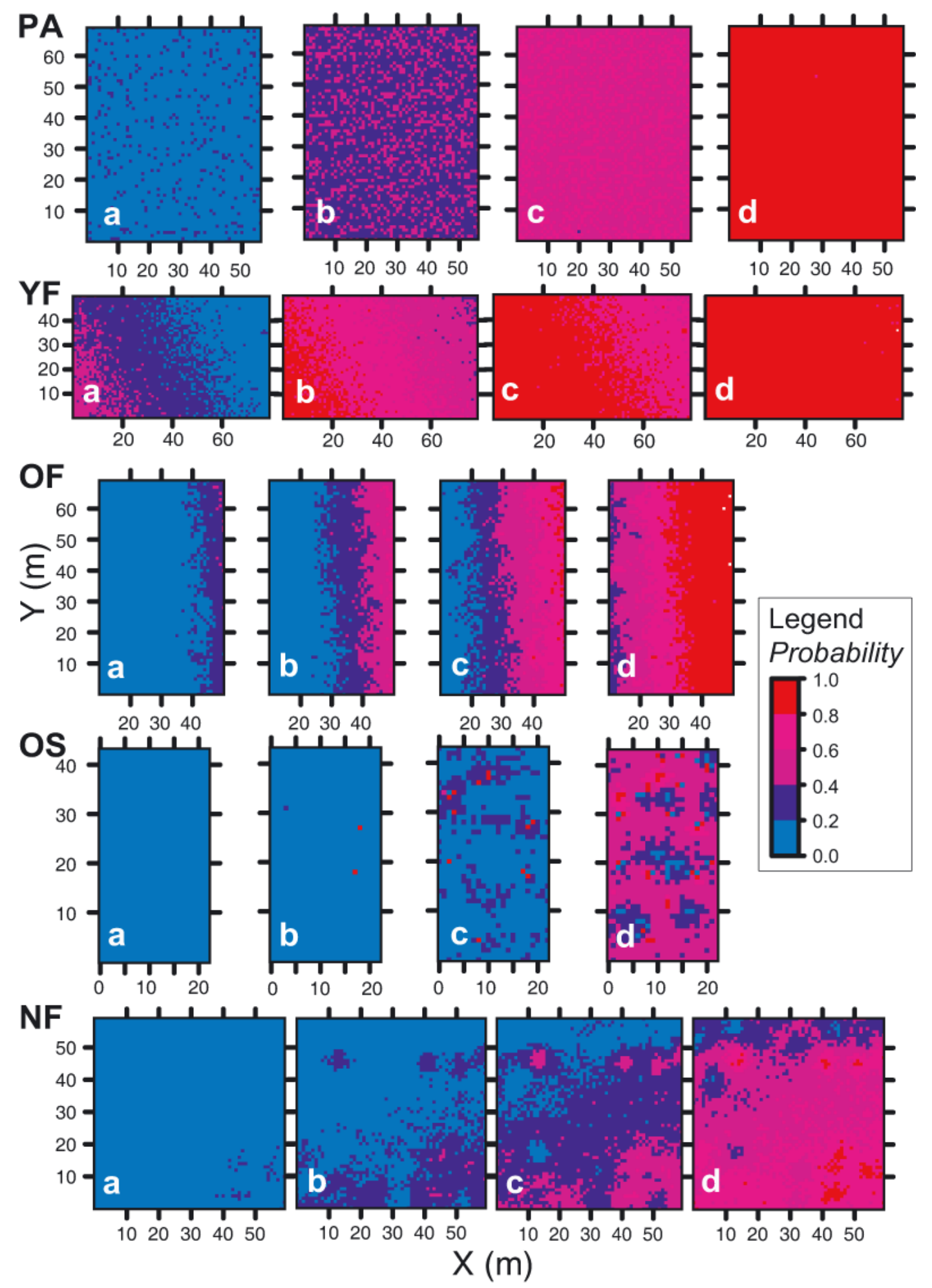

Figure 4-2. Probability maps displaying the probability that a) median, b) the upper quartile, c) the $95 \%$ percentile, d) the maximum of the maximum 30-minute rain intensities exceeds the soil permeability at $12.5 \mathrm{~cm}$ soil depth. Land-cover types are pasture (PA), young fallow (YF), old fallow (OF), old landslide (OS), and the natural forest (NF). 
Soil depth: $20 \mathrm{~cm}$

In the pasture soil, the potential for saturation excess overland flow exists during the more intensive half of the rain events. The overland flow potential is even higher for the young fallow (Figure 4-3).

Under the ridge areas of the old fallow local impermeable layers likely occur, but only the most intense storms potentially cause extensive saturation excess overland flow (Figure 4-3). For about two third of all rain events free percolation persists with some very small-scale ponding under the old landslide and natural forest. Only maximum events (less than $5 \%$ ) are associated with extensive impeding layers also at these cover types (Figure 4-3).

Soil depth: $50 \mathrm{~cm}$

The high Ks at $50 \mathrm{~cm}$ soil depth of pasture involves only small-scale local impermeable clusters during at least $95 \%$ of the annual rain events. In contrast, restricted percolation characterizes the young fallow's subsoil for the majority of storms (Figure 4-4).

Under the old fallow, impeding layers develop under the upper part of the plot at this soil depth, which become extensive for at least one third of the rain events (Figure 4-4). Permeable subsoil characterizes the old landslide where hampered percolation occurs during less than one third of the storms. A somewhat higher potential for impeding layers is associated with the natural forest subsoil (Figure 4-4). 

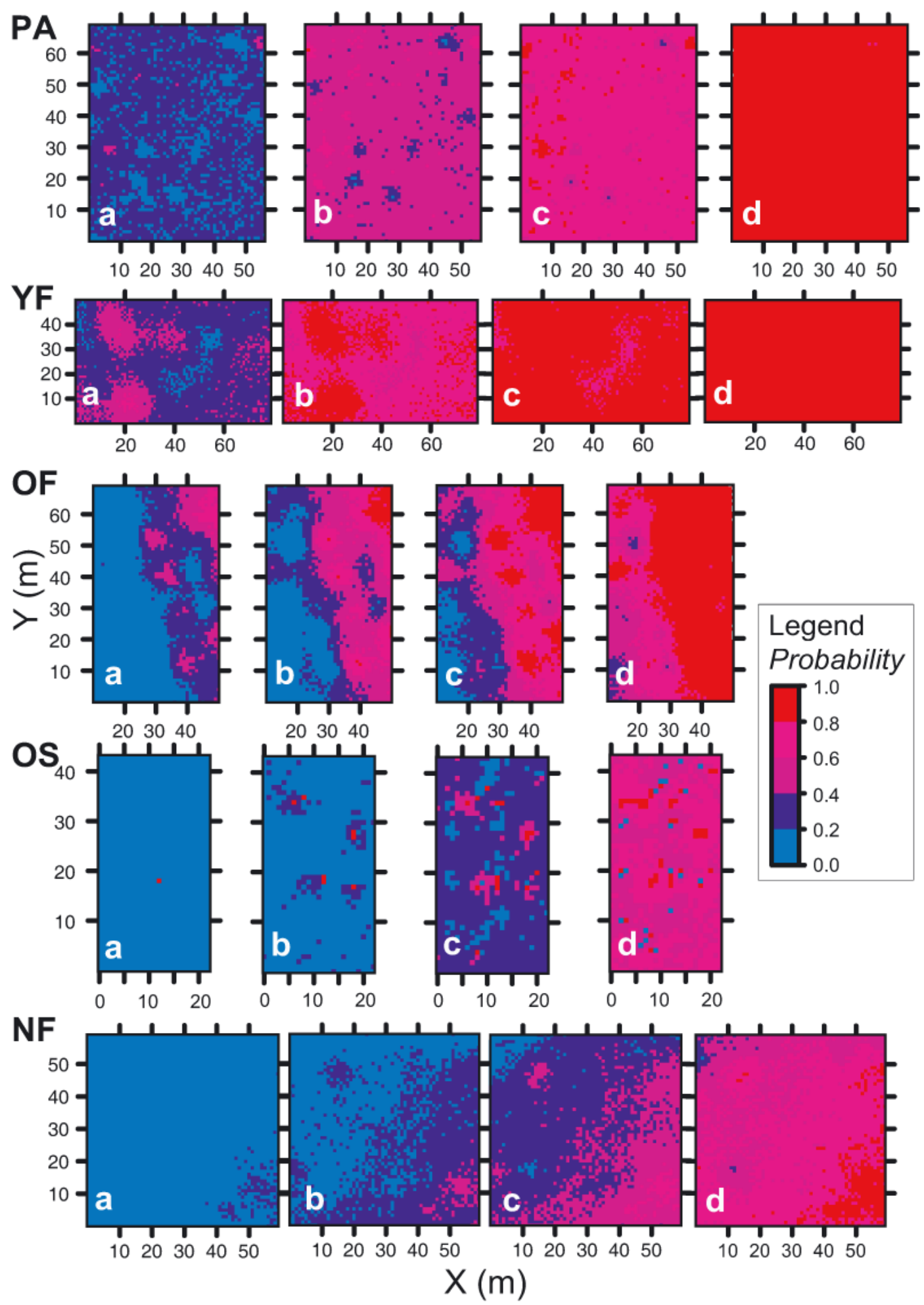

Figure 4-3. Probability maps displaying the probability that a) median, b) the upper quartile, c) the $95 \%$ percentile, d) the maximum of the maximum 30-minute rain intensities exceeds the soil permeability at $20 \mathrm{~cm}$ soil depth. Land-cover types are pasture (PA), young fallow (YF), old fallow (OF), old landslide (OS), and the natural forest (NF). 

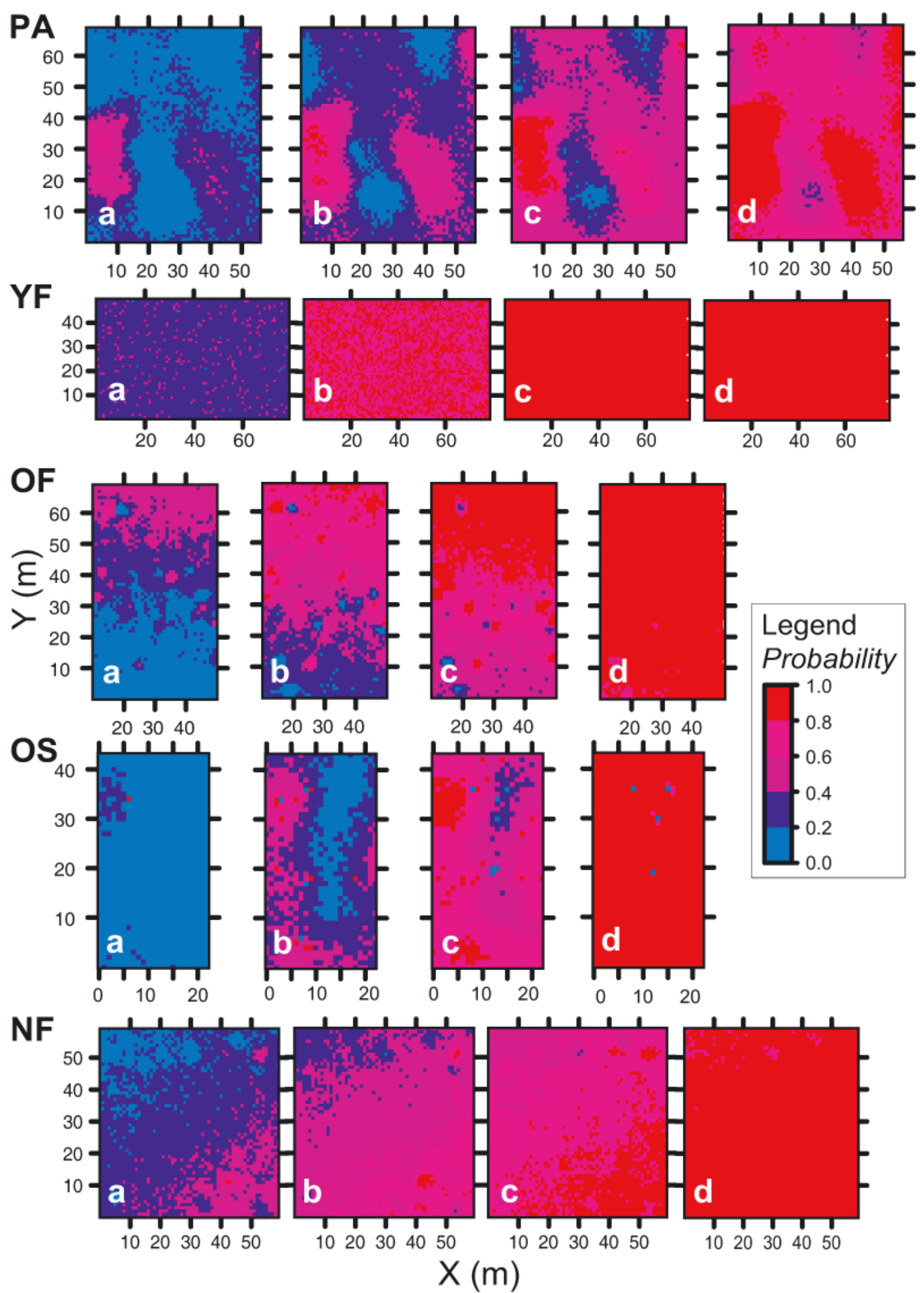

Figure 4-4. Probability maps displaying the probability that a) median, b) the upper quartile, c) the $95 \%$ percentile, d) the maximum of the maximum 30-minute rain intensities exceeds the soil permeability at $50 \mathrm{~cm}$ soil depth. Land-cover types are pasture (PA), young fallow (YF), old fallow (OF), old landslide (OS), and the natural forest (NF). 


\subsubsection{Frequency of near-surface lateral flowpaths}

For more than two third of all rain events, vertical flowpaths persist throughout the investigated depth range under pasture (Figure 4-5), and impeding layer formation is restricted to intense storms. Under the young fallow, those layers likely develop for one third and nearly half of all storms at 12.5 and $20 \mathrm{~cm}$ soil depth, respectively. Hence, lateral flowpaths are frequent under this plot (Figure 4-5).

The land-cover types old fallow, old landslide, and natural forest are clearly characterized by vertical flowpaths in the topsoil, which are forced to lateral directions below $20 \mathrm{~cm}$ soil depth for less than one third of rain events. Only maximum storms involve near-surface lateral flowpaths, with a somewhat higher frequency under the old fallow (Figure 4-5).

In the topsoil, the pine plantation and the forest are characterized by exclusive vertical flowpaths (Figure 4-6). At the $20 \mathrm{~cm}$ soil depth, only the greatest storm is associated with the potential of local impeding layers, which become extensive in the subsoil during this event. With this exception, the boxplots suggest rather local impermeable layers in the forest subsoil for all events, whereas under the pine plantation a greater number of high-intensity events involve area-wide restricted percolation at $50 \mathrm{~cm}$ depth. In summary, flowpaths characteristics of those land-cover types resembles that of the natural forest on the opposite valley side except for the latter's higher propensity to impermeable layers in the subsoil, which is due to its comparatively low Ks.

Near-surface flowpaths of the young landslide hardly differ from the natural forest except for a somewhat higher potential for impeding layers under the slide (Figure 4-6). At the $20 \mathrm{~cm}$ depth, flowpaths are undistinguishable among the two slides and the natural forest. In the subsoil, runoff behavior of the slides is similar, whereas the forest is more susceptible to the development of impermeable layers. 


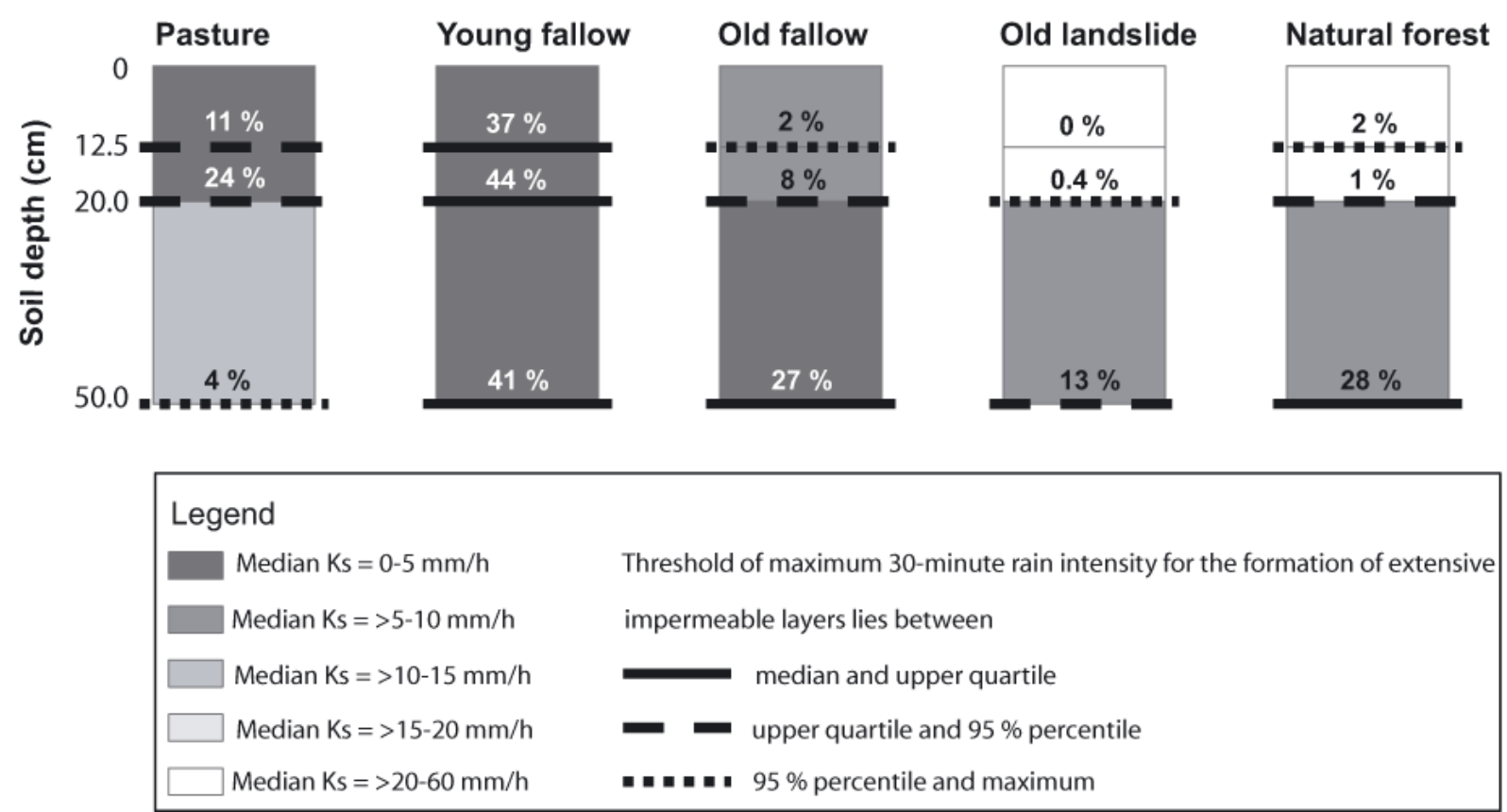

Figure 4-5. Thresholds of maximum 30-minute rain intensities for the extensive formation of impermeable layers. Percentage values within the idealized soil columns refer to the frequency of rain events that exhibit those critical intensities. 

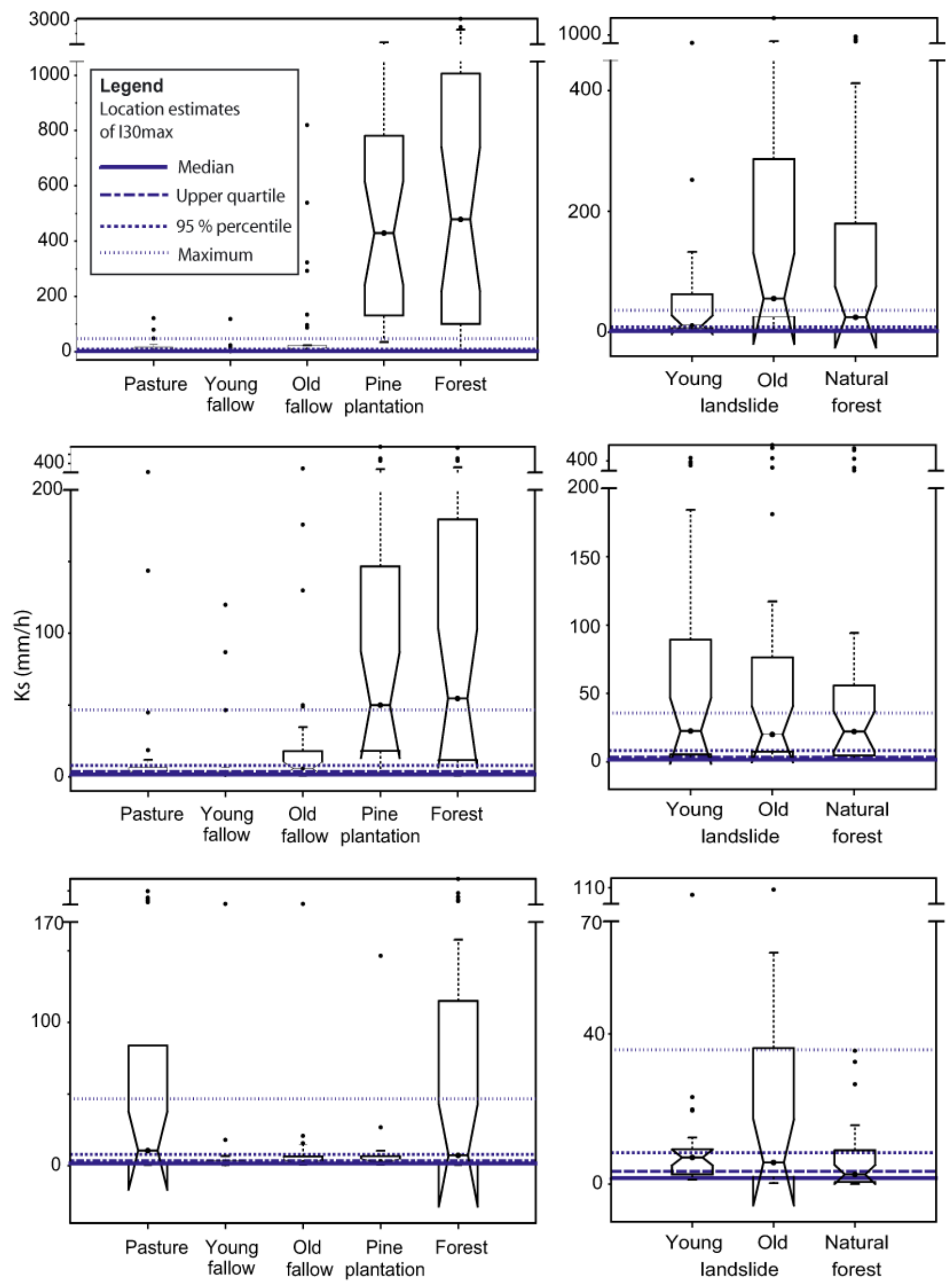

Cover type

Figure 4-6. Box plots of Ks for the human (left) and natural (right) disturbance sequence at soil depths of 12.5 $\mathrm{cm}$ (top), $20 \mathrm{~cm}$ (middle), and $50 \mathrm{~cm}$ (bottom). 


\subsubsection{Rainfall amount in lateral flowpaths}

Pronounced differences exist in the partitioning of runoff in vertical and lateral flowpaths among the cover types of the human disturbance sequence. Under pasture and the young fallow, a portion of the infiltrating rain is forced to lateral directions already in the topsoil (Figure 4-7). Therefore, a smaller amount of the percolating water reaches soil depths below $20 \mathrm{~cm}$ under pasture and the young fallow compared to the natural forest. We tentatively estimate the increase of the rain amount in near-surface lateral runoff to be twofold for pasture and sixfold for the young fallow, respectively, related to the original state. Since both disturbed land-cover types are further characterized by a weak or absent spatial structure of Ks in the topsoil, connected patches of high conductivity, which may serve as preferential pathways, are missing (Figure 4-2, Figure 4-3); hence, there is an increased likelihood of extensive impermeable layers. Though flowpaths under the old fallow resemble undisturbed conditions for the majority of rain events (Figure 4-5), a disturbance effect is still detectable as some of the rainwater cannot percolate deeper than $20 \mathrm{~cm}$ soil depth (Figure 4-7); we estimate the increase of near-surface lateral runoff to be about 1.3-fold when compared with undisturbed conditions.

The natural forest and the landslide at the opposite valley site are characterized by clearly vertical flowpaths in the topsoil. Below $20 \mathrm{~cm}$ depth, a part of the percolating water is forced to lateral directions (Figure 4-7).

In summary, the total rain amount which runs off in near-surface lateral flowpaths increased considerable under disturbed cover types though the majority of events do not reach the necessary critical intensities. In contrast, the near-surface vertical flowpaths of the forest are maintained after landslide disturbance. 


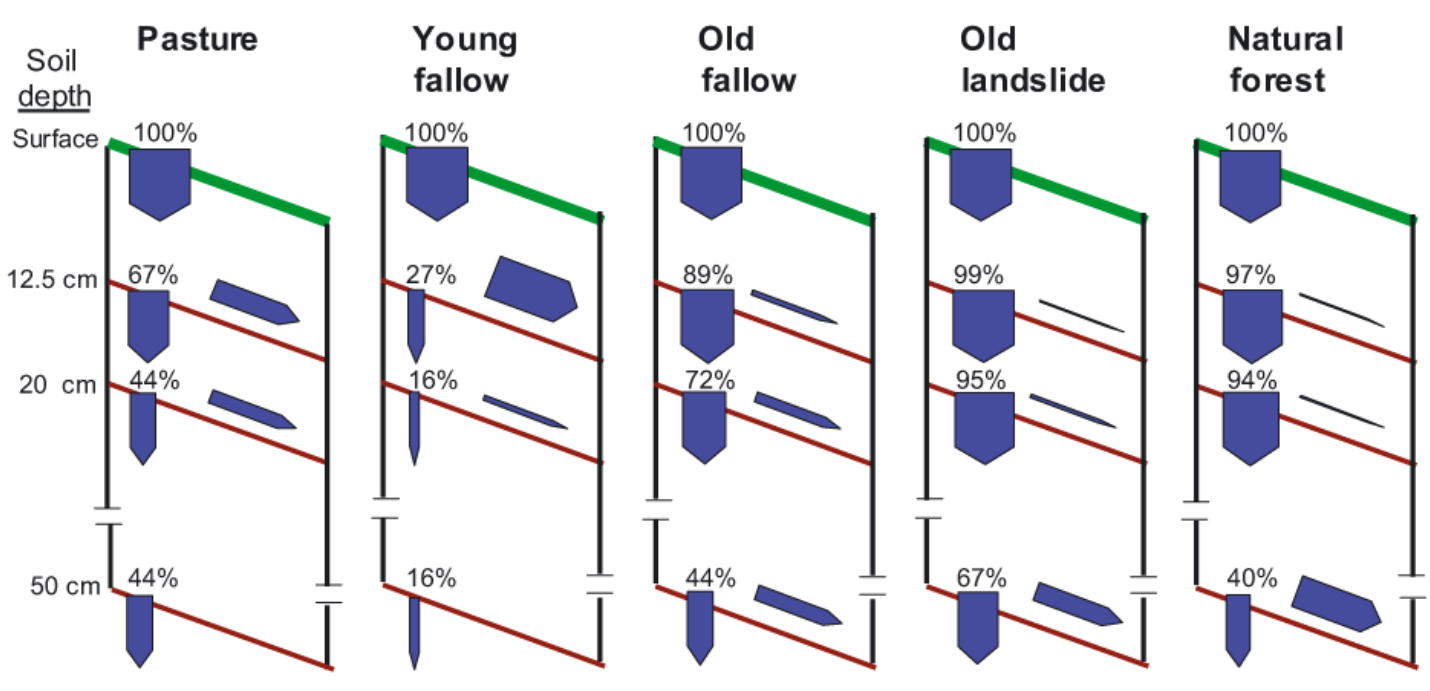

Figure 4-7. Predicted partitioning of rainwater in vertical and lateral flowpaths. Percentages refer to the portion of infiltrating rainwater that percolates further downwards minus the runoff in lateral flowpaths. This portion is likely to be a biased estimate due to unknown and possibly land-use dependent antecedent soil moisture stage, e.g. in the case of saturation excess overland flow the vertical component decreases.

\subsubsection{Comparison with a lowland tropical rainforest}

In agreement with the already mentioned higher rainfall intensities in Brazil, the median of the 10-minute rainfall intensities is similar for both sites, whereas the upper tail of the rain intensity distribution shows considerable greater values in Brazil (Table 4-2). In Ecuador, considerable more than half of all 10-minute rainfall has an intensity of maximal $1.2 \mathrm{~mm} / \mathrm{h}$, greater intensities have a much lower frequency of occurrence (Figure 4-8). The greatest portion of the total rain amount $(\sim 60 \%)$, however, is associated with rain intensities that exceed the upper quartile amounting to $1.8 \mathrm{~mm} / \mathrm{h}$ (Figure 4-8). Precipitation at the Brazilian site is characterized by a similar high frequency of low-intensity 10-minute rainfall as well as the correlation of high rain amount with high intensities (Figure 4-8).

Table 4-2. Rainfall characteristics of the montane and the lowland rair

\begin{tabular}{|c|c|c|c|c|}
\hline \multirow[b]{2}{*}{ Study site } & \multicolumn{4}{|c|}{ Location estimates of 10 -minute rain intensities $(\mathrm{mm} / \mathrm{h})$} \\
\hline & Median & 3rd quartile & Upper 20ths & Maximum \\
\hline & 1.2 & 1.8 & 6.0 & 64.2 \\
\hline Brazil & 1.5 & 6.1 & 32.0 & 114.3 \\
\hline
\end{tabular}




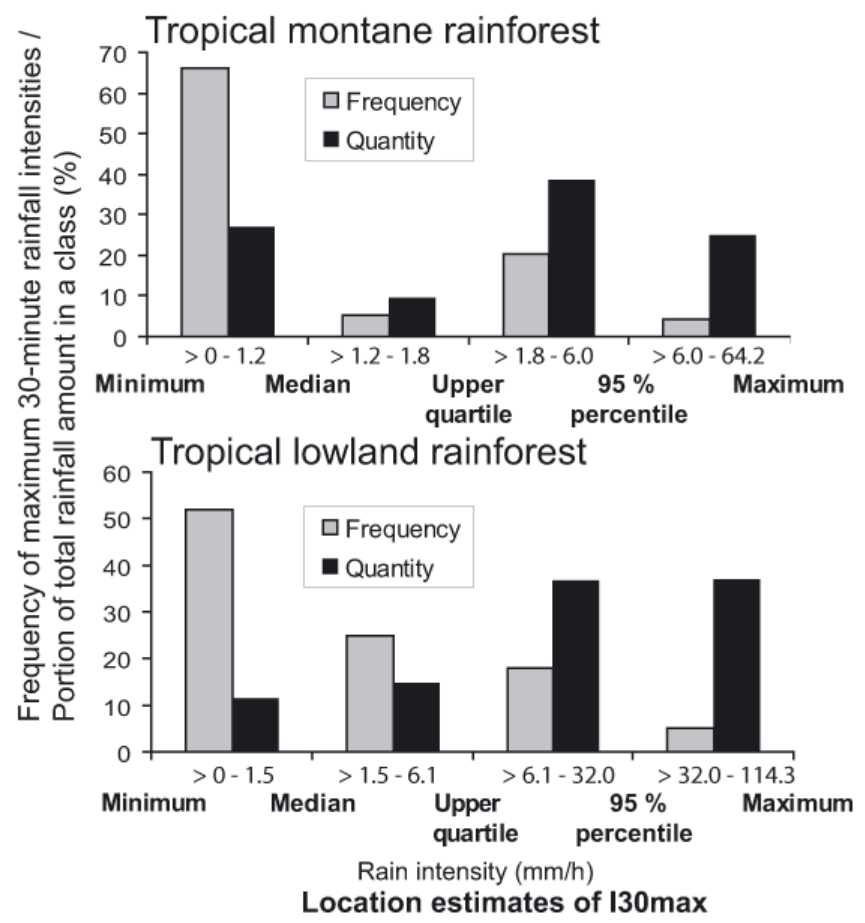

Figure 4-8. Frequency and quantity of the maximum 30-minute rain intensities in classes with intervals corresponding to location estimates of those intensities for the tropical montane and the lowland tropical rainforest.

At the $12.5 \mathrm{~cm}$ soil depth, the consequences for runoff generation under pasture are similar between the two ecosystems, i.e. the median of Ks exceeds the upper quartile of the rain intensities, but is smaller than the $95 \%$ percentile (Figure 4-9). This similarity also characterizes the other land-cover types: the threshold where the rain intensities exceed Ks is between their $95 \%$ percentile and the maximum for teak and the old fallow. Due to the marginally greater portion of the total rain amount in the higher intensity classes at the Brazilian study site (Figure 4-8), the expected lateral flowpaths may be somewhat more important for the water cycle in this lowland region. Permeability of the forests including secondary forest and the pine plantation is greater than maximum rain intensities for both sites (Figure 4-9). Hence, the consequences of land-cover change on hydrological flowpaths are comparable for the studied lowland and montane rainforest: impermeable layers have the highest probability of occurrence under pasture and a lower one under the land-cover types where pasture use stopped a decade ago, whereas all older forest types are invariably characterized by vertical flowpaths.

At the $20 \mathrm{~cm}$ depth, pasture permeability is exceeded by more than one fifth of the rain intensities for both sites (Figure 4-9). Teak has a somewhat greater propensity for impeding layers than the old fallow (Figure 4-9). Soil permeability under the Brazilian forests is exceeded by about $5 \%$ of the rain intensities, whereas in Ecuador only the maximum intensity clearly exceeds Ks of the pine plantation and the forest (Figure 4-9); hence, impermeable layers develop more frequently in Brazilian forests. In summary, runoff behaviour under pasture is similar between both sites, whereas the regenerating and 
undisturbed land-cover types in Brazil exhibit less permeable soils at $20 \mathrm{~cm}$ depth, partially due to an increase of clay content with increasing depth (Zimmermann et al., 2006), which does not exist at the Ecuadorian site.

Apart from the soil-dependent difference at $20 \mathrm{~cm}$ depth, the observed similarity in spite of differing magnitudes of the rain intensities can be explained by the more pronounced drop of Ks under the Ecuadorian pasture ( 2 orders of magnitude compared to forest, in contrast to a difference of "only" one order of magnitude between Brazilian pasture and forest).

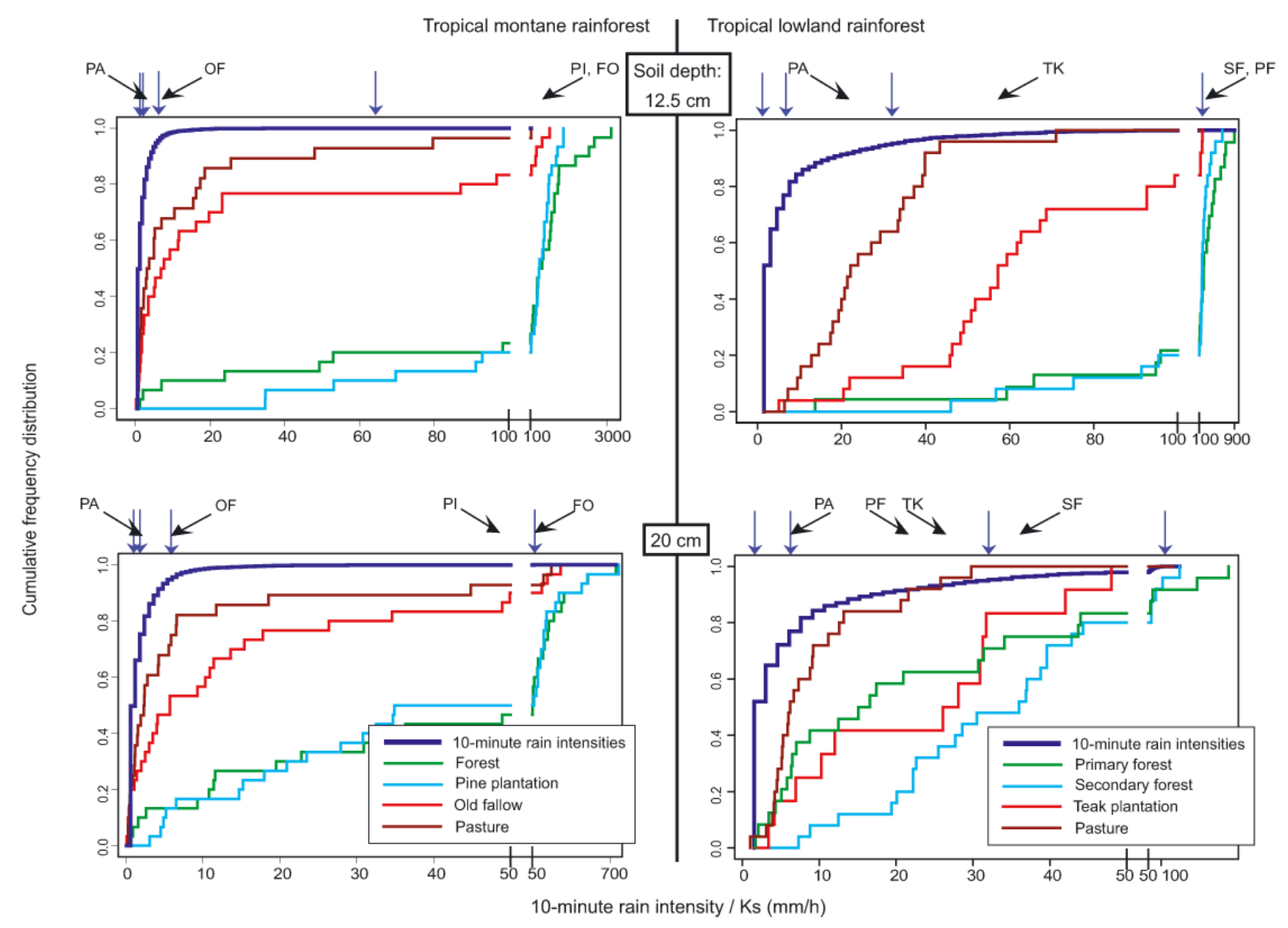

Figure 4-9. Cumulative frequency distribution of Ks for land-cover types of the compared tropical ecosystems. The blue arrows indicate the position of location estimates of the respective 10-minute rain intensities (from left to right): median, upper quartile, $95 \%$ percentile, maximum. The black arrows indicate the position of median values of the Ecuadorian cover types of pasture (PA), old fallow (OF), pine plantation (PI), and forest (FO); and of the Brazilian cover types of pasture (PA), teak plantation (TK), secondary forest (SF), and primary forest (PF).

\subsection{Discussion}

\subsubsection{Significance of the plot study at the catchment level}


Because of the limited spatial scale of our study, and an assumed topography dependence of Ks (Huwe et al., 2008), we checked the significance of our results regarding the average slope, which was between 30 and $40^{\circ}$ at our plots (Zimmermann and Elsenbeer, submitted). For this purpose, we extracted slope information for the entire study area from a digital elevation model (P. Vorpahl, unpublished), which was generated from contour lines by locally adaptive gridding (Wilson and Gallant, 2000). It turned out that the derived average slope of the DEM of $36^{\circ}$ (standard deviation $=0.1$ ) coincides very well the average slope of our plots; hence, the results of this study should represent vast parts of our study area.

\subsubsection{Flowpaths in the South Ecuadorian montane rainforest}

For a research catchment, which includes our natural forest plot, Fleischbein et al. (2006) assumed in a modeling study that a large difference between high Ks in the litter layer and lower Ks in the mineral soil may result in water ponding on top of the mineral soil and subsequent lateral flow in the organic layer or in the near-surface mineral soil. This assumption of organic layer flow was originally made by Goller et al. (2005), who also worked in this catchment. They postulated a switch to rapid water flow in the highly permeable organic layer parallel to the mineral soil surface during storm events. Their study is based on one intense rain storm using the ratio of oxygen isotopes ${ }^{18} \mathrm{O} /{ }^{16} \mathrm{O}$ as a tracer. The selected storm was characterized by high throughfall intensities, which were measured hourly and showed two maxima of 6.5 and $7.8 \mathrm{~mm} / \mathrm{h}$. Hence, this event ranks among the most intense rain events of our study area. Since soil moisture status was very high before and during the event studied by Goller et al. (2005), saturation excess overland flow might have caused the assumed flow on top of or in the near-surface mineral soil. During the majority of events, however, the prevailing vertical flowpaths likely persist to the subsoil below $20 \mathrm{~cm}$ soil depth. Nevertheless, the substantial portion of the annual rainfall associated with the rare high-intensity events emphasizes their importance regarding the water budget of this rainforest.

\subsubsection{Influence of landslides on hydrological flowpaths}

The similarity of flowpaths under the landslides and the natural forest indicate the low impact of regional landslide activity on runoff generation compared to that of land-use change. 
Nevertheless, fresh landslides may serve as local sediment sources in the study region, but this has yet to be quantified. This effect, however, subsides after a short recovery time, as shown by Larsen et al. (1999). They reported slopewash rates of recent landslide scars that decreased substantially during a study period of four years to values less than that measured on forested hillslopes. They attributed this decrease of sediment amount to extensive mats of algae and mosses on the scar surfaces. This mechanism may also be important for our study area where the abundance of mosses and lichens on young landslides potentially has the same effect (Ohl and Bussmann, 2004).

Hydrological triggering of landslides is related to positive pore-water pressures due to significant vertical changes in hydraulic conductivity (e.g. Terlien, 1997). Our results on flowpaths in the natural forest suggests that high-intensity storms in our study area emphasize the formation of an impermeable soil layer already below the $20 \mathrm{~cm}$ soil depth in forest and landslide soils, which may result in perched water tables significant for landslide initiation. This is especially true for high-intensity storms following wet antecedent conditions (Sidle and Swanston, 1982).

\subsubsection{Influence of land-cover change on hydrological flowpaths}

In addition to the direct comparison between Ecuador and Brazil, other studies also indicate the influence of land-cover change on runoff generation processes in the tropics. Larger volumes of overland flow were produced under pasture compared to forest in eastern Amazonia (Moraes et al., 2006) and in tropical karst terrain (Chandler, 2006). An intermittently grazed, grass-covered hillslope in Honduras experienced overland flow, which was not observed in adjacent coffee plantations and primary forest in Honduras (Hanson et al., 2004). In the sub-humid part of Benin, higher surface runoff occurred on plots used for agriculture (maize, cotton, beans) compared to natural vegetation or fallow (Giertz and Diekkrueger, 2003). Landscape fragmentation in mountainous Vietnam induced a higher propensity for overland flow on disturbed cover types, which reduces during regeneration towards secondary forests (Ziegler et al., 2004). Hence there is convincing evidence that in the humid tropics forest conversion for agricultural use, including pastures is associated with a shift to lateral flowpaths that is reverted to pre-disturbance conditions within a time frame of decades after site abandonment. Moreover, the land-use signal seems to override differences in soil types and ecosystems in the near-surface soil. 


\subsection{Conclusions}

1) Runoff generation under natural forest is characterized by near-surface vertical flowpaths during the majority of rain events, which switch to lateral directions for a number of more intense storms in the subsoil. Under moist antecedent conditions, perched water tables are likely to develop for those storms, which may result in saturation excess overland flow on top of the mineral soil and positive pore-water pressures.

2) The prevailing vertical flowpaths are maintained after landslide disturbance; only the young landslide has a slightly higher potential for near-surface lateral flowpaths.

3) Human disturbances involve consequences for runoff generation as part of the rainwater cannot percolate below $20 \mathrm{~cm}$ soil depth under pasture and recently abandoned pasture, though this happens for the minority of rain storms only due to the dominance of low-intensity events. A ten year-old fallow shows regeneration towards the original vertical flowpaths, but percolation is still impeded for a small portion of the annual rain at $20 \mathrm{~cm}$ soil depth. Under the assumption of negligible differences in soil moisture stage among the disturbed land-cover types and the forest, we estimate the increase of runoff in near-surface lateral flowpaths to be twofold for pasture, sixfold for the young fallow, and 1.3-fold for the old fallow compared with the reference state.

4) The implications of land-cover change on near-surface hydrological flowpaths in the studied tropical montane rainforest are comparable to a tropical lowland ecosystem. This can be explained by a more pronounced drop of permeability after pasture establishment in the montane rainforest region in spite of the prevailing much lower rain intensities.

Since our results are restricted to the flowpaths perspective it remains to be seen how the indicated differences following land-cover change affect the regional water cycle, which could be investigated by a paired catchment approach. 


\section{$\underline{5 .}$}

\section{Summary of the research results and implications for future work}

As land-cover change continues to expand into ever more remote areas due to growing populations and decreasing reserves of productive land, the associated changes in the regional water cycles modify ecosystem services such as water supply and water quality. The costvalue ratio of this conversion from natural vegetation to any land use category is largely unknown. To gain insight into this process, a first step is to quantify the response of the ecosystem to the respective change. Regarding the hydrological cycle, vegetation cover and the underlying soils are the most influential factors controlling large parts of it. Hence, their functioning has to be understood when addressing the effects of land-cover change on the regional watersheds.

With my thesis I hope to provide a basis for future work regarding the role of the soil. In face of the limitations of the study (see below), this is only a small piece of the puzzle, which has to be combined with others to reveal a picture.

\subsection{Summary of the research results}

\subsubsection{Spatial analysis of soil hydraulic data}

As the first step in the course of the analysis, we inspected both univariate and bivariate data distributions, and produced diagnostic plots to detect non-stationarity of the mean. The indicated trends turned out to be significant at each of the three investigated soil depth, which were most pronounced in the topsoil. We showed that not taking them into account would distort spatial prediction results considerably.

After log-transformation, the uni- and bivariate distributions did not indicate the presence of extreme values, although some skewness remained at the $50 \mathrm{~cm}$ soil depth. In order to decide on robust estimation requirements, we used a statistics $\theta$ as proposed by Lark (2000a). It turned out that robust estimation techniques were not needed; furthermore, their arbitrary use has the potential to modify prediction results. 
The de-trended data did not exhibit anisotropic variations. Anisotropic variograms of the trend-containing data illustrated the greater correlation length and sill variance associated with the direction of the non-stationary mean.

The next step was the spatial data modeling by various techniques, which were mainly subdivided into least-squares approaches using the residuals of the trend and maximum likelihood estimation of fixed and random effects. This comparison revealed that the estimated covariance parameters depend on the estimation method and on the experimental variograms used for the least - squares based model development, respectively.

We also tested several theoretical models, such as the Matérn correlation function. We found rather small differences between this function and 'standard' models. Due to flat likelihood functions when incorporating the additional smoothness parameter of the Matérn function, it was not always possible to estimate its parameters, but in one case this model was associated with a higher likelihood.

Another aspect we considered was the nugget variance. In some cases, the variogram modeling resulted in an estimate, which appeared to be too small. Therefore we also produced models where we fixed the nugget variance to the first separation distance. This approach had the potential to modify all parameters of the covariance function and may therefore have an impact on spatial prediction. Conflicting arguments did not allow any concluding statements. In the framework of spatial prediction we showed that in our case the model differences did not influence average values, e.g. the average probability that rainfall intensities exceed the soil permeability. The spatial arrangement, particularly the connectivity of zones with high or low Ks, however, depended on the used model, and local deviations in kriging maps could be considerable.

The literature review on the spatial variability of Ks revealed the impossibility of any general conclusions; i.e. there was no relationship between the spatial structure of the saturated hydraulic conductivity and attributes as e.g. soil type, land use, and measurement techniques. The review and our results indicated, however, a possible dependence of the spatial structure on soil conditions as a result of disturbances.

On the basis of our results, we were able to give some general recommendations. First, the discussion of a plausible estimate of the nugget variance emphasized the advantage of a sampling design which allows for calculating the semivariance at short lags. Second, under bivariate normal conditions we encouraged estimation by restricted maximum likelihood, mainly because it does not require the arbitrary selection of lag classes. When robust estimation is needed, the variogram model should only be fitted over half the separation 
distance to avoid edge effects. Third, in the framework of REML estimation we proposed to use the Matérn correlation function when possible and to compare it to some standard models by means of the maximized likelihoods.

\subsubsection{Spatial and temporal variability of the saturated hydraulic conductivity}

With respect to the temporal variability of Ks in land use gradients, our main conclusion was that the natural and the human disturbance sequence differ in their soil hydraulic response. Soil permeability of the landslide soils did not differ significantly relating to regeneration time and in comparison to the natural forest at any investigated soil depth. We therefore suggested that the regional landslide activity impacts on the soil hydrology to a marginal extend only. This was in contrast to the results from the human disturbance cycle, where forest conversion to pasture caused an enormous drop of Ks of two orders of magnitude at shallow soil depths, and a slow regeneration after pasture abandonment. We estimated the recovery time of soil permeability to be at least one decade.

In the topsoil, the Ks spatial structure seemed to be affected by disturbances, which is why we found the strongest spatial dependence under forest and on an old fallow. The largest differences in spatial patterns, however, were related to the subsoil permeability, which could not be explained by disturbance. In addition to these site-specific effects, the overall short correlation lengths challenge the usefulness of geostatistical methods for upscaling purposes in the study area.

\subsubsection{Hydrological flowpaths in the studied tropical montane rainforest ecosystem}

Combining the spatial-temporal Ks-pattern with local rainfall intensities suggested that the undisturbed montane rainforest is characterized by prevailing vertical flowpaths in the topsoil, which can switch to lateral directions below $20 \mathrm{~cm}$ depth. Though this lateral flow component likely develops for a rather small number of the prevailing low-intensity rain events, the thereby transported portion of the annual rain amount might be considerable. Hydrological flowpaths in the landslide soils appeared to be comparable to the forest due to the observed similarity of Ks. In consequence of the reduced permeability under the disturbed land-cover types of the human disturbance sequence, we predicted pronounced differences in runoff 
behavior among them, e.g. a high probability of impeding layer formation for one fourth and half of the rain storms under pasture and an abandoned pasture, respectively. We estimated the associated increase of the total rain amount in near-surface lateral flowpaths to be twofold and sixfold for those cover types, respectively, compared to the reference forest. Although Ks under an older fallow showed regeneration towards the original vertical flowpaths, we still predicted an increased portion of near-surface lateral runoff.

\subsection{Implications for future research}

The study, upon which my thesis is based, had two main limitations: the plot scale and the limitation to one single parameter of such a complex interactive system as is a soil. Hence, the transferability of the results to larger scales, as well as a distortion of some findings due to other influencing factors remains unknown. Nevertheless, this study serves as a first evidence of disturbance impacts on soil functioning in the tropical montane rainforest ecosystem. In the framework of (soil-) hydrological investigations, I see the following research needs at our study site:

1) The impact of the landslides and human disturbances on the soil moisture regime. Due to the absence of the protective forest cover, the near-surface soil likely desiccates to a stronger extend under landslides, pastures, and (young) fallows; this might be balanced by the greater water consumption of forests. If pre-event soil water conditions differ considerably among the stages of disturbance and recovery, the saturated hydraulic conductivity does not suffice to infer the portion of percolating water that runs off in near-surface hydrological flowpaths. 2) There has been much discussion on a possible difference in the soils between the southand the north-facing side of the Rio San Francisco. Some can be explained by the human impact at the south-facing valley side, most obviously the loss of the thick organic layer typically for the montane rainforest. Others are more difficult to explain, e.g. we observed a comparatively tremendous A-horizon in soil profiles at the young fallow, the pine plantation and in the forest of the south-facing valley side, but not in the natural forest. Possible environmental controls for the contrasting valley sides are the higher frequency of fires, the different exposure, and rarer landslides at the human-influenced site. Knowledge of the actual factors would help explain the considerable difference of soil permeability between our reference forests.

3) In order to fully quantify the effect of disturbances on the water cycle at a regional scale, physically-based distributed hydrological models should be used because they are capable of 
taking into account spatial variations in topography, soils, vegetation and climate. Their main drawback is the huge amount of required input data, which vary in several dimensions. The example of saturated hydraulic conductivity shows what this means practically: its incorporation into any hydrological model requires a database that captures its spatialtemporal variation, i.e. mirrors the differences in Ks distributions, e.g. among land uses, between topsoil and subsoil, and - at a respective scale - between the valley sites. Hence, the first step would be to identify an appropriate upscaling technique. Our results and investigations at the small catchment scale (Huwe et al., 2008) imply the infeasibility of geostatistics for this purpose. Indirect estimation by pedotransfer functions might be an alternative, but the two already tested functions highly underestimated the saturated hydraulic conductivity (Marquardt, 2005). Another possibility for a rather coarse-level prediction of Ks is the use of functional soil morphological descriptors, namely field texture, grade of structure, areal porosity, bulk density, dispersion index, and horizon type (McKenzie and Jacquier, 1997). Regarding this approach, I applied the water replacement method to estimate bulk density, which worked very well, and tried to evaluate areal porosity, which seems to be generally low at the study site. I think it is worth to test on this further, especially when moving to large scales. 


\section{$\underline{6 .}$}

\section{References}

Ahuja, L.R., Naney, J.W., Gree, R.E. \& Nielsen, D.R., 1984. Macroporosity to characterize spatial variability of hydraulic conductivity and effects of land management. Soil Science Society of America Journal, 48, 699-702.

Alegre, J.C. \& Cassel, D.K., 1996. Dynamics of soil physical properties under alternative systems to slash-and-burn. Agriculture, Ecosystems \& Environment, 58, 39-48.

Alakukku, L., 1998. Properties of compacted fine-textured soils as affected by crop rotation and reduced tillage. Soil \& Tillage Research, 47, 83-89.

Amoozegar, A., 1989a. A compact, constant-head permeameter for measuring saturated hydraulic conductivity of the vadose zone. Soil Science Society of America Journal, 53, 1356-1361.

Amoozegar, A., 1989b. Comparison of the Glover solution with the simultaneous equations approach for measuring hydraulic conductivity. Soil Science Society of America Journal, 53, 1362-1367.

Amoozegar, A., 1993. Comments on "Methods for analyzing constant-head well permeameter data", Soil Science Society of America Journal, 57, 559-560.

Barnes, R.J., 1991. The variogram sill and the sample variance. Mathematical Geology, 23, 673678.

Bautista-Cruz, A. \& Del Castillo, R.F., 2005. Soil changes during secondary succession in a tropical montane cloud forest area. Soil Science Society of America Journal, 69, 906914.

Bell, T.I.W., 1973. Erosion in the Trinidad teak plantations. Commonwealth Forestry Review, 52, 223-233.

Biggs, T.W., Dunne, T. \& Muraoka, T., 2006. Transport of water, solutes and nutrients from a pasture hillslope, southwestern Brazilian Amazon. Hydrological Processes, 20, $2527-$ 2547.

Bjørnstad, O.M. \& Falck, M., 2001. Nonparametric spatial covariance functions: estimation and testing. Environmental and Ecological Statistics, 8, 53-70.

Bloeschl, G., 1999. Scaling issues in snow hydrology. Hydrological Processes, 13, 2149 2175. 
Bonell, M. \& Gilmour, D.A., 1978. The development of overland flow in a tropical rainforest catchment. Journal of Hydrology, 39, 365-382.

Bosch, D. D. \& West, L.T., 1998. Hydraulic conductivity variability for two sandy soils. Soil Science Society of America Journal, 62, 90-98.

Box, G. E. P. \& Cox, D.R., 1964. An analysis of transformations. Journal of the Royal Statistical Society, Series B, 26, 211-246.

Brenning, A., 2005. Spatial prediction models for landslide hazards: review, comparison and evaluation. Natural Hazards and Earth System Sciences, 5, 853-862.

Brooks, S.M. \& Spencer, T., 1997. Changing soil hydrology due to rain forest logging: an example from Sabah Malaysia. Journal of Environmental Management, 49, 297-310.

Bruijnzeel, L.A. \& Hamilton, L.S., 2000. Up in the clouds. Decision Time for Cloud Forests. IHP Humid Tropics Programme Series, vol. 13. IHP-UNESCO, Paris.

Bruijnzeel, L.A., 2001. Hydrology of tropical montane cloud forests: A Reassessment. Land Use and Water Resources Research, 1, 1.1-1.18.

Buttle, J. M. \& House, D.A., 1997. Spatial variability of saturated hydraulic conductivity in shallow macroporous soils in a forested basin. Journal of Hydrology, 203, 127-142.

Cambardella, C.A., Moorman, T.B., Novak, J.M., Parkin, T.B., Karlen, D.L., Turco, R.F. \& Konopka, A.E., 1994. Field-scale variability of soil properties in central Iowa soils, Soil Science Society of America Journal, 58, 1501-1511.

Carman, P.C., 1956. Flow of Gases Through Porous Media. Academic Press, New York.

Chandler, D.G., 2006. Reversibility of forest conversion impacts on water budgets in tropical karst terrain. Forest Ecology and Management, 224, 95-103.

Chilés, J.-P. \& Delfiner, P., 1999. Conditioning by kriging. In: Geostatistics: Modeling Spatial Uncertainty, edited by V. Barnett et al., pp. 465-472, John Wiley \& Sons, New York.

Cressie, N. \& Hawkins, D., 1980. Robust estimation of the variogram. Mathematical Geology, 12, 115-125.

Cressie, N.A.C., 1993. Statistics for Spatial Data, John Wiley \& Sons, New York.

Dowd, P.A., 1984. The variogram and kriging: robust and resistant estimators. In: Geostatistics for Natural Resources Characterization, edited by G. Verly et al., pp. 91-106, D. Reidel, Dordrecht.

Duffera, M., White, J.G. \& Weisz, R., 2007. Spatial variability of southeastern U.S. coastal plain soil physical properties: implications for site-specific management. Geoderma, 137, 327-339. 
Dunne, T., 1978. Field studies of hillslope flow processes. In: Hillslope Hydrology, edited by M.J. Kirkby, pp. 227-293, J. Wiley, New York.

Elrick, D.E. \& Reynolds, W.D., 1992. Methods for analyzing constant-head well permeameter data, Soil Science Society of America Journal, 56, 320-323.

Elsenbeer, H. \& Vertessy, R.A., 2000. Stormflow generation and flowpath characteristics in an Amazonian rainforest catchment. Hydrological Processes, 14, 2367-2381.

Elsenbeer, H., 2001. Hydrologic flowpaths in tropical rainforest soilscapes-a review. Hydrological Processes, 15, 1751-1759.

Fleischbein, K., Wilcke, W., Valarezo, C., Zech, W. \& Knoblich, K., 2006. Water budgets of three small catchments under montane forest in Ecuador: experimental and modelling approach. Hydrological Processes, 20, 2491-2507.

Fisher, R.A., 1972. Statistical methods for research workers. Oliver \& Boyd, Edinburgh.

Gascuel-Odoux, C. \& Boivin, P., 1994. Variability of variograms and spatial estimates due to soil sampling: a case study. Geoderma, 62, 165-182.

Geiler, H., F. Aschenbrenner, H.S. Dengel, A. Donsbach, R. Ostermann, K. Knoblich \& Maurer, W., 1997. Räumliche Variabilität und Verteilung von Schwermetallen in den Böden einer $1 \mathrm{~km}^{2}$ großen Modellfläche im Siegerland, Zeitschrift für Pflanzenernährung und Bodenkunde, 160, 603-612.

Genton, M.G., 1998. Highly robust variogram estimation. Mathematical. Geology, 30, $213-$ 221.

Germer, S., Elsenbeer, H. \& Moraes, J. M., 2006. Throughfall and temporal trends of rainfall redistribution in an open tropical rainforest, south-western Amazonia (Rondonia, Brazil). Hydrology and Earth System Sciences, 10, 383-393.

Germer, S., Neill, C., Vetter, T., Chaves, J., Krusche, A.V. \& Elsenbeer, H. Implications of long-term land-use change for the hydrology and solute budgets of small catchments in Amazonia, submitted to Journal of Hydrology.

Giertz, S. \& Diekkrueger, B., 2003. Analysis of the hydrological processes in a small headwater catchment in Benin (West Africa). Physics and. Chemistry of the Earth, 28, $33-36$.

Godsey, S. \& Elsenbeer, H., 2002. The soil hydrologic response to forest regrowth: a case study from southwestern Amazonia. Hydrological Processes, 16, 1519-1522.

Goller, R., Wilcke, W., Leng, M.J., Tobschall, H.J., Wagner, K., Valarezo, C. \& Zech, W., 2005. Tracing water paths through small catchments under a tropical montane rain 
forest in south Ecuador by an oxygen isotope approach. Journal of Hydrology, 308, 67-80.

Goovaerts, P., 1997a. Kriging with a trend model. In: Geostatistics for Natural Resources Evaluation, edited by A.G. Journel, pp. 139-152, Oxford University Press, New York. Goovaerts, P., 1997b. Visualization of spatial uncertainty. In: Geostatistics for Natural Resources Evaluation, edited by A.G. Journel, pp. 431-434, Oxford University Press, New York.

Goovaerts, P., 1997c. The practice of modeling. In: Geostatistics for Natural Resources Evaluation, edited by A.G. Journel, pp. 97-107, Oxford University Press, New York.

Görner, A., 2006. Remote sensing monitoring of land cover change in a rainforest environment in Southern Ecuador. Diploma thesis, Freiberg, Germany.

Guenter, S., Weber, M., Erreis, R. \& Aguirre, N., 2006. Influence of distance to forest edges on natural regeneration of abandoned pastures: a case study in the tropical mountain rain forest of Southern Ecuador. European Journal of Forest Research, doi: 10.1007/s10342-006-0156-0.

Hafkenscheid, R., 2000. Hydrology and biogeochemistry of tropical montane rain forests of contrasting stature in the Blue Mountains, Jamaica. Doctoral dissertation, Free University of Amsterdam.

Hanson, D.L., Steenhuis, T.S., Walter, M.F. \& Boll, J., 2004. Effects of soil degradation and management practices on the surface water dynamics in the Talgua River Watershed in Honduras. Land Degradation \& Development, 15, 367-381.

Hartig, K. \& Beck, E., 2003. The bracken fern (Pteridium aquilinum) dilemma in the Andes of South Ecuador. Ecotropica, 9, 3-13.

Heuvelink, G.B.M. \& Webster, R., 2001. Modelling soil variation: past, present, and future. Geoderma, 100, 269-301.

Hou, P.C.L., Zou, X.M., Huang, C.Y. \& Chien, H.J., 2005. Plant litter decomposition influenced by soil animals and disturbance in a subtropical rainforest of Taiwan. Pedobiologia, 49, 539-547.

Huwe, B., Zimmermann, B., Zeilinger, J., Quizhpe, M. \& Elsenbeer, H., 2008. Gradients and patterns of soil physical parameters at local, field and catchment scales. In: Gradients in a Tropical Mountain Ecosystem of Ecuador. (eds Beck, E., Bendix, J., Kottke, I., Makeschin, F., Mosandl, R.), Ecological Studies, Springer-Verlag. 
Iglewicz, B., 1983. Robust scale estimators and confidence intervals for location. In:

Understanding Robust and Exploratory Data Analysis. (eds Hoaglin, D.C., Mosteller, F., Tukey, J.W.Wiley), New York, pp. 404-429.

Iqbal, J., Thomasson, J.A., Jenkins, J.N., Owens, P.R. \& Whisler, F.D., 2005. Spatial variability analysis of soil physical properties of alluvial soils, Soil Science Society of America Journal, 69, 1338-1350.

Lal, R., 1996. Deforestation and land-use effects on soil degradation and rehabilitation in western Nigeria .1. Soil physical and hydrological properties. Land Degradation \& Development, 7, 19-45.

Lark, R.M., 2000a. A comparison of some robust estimators of the variogram for use in soil survey. European Journal of Soil Science, 51, 137-157.

Lark, R.M., 2000b. Estimating variograms of soil properties by the method-of-moments and maximum likelihood. European Journal of Soil Science, 51, 717-728.

Lark, R.M., 2002. Modelling complex soil properties as contaminated regionalized variables. Geoderma, 106, 173-190.

Lark, R.M., Cullis, B.R. \& Welham, S.J., 2006. On spatial prediction of soil properties in the presence of a spatial trend: the empirical best linear unbiased predictor (E BLUP) with REML. European Journal of Soil Science, 57, 787-799.

Larsen, M.C., Torres-Sanchez, A.J. \& Concepcion, I.M., 1999. Slopewash, surface runoff and fine-litter transport in forest and landslide scars in humid-tropical steeplands, Luquillo Experimental Forest, Puerto Rico. Earth Surface Processes and Landforms, 24, 481502.

Leuangthong, O. \& Deutsch, C.V., 2004. Transformation of residuals to avoid artifacts in geostatistical modelling with a trend. Mathematical Geology, 36, 287-305.

Lophaven, S., Carstensen, J. \& Rootzen, H., 2002. Methods for estimating the semivariogram. Symposium i Anvendt Statistik, 128-144, Institut for Informationsbehandling, Handelshøjskolen i Århus.

Makeschin, F., Haubrich, F., Abiy, M., Burneo, J.I. \& Klinger, T., 2008. Pasture management and natural soil regeneration. In: Gradients in a Tropical Mountain Ecosystem of Ecuador. (eds E. Beck, J. Bendix, I. Kottke, F. Makeschin, R. Mosandl), Ecological Studies, Springer-Verlag.

Mallants, D., Mohanty, B.P., Jacques, D. \& Feyen, J., 1996. Spatial variability of hydraulic properties in a multi-layered soil profile. Soil Science, 161, 167-181. 
Malmer, A., 1996. Hydrological effects and nutrient losses of forest plantation establishment on tropical rainforest land in Sabah, Malaysia. Journal of Hydrology, 174, 129-148.

Maraun, M., Illig, J., Sandmann, D., Krashevskaya, V., Norton, R.A. \& Scheu, S., 2008. Soil Fauna: Composition and function. In: Gradients in a Tropical Mountain Ecosystem of Ecuador. (eds E. Beck, J. Bendix, I. Kottke, F. Makeschin, R. Mosandl), Ecological Studies, Springer-Verlag.

Marchant, B.P. \& Lark, R.M., 2004. Estimating variogram uncertainty, Mathematical Geology, 36, 867-898.

Marquardt, S., 2005. Validity of two pedotransfer functions in two microcatchments of a tropical mountain rainforest in Southern Ecuador. Diploma thesis, Bayreuth, Germany.

Martinez, L.J. \& Zinck, J.A., 2004. Temporal variation of soil compaction and deterioration of soil quality in pasture areas of Colombian Amazonia. Soil \& Tillage Research, 75, $3-17$.

Matérn, B., 1960. Spatial variation. Meddelanden fr3n Statens Skogsforskningsinstitut, 49, No. 5. [2nd Edition (1986), Lecture Notes in Statistics, No. 36, Springer, New York].

Matheron, G., 1962. Traité de Géostatistique Appliqué, Tome 1. Memoires du Bureau de Recherches Géologiques et Minières, Paris.

McDonald, M.A. \& Healey, J.R., 2000. Nutrient cycling in secondary forests in the Blue Mountains of Jamaica. Forest Ecology and Management, 139, 257-278.

McDowell, R.W., Drewry, J.J., Paton, R.J., Carey, P.L., Monaghan, R.M. \& Condron, L.M., 2003. Influence of soil treading on sediment and phosphorus losses in overland flow. Australian Journal of Soil Research, 41, 949-961.

McGlynn, B.L., McDonnel, J.J. \& Brammer, D.D., 2002. A review of the evolving perceptual model of hillslope flowpaths at the Maimai catchments, New Zealand. Journal of Hydrology, 257, 1-26.

McKenzie, N. \& Jacquier, D., 1997. Improving the field estimation of saturated hydraulic conductivity in soil survey. Australian Journal of Soil Research, 35, 803-825.

Minasny, B. \& McBratney, A.B., 2005. The Matérn function as a general model for soil variograms. Geoderma, 128, 192-207.

Mohanty, B.P., Kanwar, R.S. \& Horton, R., 1991. A robust-resistant approach to interpret spatial behavior of saturated hydraulic conductivity of a glacial till soil under notillage system, Water Resources Research, 27, 2979-2992. 
Mohanty, B.P. \& Mousli, Z., 2000. Saturated hydraulic conductivity and soil water retention properties across a soil-slope transition. Water Resources Research, 36, 3311-3324.

Moraes J.M., Schuler, A.E., Dunne, T., Figueiredo, R. O. \& Victoria, R.L., 2006. Water storage and runoff processes in plinthic soils under forest and pasture in Eastern Amazonia. Hydrological Processes, 20, 2509-2526.

Motzer, T., Munz, N., Kuppers, M., Schmitt, D. \& Anhuf, D., 2005. Stomatal conductance, transpiration and sap flow of tropical montane rain forest trees in the southern Ecuadorian Andes. Tree Physiology, 25, 1283-1293.

Muñoz, J.C., 2005. Cuantificación de la variabilidad de las propiedades del suelo, a pequeña escala, utilizando métodos geoestadísticos en la Estación Científica San Francisco. Diploma thesis, Universidad Nacional de Loja, Ecuador.

Noguchi, S., Kasran, B., Yusop, Z., Tsuboyama, Y. \& Tani, M., 2003. Depth and physical properties of soil in a forest and a rubber plantation in peninsular Malaysia. Journal of Tropical Forest Science, 15, 513-530.

Ohl, C. \& Bussmann, R., 2004. Recolonisation of natural landslides in tropical mountain forests of Southern Ecuador. Feddes Repertorium, 115, 248-264.

Osunbitan, J.A., Oyedele, D.J. \& Adekalu, K.O., 2005. Tillage effects on bulk density, hydraulic conductivity and strength of a loamy sand soil in southwestern Nigeria. Soil \& Tillage Research, 82, 57-64.

Pardo-Igúzquiza, E., 1998. Maximum likelihood estimation of spatial covariance parameters, Mathematical Geology, 30, 95-108.

Pebesma, E.J., 2004. Multivariable geostatistics in S: the gstat package. Computers \& Geosciences, 30, 683-691.

Rab, M.A., 1996. Soil physical and hydrological properties following logging and slash burning in the Eucalyptus Regnans forest of southeastern Australia. Forest Ecology and Management, 84, 159-176.

R Development Core Team, 2004. R: A language and environment for statistical computing. $R$ Foundation for Statistical Computing, Vienna, Austria.

Reynolds, W.D. \& Zebchuk, W.D., 1996. Hydraulic conductivity in a clay soil: two measurement techniques and spatial characterization. Soil Science Society of America Journal, 60, 1679-1685.

Ribeiro, P.J. \& Diggle, P.J., 2001. GeoR: a package for geostatistical analysis. R-NEWS Vol 1, No 2. (URL: http://cran.r-project.org/doc/Rnews) 
Richter, M., 2003. Using plant functional types and soil temperatures for eco-climatic interpretation in southern Ecuador. Erdkunde, 57, 161-181.

Ringrose-Voase, A.J., 1991. Micromorphology of soil structure: description, quantification, application. Australian Journal of Soil Research, 29, 777-813.

Rollenbeck, R., Bendix, J., Fabian, P., Boy, J., Dalitz, H., Emck, P., Oesker, M. \& Wilcke, W., 2007. Comparison of different techniques for the measurement of precipitation in tropical montane rain forest regions. Journal of atmospheric and oceanic technology, 24, 156-168.

Russo, D., Russo, I. \& Laufer, A., 1997. On the spatial variability of parameters of the unsaturated hydraulic conductivity. Water Resources Research, 33, 947-956.

Schellekens, J., Scatena, F.N., Bruijnzeel, L.A. \& Wickel, A.J., 1999. Modelling rainfall interception by a lowland tropical rain forest in northeastern Puerto Rico. Journal of Hydrology, 225, 168-184.

Schrumpf, M., Guggenberger, G., Valarezo, C. \& Zech, W., 2001. Tropical montane rain forest soils, development and nutrient status along an altitudinal gradient in the south Ecuadorian Andes. Die Erde, 132, 43-60.

Schrumpf, M., Zech, W., Lehmann, J. \& Lyaruu, H.V.C., 2006. TOC, TON, TOS and TOP in rainfall, throughfall, litter percolate and soil solution of a montane rainforest succession at Mt. Kilimanjaro, Tanzania. Biogeochemistry, 78, 361-387.

Shapiro, S.S. \& Wilk, M.B., 1965. An analysis of variance test for normality (complete samples). Biometrika, 52, 591-611.

Shukla, M. K., Slater, B.K., Lal, R. \& Cepuder, P., 2004. Spatial variability of soil properties and potential management classification of a chernozemic field in lower Austria, Soil Science, 169, 852-860.

Sidle, R.C. \& Swanston, D.N., 1982. Analysis of a small debris slide in coastal Alaska. Canadian Geotechnical Journal, 19, 167-174.

Sidle, R.C. \& Ochiai, H., 2006. Subsurface flow processes. In: Landslides: Processes, Prediction, and Land Use, pp. 76-80. American Geophysical Union, Washington, DC.

Singh, K.P., Mandal, T.N. \& Tripathi, S.K., 2001. Patterns of restoration of soil physicochemical properties and microbial biomass in different landslide sites in the sal forest ecosystem of Nepal Himalaya. Ecological Engineering, 17, 385-401.

Singleton, P.L. \& Addison, B., 1999. Effects of cattle treading on physical properties of three soils used for dairy farming in the Waikato, North Island, New Zealand. Australian Journal of Soil Research, 37, 891-902. 
Skøien, J. O. \& Bloeschl, G., 2006. Scale effects in estimating the variogram and implications for soil hydrology, Vadose Zone Journal, 5, 153-167.

Sobieraj, J. A., Elsenbeer, H., Coelho, R.M. \& Newton, B., 2002. Spatial variability of soil hydraulic conductivity along a tropical rainforest catena. Geoderma 2 108, 79-90.

Sobieraj, J.A., Elsenbeer, H. \& Cameron, G., 2004. Scale dependency in spatial patterns of saturated hydraulic conductivity. Catena, 55, 49-77.

Soethe, N., Lehmann, J. \& Engels, C., 2006. Root morphology and anchorage of six native tree species from a tropical montane forest and an elfin forest in Ecuador. Plant and Soil, 279, 173-185.

Soil Survey Staff, 1999. Soil Taxonomy-A Basic System of Soil Classification for Making and Interpreting Soil Surveys, second ed., US Government Printing Office, Washington, DC.

Stein, M.L., 1999. Interpolation of Spatial Data: Some Theory for Kriging, Springer, New York.

Terlien, M.T.J., 1997. Hydrological landslide triggering in ash-covered slopes of Manizales (Colombia). Geomorphology, 20, 165-175.

Tomasella, J. \& Hodnett, M.G., 1996. Soil hydraulic properties and van Genuchten parameters for an oxisol under pasture in central Amazonia. In: Amazonian Deforestation and Climate (eds J.H.C. Gash, C.A. Nobre, J.M. Roberts \& R.L. Victoria), pp. 101-124, John Wiley \& Sons, Chichester.

Unlu, K., Nielsen, D.R., Biggar, J.W. \& Morkoc, F., 1990. Statistical parameters characterizing the spatial variability of selected soil hydraulic properties, Soil Science Society of America Journal, 54, 1537-1547.

Vieira, B.C. \& Fernandes, N.F., 2004. Landslides in Rio de Janeiro: The role played by variations in soil hydraulic conductivity. Hydrological Processes, 18, 791-805.

Walker, L.R., Zarin, D.J., Fetcher, N., Myster, R.W. \& Johnson, A.H., 1996. Ecosystem development and plant succession on landslides in the Caribbean. Biotropica, 28, 566576.

Watson, S., 1997. Evaluation of semivariance estimators under normal conditions, The Statistician, 46, 495-503.

Webster, R. \& Oliver, M.A., 1992. Sample adequately to estimate variograms of soil properties, Journal of Soil Science, 43, 177-192. 
Webster, R. \& Oliver, M.A., 2001a. Reliability of the experimental variogram. In: Geostatistics for Environmental Scientists, edited by V. Barnett, pp. 78-92, John Wiley \& Sons, Chichester.

Webster, R. \& Oliver, M.A., 2001b. Authorized models. In: Geostatistics for Environmental Scientists, edited by V. Barnett, pp. 78-92, John Wiley \& Sons, Chichester.

Western, A.W. \& Bloeschl, G., 1999. On the spatial scaling of soil moisture, Journal of Hydrology, 217, 203-224.

Wilcke, W., Valladarez, H., Stoyan, R., Yasin, S., Valarezo, C. \& Zech, W., 2003. Soil properties on a chronosequence of landslides in montane rain forest, Ecuador, Catena, 53, 79-95.

Williams, M.R., Filoso, S. \& Lefebvre, P., 2004. Effects of land use change on solute fluxes to floodplain lakes of the central Amazon. Biogeochemistry, 68, 259-275.

Wilson, J.P. \& Gallant, J.C., 2000. Locally adaptive gridding. In: Terrain Analysis, p. 36. John Wiley \& Sons, New York.

Whittle, P., 1954. On stationary processes in the plane. Biometrika, 41, 434- 449.

Zaitchik, B.F., Van Es, H.M. \& Sullivan, P.J., 2003. Modeling Slope Stability in Honduras: Parameter Sensitivity and Scale of Aggregation. Soil Science Society of America Journal, 67, 268-278.

Ziegler, A.D., Giambelluca, T.W., Tran, L.T., Vana, T.T., Nullet, M.A., Fox, J., Vien, T.D., Pinthong, J., Maxwell, J.F. \& Evett, S., 2004. Hydrological consequences of landscape fragmentation in mountainous northern Vietnam: evidence of accelerated overland flow generation. Journal of Hydrology, 287, 124-146.

Zimmermann, B., Elsenbeer, H. \& De Moraes, J.M., 2006. The influence of land-use changes on soil hydraulic properties: Implications for runoff generation. Forest Ecology and Management, 222, 29-38.

Zimmermann, B., Zehe, E., Hartmann, N. \& Elsenbeer, H. Analyzing spatial data - an assessment of assumptions, new methods, and uncertainty using soil hydraulic data, submitted to Water Resources Research. 


\section{CURRICULUM VITAE}

\section{BEATE ZIMMERMANN}

\section{PERSONAL DETAILS}

$\begin{array}{ll}\text { Profession } & \begin{array}{l}\text { Geoecologist } \\ \text { Address }\end{array} \\ & \begin{array}{l}\text { Hauptstrasse 5 } \\ \text { Germany }\end{array} \\ \text { Phone } & \text { 0049-33208-23694 (home) } \\ & \text { 0049-331-9772242 (work) } \\ \text { Email } & \text { bzimmer@uni-potsdam.de } \\ \text { Date of Birth } & \text { July 22, 1977 } \\ \text { Place of Birth } & \text { Weissenfels, Germany } \\ \text { Nationality } & \text { German }\end{array}$

\section{EDUCATION}

Since $03 / 2005$

$1998-2005$

Ph.D. program in Geoecology, University of Potsdam, Germany Diploma program in Geoecology, University of Potsdam, Germany

$1991-1997$

High school, Finsterwalde, Germany

\section{VOLUNTEER EXPERIENCE}

$\begin{array}{ll}\text { 10/2004 - 12/2004 } & \text { Smithsonian Tropical Research Institute, Barro Colorado Island, } \\ & \text { Panama } \\ \text { 02/1998 - 07/1998 } & \text { Research Institute of Post-mining Landscapes, Finsterwalde, } \\ \text { Germany }\end{array}$

\section{PROFESSIONAL EXPERIENCE}

Since 04/2005

Research assistant, Institute of Geoecology, University of Potsdam

\section{PUBLICATIONS}

- Zimmermann, B., Elsenbeer, H. The soil hydraulic response to disturbance and recovery. I. Spatial and temporal variability of the saturated hydraulic conductivity. Submitted to Journal of Hydrology.

- Zimmermann, B., Elsenbeer, H. The soil hydraulic response to disturbance and recovery. II. Partitioning of rainfall in vertical and lateral flowpaths. Submitted to Journal of Hydrology.

- Zimmermann, B., Zehe, E., Hartmann, N., Elsenbeer, H. Geostatistical analysis of soil hydraulic data - a discussion on assumptions, new methods and uncertainties. Under review with Water Resources Research.

- Huwe, B., Zimmermann, B., Zeilinger, J., Quizhpe, M., Elsenbeer, H. (2007) Gradients and patterns of soil physical parameters at local, field and catchment scales. In: Gradients in a Tropical Mountain Ecosystem of Ecuador. (eds E. Beck, J. Bendix, I. Kottke, F. Makeschin, R. Mosandl), Ecological Studies, Springer-Verlag, in press

- Zimmermann, B., Elsenbeer, H., De Moraes, J.M. (2006) The influence of land-use changes on soil hydraulic properties: Implications for runoff generation. Forest Ecology and Management, 222(1-3): 29 


\section{CONFERENCE PRESENTATIONS}

- Zimmermann, B., Zehe, E., Elsenbeer, H. (2007) Use of geostatistical simulation methods to assess the probability of overland flow occurrence, Pedometrics 2007, Biannual Conference of Commission 1.5 Pedometrics, Division 1 of the International Union of Soil Sciences (IUSS), 27-30 Aug 2007, Tübingen, Germany (oral presentation)

- Zimmermann, B., Elsenbeer, H. (2006) Spatial and temporal variability of saturated hydraulic conductivity in gradients of disturbance, 70th SSSA Annual Meeting, 12-16 Nov 2006, Indianapolis, USA (oral presentation)

- Zimmermann, B., Elsenbeer, H. (2006) Spatial and temporal variability of soil saturated hydraulic conductivity, 19th annual GTOE (Society for Tropical Ecology) meeting, 21-24 Febr 2006, Kaiserslautern, Germany (poster)

- Zimmermann, B., Elsenbeer, H. (2005) The effects of pasture and fallow on soil saturated hydraulic conductivity. III. Congreso de Conservación de la Biodiversidad de los Andes y de la Amazonía 2005, 14-17 Nov 2005, Loja, Ecuador (poster)

\section{WORKSHOPS}

- Summer school statGIS06. Recent Developments in Spatial Statistics, 11-15 Sep 2006, Klagenfurt, Austria

- University courses in Pedometrics and practical modeling

\section{SKILLS}

- Fluency in R and S-Plus (statistical programming environments), MS-Office, Adobe Photoshop/GoLive/Illustrator, MatLab, ArcGIS

\section{LANGUAGES}

German

English

Spanish

\section{AWARDS}

$07 / 2003-09 / 2003$

\author{
Native language \\ Fluency \\ Very good oral and reading, good writing skills
}

DAAD (German Academic Exchange Service) fellowship for overseas research

\section{RESEARCH INTERESTS}

- Spatial-temporal patterns of key properties in the hydrologic cycle

- Application and development of new techniques in spatial-temporal modeling

- Input parameters for hydrological modeling: Uncertainties and required resolution for upscaling applications from the hillslope to catchment and regional scales

- The influence of land use changes on threshold processes of runoff generation

- Quantifying the changes of the water cycle in gradients of varying anthropogenic influence at the small catchment scale

- Linking biodiversity with pedodiversity 